\title{
Progression to Compatibility Evaluations in Flowing Molten Salts
}

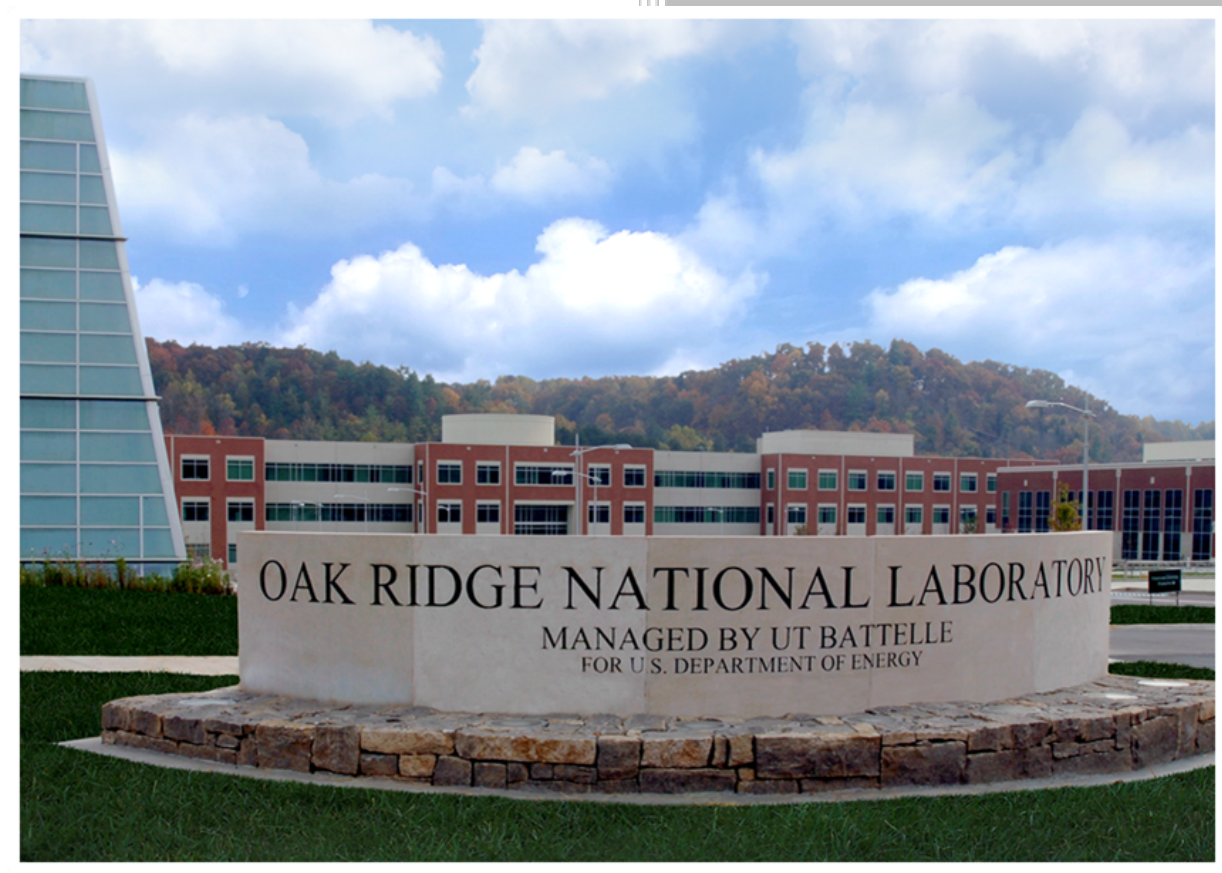

Bruce A. Pint

July 2020

Approved for public release. Distribution is unlimited. 


\title{
DOCUMENT AVAILABILITY
}

Reports produced after January 1, 1996, are generally available free via US Department of Energy (DOE) SciTech Connect.

Website www.osti.gov

Reports produced before January 1, 1996, may be purchased by members of the public from the following source:

\author{
National Technical Information Service \\ 5285 Port Royal Road \\ Springfield, VA 22161 \\ Telephone 703-605-6000 (1-800-553-6847) \\ TDD 703-487-4639 \\ Fax 703-605-6900 \\ E-mail info@ntis.gov \\ Website http://classic.ntis.gov/
}

Reports are available to DOE employees, DOE contractors, Energy Technology Data Exchange representatives, and International Nuclear Information System representatives from the following source:

Office of Scientific and Technical Information

PO Box 62

Oak Ridge, TN 37831

Telephone 865-576-8401

Fax 865-576-5728

E-mail reports@osti.gov

Website http://www.osti.gov/contact.html

This report was prepared as an account of work sponsored by an agency of the United States Government. Neither the United States Government nor any agency thereof, nor any of their employees, makes any warranty, express or implied, or assumes any legal liability or responsibility for the accuracy, completeness, or usefulness of any information, apparatus, product, or process disclosed, or represents that its use would not infringe privately owned rights. Reference herein to any specific commercial product, process, or service by trade name, trademark, manufacturer, or otherwise, does not necessarily constitute or imply its endorsement, recommendation, or favoring by the United States Government or any agency thereof. The views and opinions of authors expressed herein do not necessarily state or reflect those of the United States Government or any agency thereof. 
Solar Energy Technology Office

\title{
PROGRESSION TO COMPATIBILITY EVALUATIONS IN FLOWING MOLTEN SALTS
}

Bruce A. Pint

Date Published:

July 2020

\author{
Prepared by \\ OAK RIDGE NATIONAL LABORATORY \\ Oak Ridge, TN 37831-6283 \\ managed by \\ UT-BATTELLE, LLC \\ for the \\ US DEPARTMENT OF ENERGY \\ under contract DE-AC05-00OR22725
}




\section{Final Technical Report (FTR)}

Project Title: Progression to Compatibility Evaluations in Flowing Molten Salts

Project Period: $\quad$ 2/01/18 $-1 / 31 / 20$

Submission Date: $\quad 6 / 25 / 2020$

Recipient: Oak Ridge National Laboratory

Address: $\quad 1$ Bethel Valley Rd.

Oak Ridge, TN 37831-6156

Website (if available) www.ornl.gov

Award Number: $\quad$ CPS 33873

Project Team: Oak Ridge National Laboratory

Principal Investigator: Bruce A. Pint, Distinguished Research Staff

Phone: 865-576-2897

Email: pintba@ornl.gov

Business Contact: Dominic F. Lee, Program Manager

Phone: 865-241-0775

Email: leedf@ornl.gov

Technology Manager: Levi Irwin

Project Officer: Christine Bing 


\section{Progression to Compatibility Evaluations in Flowing Molten Salts}

\section{Executive Summary}

Molten salt compatibility with structural alloys has been identified as a key issue for the development of Generation 3 concentrating solar power (CSP) systems with thermal storage. To accelerate this evaluation to pumped systems, the goal of this project was to conduct thermal convection loop (TCL) experiments with a peak temperature of $\geq 700^{\circ} \mathrm{C}$ and a typical temperature gradient of $\sim 100^{\circ} \mathrm{C}$. The experiments indicated that conventional $\sim 16 \mathrm{wt} . \% \mathrm{Cr}$ Ni-based alloys are compatible up to $700^{\circ} \mathrm{C}$ with purified (i.e. low $\mathrm{O}$ ) or dried (low $\mathrm{H}_{2} \mathrm{O}$ ) industrial-sourced $\mathrm{Mg}-\mathrm{K}-\mathrm{Na}$ chloride salt with $<10 \mu \mathrm{m} / \mathrm{yr}$ loss.

This two-year project was conducted based on the experimental and mechanistic understanding developed more than 60 years ago at Oak Ridge National Laboratory (ORNL). The first TCL experiment met the $<15 \mu \mathrm{m} / \mathrm{yr}$ corrosion metric for this project with specimens of Ni-based alloy 600 exposed at $580^{\circ}-700^{\circ} \mathrm{C}$ for $1000 \mathrm{~h}$ and postexposure room temperature tensile tests showed minimal degradation. The second TCL experiment successfully deployed an electrochemical sensor from Argonne National Laboratory and had a peak temperature of $750^{\circ} \mathrm{C}$ but only ran for $\sim 110 \mathrm{~h}$ due to a furnace failure. Both experiments used highly purified industrial-sourced salt with an $\mathrm{O}$ content of $\sim 3 \mu \mathrm{g} \mathrm{O} / \mathrm{g}$ salt and a Mg addition of $0.04 \mathrm{wt} . \%$. In the second year, the Chloride Collective developed a more economical drying procedure such that the $\mathrm{O}$ content was much higher (>20,000 $\mathrm{\mu g}$ O/g salt). A third TCL experiment was conducted with a sensor and a peak temperature of $700^{\circ} \mathrm{C}$ using dried salt from the same industrial source and increased $\mathrm{NaCl}$ content ( $20 \mathrm{wt} . \%)$. In addition to a $0.05 \% \mathrm{Mg}$ addition to the salt, a Mg coupon was added in the coldest part of the loop which dissolved during the experiment. Again, small mass changes were noted for specimens of alloys 600 and $\mathrm{C} 276$ but the values were slightly higher than those measured in purified salt with Mg. A thin non-continuous and non-adherent oxide layer was deposited on most specimens containing $\mathrm{Mg}, \mathrm{Si}$ and $\mathrm{Al}$ but $\mathrm{Cr}$ depletion also was observed.

Both years included facilities qualification crucible experiments and then capsule experiments to confirm a baseline isothermal reaction rate. The first year capsule experiment led to the conclusion that the two-stage ORNL purification process using $\mathrm{NH}_{4} \mathrm{Cl}$ and $\mathrm{CCl}_{4}$ left the salt with a high $\mathrm{Cl}$ potential and a $\mathrm{Mg}$ addition ( $\left.0.05 \mathrm{wt} . \%\right)$ was needed to lower the potential. The second year capsule experiments at $600^{\circ}$ and $700^{\circ} \mathrm{C}$ found little difference in depth of attack for $0-0.25 \% \mathrm{Mg}$ additions. In general, the complex reactions where salt can be trapped in the porous surface layer of metal indicated that mass change is an unreliable metric and average depth of $\mathrm{Cr}$ depletion is a better metric for assessing the extent of attack.

These results have created a new baseline that is contrary to the recent published literature for chloride salts where mass losses have been reported that can be extrapolated to very significant annual metal loss rates. Chloride salt corrosion can be controlled and the results also indicate that salt purification to low $O$ levels may not be necessary. However, additional TCL experiments are needed at different times and temperatures to generate important engineering information such as temperature dependent corrosion rates and reaction rate laws for extrapolation to long-term behavior and isolate the effect of salt additives and impurities. 


\section{Table of Contents}

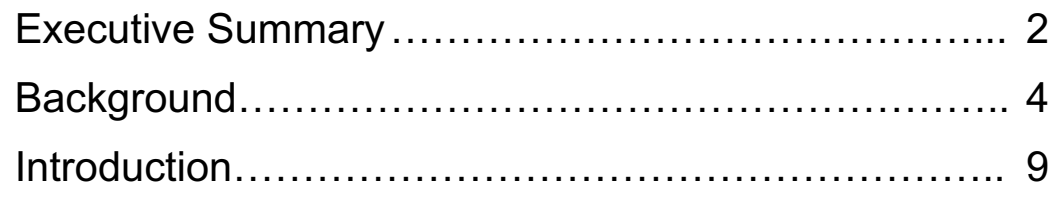

Project Results and Discussion

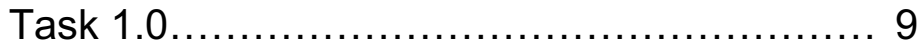

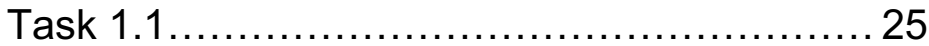

Task 1.2 ...................................... 28

Task 1.3.......................................... 35

Task 2.0...................................... 38

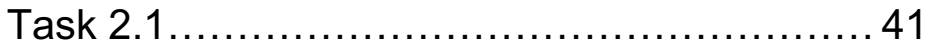

Task 2.2...................................... 45

Significant Accomplishments and Conclusions...........54

Publications............................................ 55

Path Forward ....................................... 55

References............................................ 56

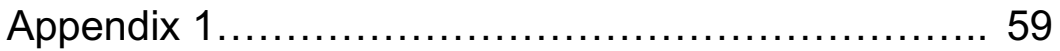




\section{Background}

Several key points should be made to understand the philosophy behind the approach to this project. The first is that the molten salt research community collapsed several decades ago. While this may be difficult for non-experts to perceive or appreciate, what this unfortunately means is that there are no current standards for molten salt experimental work, there are very few people with formal training in molten salt research standard practices, and there are no journals with obvious editorial expertise in this area. Thus, much of the research is misguided with low quality and the status of molten salts in the 2017 CSP Generation 3 roadmap is not surprising. Most importantly, the roadmap has no discussion about moving to a flowing salt experiment, which has long been the ultimate test for molten salt compatibility [Susskind 1960, DeVan 1979, Keiser 1979, Bradshaw 1987]. Like liquid metals, molten salts represent a unique form of corrosion, which is better described as compatibility or limited (i.e. acceptable) interaction/degradation. The goal is to identify structural materials, claddings or coatings that are compatible for extended periods with molten salts such that they can operate as required. Molten salts don't operate in a quartz capsule or in an electrochemical cell. They flow within structural components with a temperature gradient. A major concern with liquid metals or salts is dissolution and solubility affects the rate of dissolution. For molten salts, oxidation of conventional alloying elements like $\mathrm{Cr}, \mathrm{Al}, \mathrm{Ti}$ and $\mathrm{Mn}$ leads to their selective removal from the containing material unless highly reducing conditions are maintained, i.e. low impurity levels of $\mathrm{O}_{2}$ and $\mathrm{H}_{2} \mathrm{O}$ [DeVan 1979]. If impurities cannot be controlled in a commercial process, then it may not be possible to deploy a chloride salt.

The ORNL paradigm for molten salt compatibility revolves around several fundamental concepts:

1. Salts must be purified to achieve good compatibility, HF was used for fluoride salts but a similar process with $\mathrm{HCl}$ for chloride salts has not been found

2. Once purified, impurity ingress must be eliminated during experiments by welding shut capsules and evacuating a thermal convection loop (TCL) prior to operation

3. The $\mathrm{Cl}$ (or F) potential must be lowered to inhibit reaction with alloying elements in structural alloys such as $\mathrm{Cr}, \mathrm{Al}, \mathrm{Ti}$ and $\mathrm{Mn}$.

4. Low $\mathrm{Cr}$, Ni-base alloys provided the best compatibility among structural alloys in fluoride salts

5. Compatibility is affected by solubility of the diffusing species in the liquid, therefore, in an isothermal, static system the salt saturates with time slowing the reaction, preventing a relevant reaction rate from being determined and obviating the need for long static corrosion experiments

6. A temperature gradient is needed to assess the mass transfer behavior in a molten salt where dissolution can continue at the highest temperatures and precipitation can occur as the liquid cools and the solubility decreases.

7. The container in a molten salt experiment should either be inert to the salt (e.g. $\mathrm{Mo}$ ) or the same material as the specimen to prevent unintended reactions. 
These concepts are based on more than a decade of experience leading up to the Molten Salt Reactor Experiment at ORNL (Haubenreich 1970) where FLiBe was contained by Hastelloy $\mathrm{N}(\mathrm{Ni}-7 \% \mathrm{Cr}-16 \% \mathrm{Mo}-4 \% \mathrm{Fe})$, an alloy that was specifically developed for this application. Unfortunately, the preliminary data to explicitly prove or demonstrate these points is not readily available and there are no specific criteria for "pure" salt. The older literature predominantly provides results for purified fluoride salts with Hastelloy N. It must also be acknowledged that for all of the expertise that was developed, it appears that no specific mechanism was ever clearly identified for the metal-salt reaction to specify, for example, how a $\mathrm{Cr}$ atom in the metal is transferred to the salt. The lack of mechanistic understanding has led to confusion about which parameters to control and sometimes makes it difficult to design experiments and interpret results. Ongoing research is attempting to improve that understanding.

It appears that some researchers do not believe that chloride salts need to be purified and/or make no effort to quantify the starting salt impurity levels [Vignarooban 2014, Gomez-Vidal 2017, Ding 2018, Sun 2018]. Alternatively, they may not have the ability or an understanding of how to purify these salts. Relatively few studies have reported in-depth details on salt purification methods in molten chloride salts as well as mass change data from capsule experiments where the ingress of impurities was prevented. Although not published in the open literature, James Ambrosek's Ph.D. dissertation [2011] details a comparison of several salt purification methods, including sparging with argon, an $\mathrm{HCl}$ sparge, a $\mathrm{CCl}_{4}$ sparge, and contacting with $\mathrm{Mg}$. It was found that $\mathrm{Mg}$ treatment and sparging with $\mathrm{CCl}_{4}$ produced the best (i.e. lowest mass loss) results, and the Mg method was chosen due to its easier implementation. Susskind et al. [1960] contacted their salt that included $\mathrm{Bi}$ with trace amounts of $\mathrm{Mg}, \mathrm{U}$, and $\mathrm{Zr}$ to remove impurities. While Ambrosek found a simple Ar sparge to be less effective, Indacochea et al. [1999] reported low corrosion rates in Ar sparged chloride salts. ORNL has a strong advantage in that expertise in salt purification has been retained and passed along to a new generation of researchers and the current techniques are outlined in the report.

To understand the potential metal-salt reactions, thermodynamic calculations were conducted using FactSage (version 7.2, FactPS database) [Pint 2019]. Figure 1a shows the relative stability of some of the various metal chlorides of interest. The salt components $\mathrm{KCl}$ and $\mathrm{NaCl}$ are some of the most stable chlorides followed by $\mathrm{MgCl}_{2}$, i.e. they have the most negative Gibbs energy relative to elements in the standard state. Some of the minor additions such as $\mathrm{Al}$ and $\mathrm{Mn}$ are next followed by $\mathrm{Cr}$, which is expected to be selectively attacked and removed from alloys in contact with a chloride salt [Ding 2018, Sun 2018]. Some of the least stable chlorides are Ni and Mo. Based on Olander's analysis for fluoride salts [2002], a similar calculation was made for $\mathrm{Cr}$ solubility in $\mathrm{MgCl}_{2}$, Figure $1 \mathrm{~b}$. While this may be simplistic (i.e. not considering a binary or ternary salt or the effect of impurities), it does indicate that the Cr solubility is increasing with temperature and relatively low. This change in solubility can drive mass transfer in a flowing system with a temperature gradient.

The isothermal solute driven $\mathrm{Cr}$ dissolution reaction should be governed by:

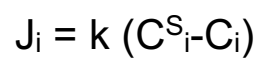



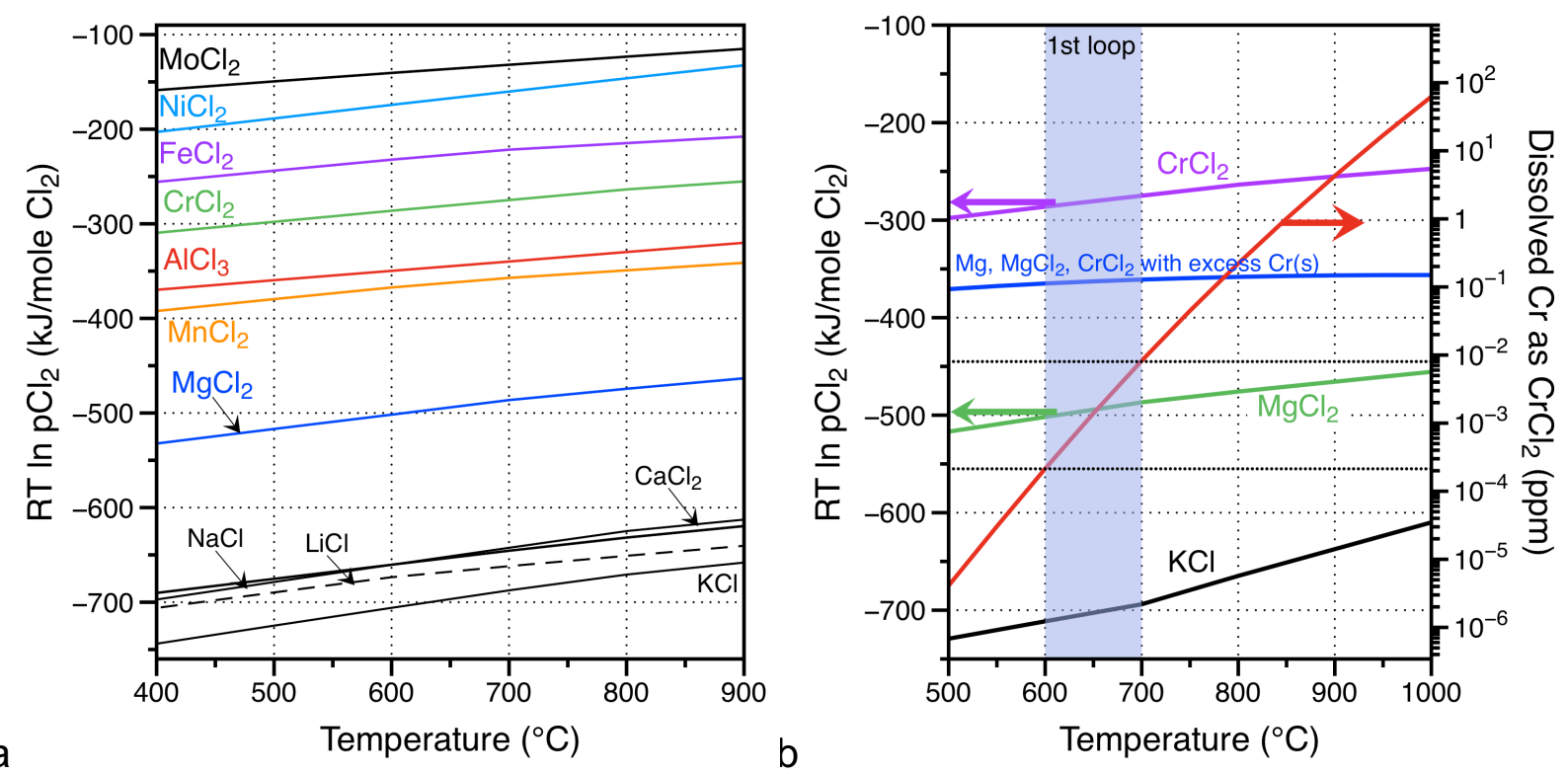

Figure 1 Thermodynamic calculations (a) $\mathrm{Cl}$ potential for various chlorides as a function of temperature and (b) equilibrium chlorine potential and equilibrium $\mathrm{CrCl}_{2}$ activity (mole fraction) in a mixture of molten $\mathrm{Mg}, \mathrm{CrCl}_{2}$, and $\mathrm{MgCl}_{2}$ using the ideal solution model and the reaction $\mathrm{Cr}(\mathrm{s})+\mathrm{MgCl}_{2}(\mathrm{I})=\mathrm{CrCl}_{2}(\mathrm{I})+\mathrm{Mg}(\mathrm{l})$.

where $J_{i}$ is the flux of species $i$ (e.g. Cr) into the liquid, $k$ is a constant, $C^{S_{i}}$ is the solubility limit of $i$ in the liquid salt and $C_{i}$ is the instantaneous concentration of $i$ in the liquid [Epstein 1957, Tortorelli 1992]. Thus, as Cr dissolves into the liquid, the reaction should slow and stop as the liquid becomes saturated. This is the reason for specifying a preferred ratio of $>10$ between the salt volume and the specimen surface area in an isothermal capsule experiment with an inert container. A small ratio may cause quick saturation and a misleadingly small mass loss.

While measuring corrosion rates via electrochemical methods has been attempted [e.g., Vignarooban 2014], it does not appear that these data are easily relatable to more traditional mass change data from isothermal capsule or crucible "immersion" tests where the specimen is immersed in the salt for a specific period of time at an isothermal temperature. Figure 2a shows examples of the mass loss data from the literature, typically associated with the selective removal of $\mathrm{Cr}$. Figure $2 \mathrm{~b}$ shows recent data where there was little effect of measured alloy $\mathrm{Cr}$ content on the mass loss after $100 \mathrm{~h}$ at $700^{\circ} \mathrm{C}$ [Sun 2018]. If $\mathrm{Cr}$ is selectively removed, this result is difficult to explain.

While metrics are important scientific and project management tools, they must be well chosen. It is common to extrapolate these isothermal results and report an annualized rate of attack (i.e. $\mu \mathrm{m} / \mathrm{yr}$ ) as a performance metric [Vignarooban 2014, Ding 2018, Sun 2018]. That is inappropriate for several reasons: first, an assumption must be made about the kinetics and the assumption of a linear extrapolation is not based on any mechanistic understanding or data. Second, a review of the literature shows that most 

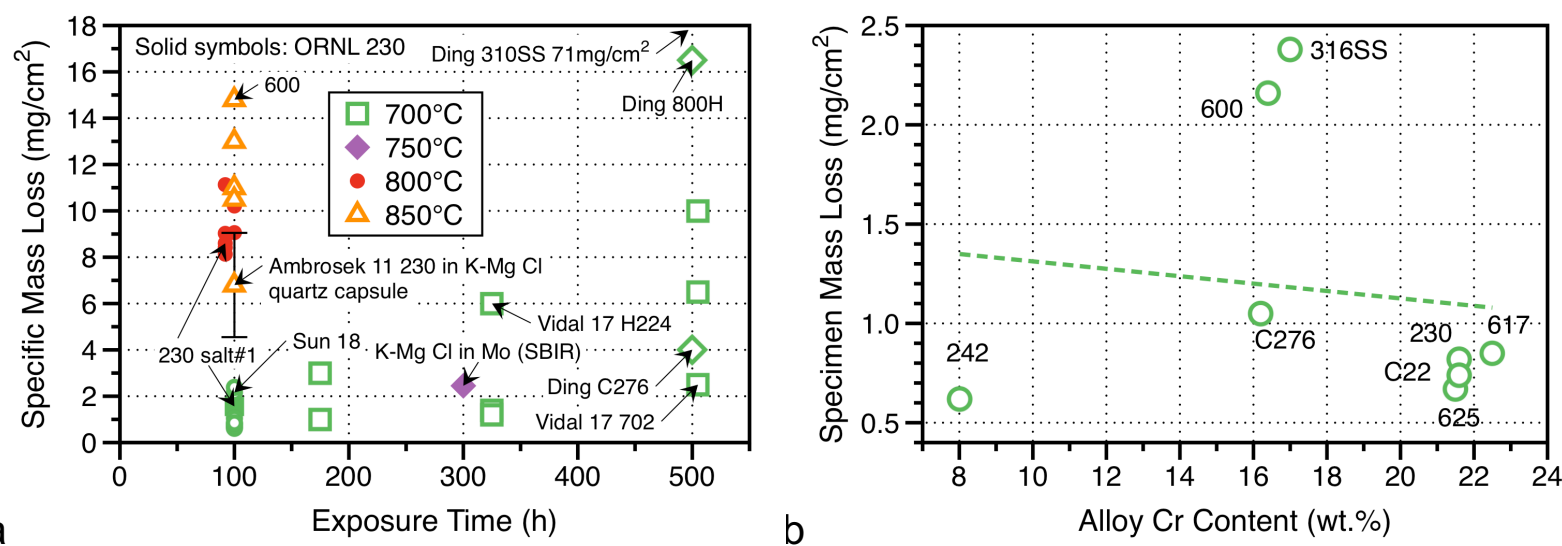

Figure 2. (a) Mass loss as a function of total exposure time for several chloride salt studies [Ambrosek 2011, Gomez-Vidal 2017, Ding 2018, Sun 2018, Raiman 2019] including some results from this study. (b) Mass loss after $100 \mathrm{~h}$ at $700^{\circ} \mathrm{C}$ [Sun 2018].

rates are calculated by using the alloy density and the mass loss data like that shown in Figure 2. However, as mentioned above, there is not uniform dissolution of the alloy, but rather selective attack of $\mathrm{Cr}$ so the behavior is much more complex. Third, when the specimens are characterized after salt exposure, it appears that salt or some type of M$\mathrm{O}-\mathrm{Cl}$ species (perhaps forming as a precursor to dissolution) is actually trapped in the porous sample. An example is shown in Figure 3. Thus, simple mass change is a poor metric for quantifying the extent of attack. Instead, affected alloy microstructure would be a much better parameter to assess the amount of attack.

If there is any question if Equation 1 is applicable, time series experiments show decreasing mass change or rate with increasing exposure time as the salt becomes

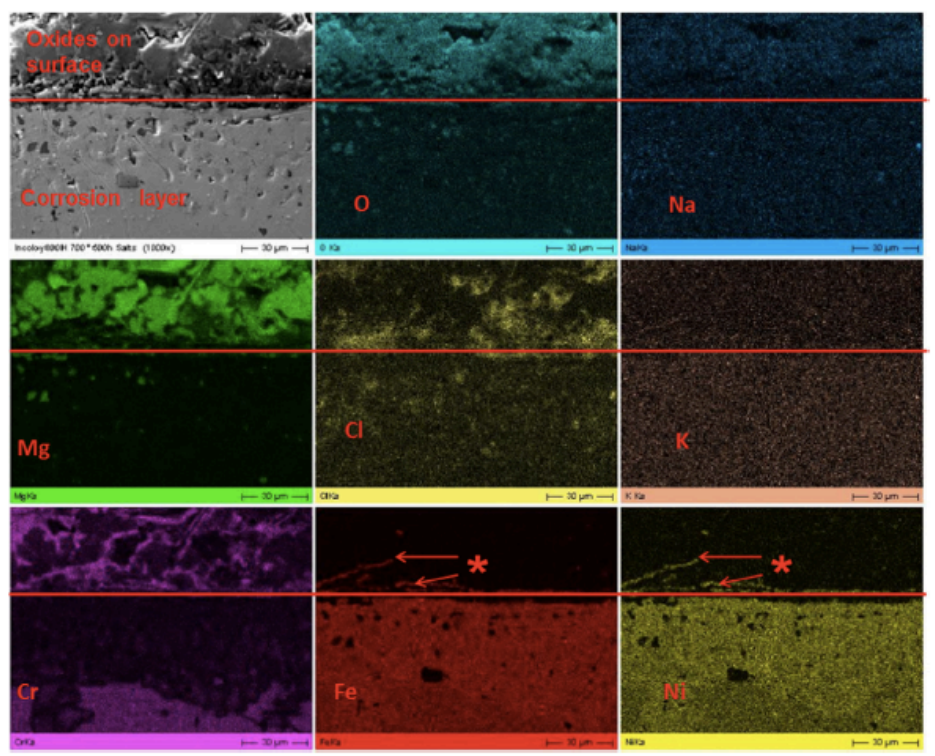

Figure 3. SEM/EDX maps of alloy $800 \mathrm{H}$ cross-section exposed for $500 \mathrm{~h}$ at $700^{\circ} \mathrm{C}$ in $60 / 20 / 20 \mathrm{Mg} / \mathrm{K} / \mathrm{Na}$ salt [Ding 2018]. 

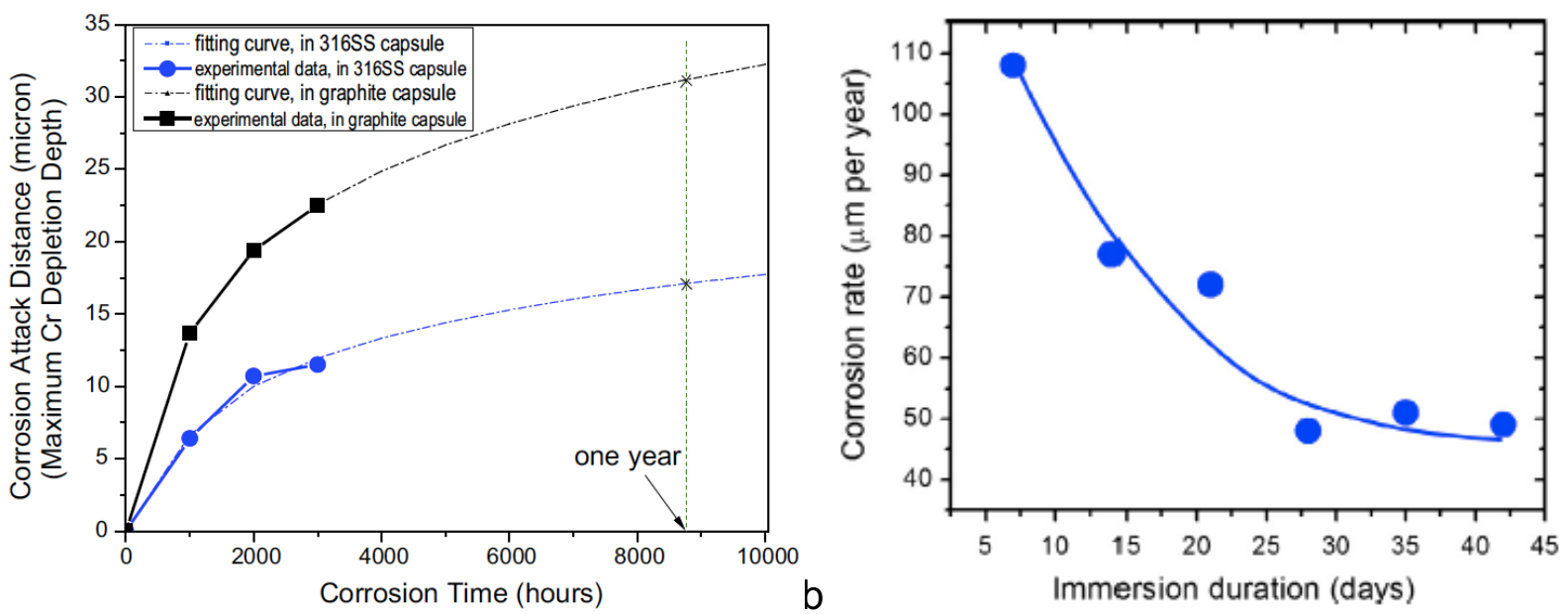

Figure 4. Literature examples showing decreasing (a) attack in FLiBe [Zheng 2018] or (b) rate in $\mathrm{Zn}-\mathrm{K}-\mathrm{Na} \mathrm{Cl}$ salt at $500^{\circ} \mathrm{C}$ [Vignarooban 2014].

saturated, Figure 4. At a minimum, it must be concluded that linear extrapolations are incorrect. Furthermore, a recent analysis of the molten salt literature review concluded that purified salts and sealed containers had a significant effect on corrosion rates [Raiman 2018].

The ORNL paradigm derived from the MSRE is largely forgotten in the current literature. It is much more common to discuss molten salt results in terms of a conventional corrosion problem where a protective oxide is needed to protect the underlying alloy and the salt exposure is a form of hot corrosion [e.g. Ding 2018]. The thermodynamics in Figure 1a indicate that conventional protective oxides rich in $\mathrm{Al}$ or $\mathrm{Cr}$ are readily attacked by chloride salts and the protective oxide strategy has never been successful for flowing halide salts.

In summary,

1. Several groups are studying molten salt compatibility but most of the experiments are isothermal with low purity salt. The TCL work at ORNL will be an important step forward in understanding chloride salt compatibility.

2. Few groups have adequately studied salt chemistry and purification techniques in order to document the salt condition for their compatibility experiment or explain why that particular salt condition was used (other than expediency).

3. There appear to be significant gaps in understanding that remain, particularly in how alloy composition affects compatibility, particularly as the temperature increases to $800^{\circ} \mathrm{C}$.

4. Another gap regards how salt chemistry affects compatibility and the interrelationship between impurities (e.g. $\mathrm{O}, \mathrm{H}, \mathrm{S}$ ) and additives (i.e. $\mathrm{Mg}$ and $\mathrm{Zr}$ ) including identifying the optimal salt as well as the most economical purification process. 


\section{Introduction}

The first year of this project was designed to quickly transition from isothermal to flowing experiments. The first two tasks involved static experiments. Task 1.0 was the "facility qualification" test for all of the "Chloride Collective" consisting of ORNL, NREL and SRNL. Task 1.1 was to explore the conditions expected in the first flowing test (i.e. Nibased alloy 600 at $600^{\circ}-700^{\circ} \mathrm{C}$ ). Task 1.2 was the first thermal convection loop (TCL) and Task 1.3 the second TCL, which was originally intended to include some type of corrosion mitigation but instead targeted a higher temperature and deploying a sensor.

In the second year of the project, the tasks were restructured to use the more economical salt drying process developed by the Chloride Collective and a higher $\mathrm{Na}$ content salt. Task 2.0 repeated the facility qualification experiment with new parameters and the new salt. Task 2.1 conducted capsule experiments with the dried salt to optimize the $\mathrm{Mg}$ addition and create a baseline for the flowing experiment. Task 2.2 was the third $\mathrm{TCL}$ experiment with a peak temperature of $700^{\circ} \mathrm{C}$ and a sensor.

\section{Project Objective:}

Molten salt compatibility with structural alloys has been identified as a key issue for the development of Generation 3 concentrated solar power (CSP) systems with thermal storage. To accelerate this evaluation to pumped systems, the goal of this project was to identify salt-alloy combinations that are sufficiently compatible in isothermal capsule tests and then conduct thermal convection loop (TCL) experiments with a peak temperature of $\geq 700^{\circ} \mathrm{C}$ and a typical temperature gradient of $\sim 100^{\circ} \mathrm{C}$. The second TCL deployed a sensor and had a peak temperature of $750^{\circ} \mathrm{C}$. The third TCL experiment in Phase 2 used a different salt and a $700^{\circ} \mathrm{C}$ peak temperature with a sensor.

Tasks were broken down per the following:

Task 1.0 Chloride corrosion facilities qualification

Task 1.1 Capsule testing to support loop experiment

Task 1.2 First thermal convection loop test

Task 1.3 Second thermal convection loop test

Task 2.0 Chloride corrosion facilities qualification

Task 2.1 Capsule testing to support loop experiment

Task 2.2 Third thermal convection loop test

\section{Project Results and Discussion:}

This section is broken down by task.

Task 1.0 Chloride corrosion facilities qualification

The parameters for this isothermal demonstration experiment were defined by DOE SETO and the Chloride Collective. They included a Ni container, Haynes 230 specimen (from the same heat) with 120 grit surface finish, industrial-sourced salt provided by ICL to each participant and an exposure of $800^{\circ} \mathrm{C}$ for $100 \mathrm{~h}$. Originally, salt purification was 
determined by each participant but the salt was to contain no additives. The task was later redefined to include $\mathrm{a} \sim 1.7 \% \mathrm{Mg}$ addition. The task criteria are shown in Table 1.

Table 1. Project Evaluation Criteria for Task 1.0

\begin{tabular}{|c|l|l|l|c|c|}
\hline Task & Description & Criteria & $\begin{array}{l}\text { Measured } \\
\text { values }\end{array}$ & Goal Met? & $\begin{array}{c}\text { Supporting } \\
\text { data }\end{array}$ \\
\hline 1.0 & $\begin{array}{l}\text { Complete qualification } \\
\text { capsule testing: conduct } \\
\text { tests based on set } \\
\text { parameters and report } \\
\text { results }\end{array}$ & $\begin{array}{l}\text { 1. Specimen } \\
\text { mass loss } \\
2 .<15 \mu \mathrm{m} / \mathrm{yr} \\
\text { 3. Repeat } \geq 3\end{array}$ & Figure 11 & Yes & Figure 13 \\
& Figure 16 \\
\hline
\end{tabular}

\section{Subtask 1.0.1 Preparation of chloride corrosion crucibles.}

Initially, samples were exposed to molten chloride salt in Alloy 200 ( $>99 \% \mathrm{Ni}, \leq 0.15 \% \mathrm{C}$ ) capsules measuring $2.54 \mathrm{~cm}$ in diameter and $10.2 \mathrm{~cm}$ length, with one sample per capsule. Experiments in molybdenum (LCAC, low carbon arc-cast) capsules also were included for comparison to the ORNL standard protocol that the capsule be inert. A schematic of the capsule design is shown in Fig. 5a. Samples were tethered to one endcap of the capsule using Ni wire. Once the capsule was loaded it was welded shut and then welded inside a type 316 stainless steel capsule to prevent oxidation of the $\mathrm{Ni}$ capsule and provide secondary containment during the experiment, Fig. 5b. Graphite spacers were used to ensure that no interaction occurred between the inner and outer capsules.

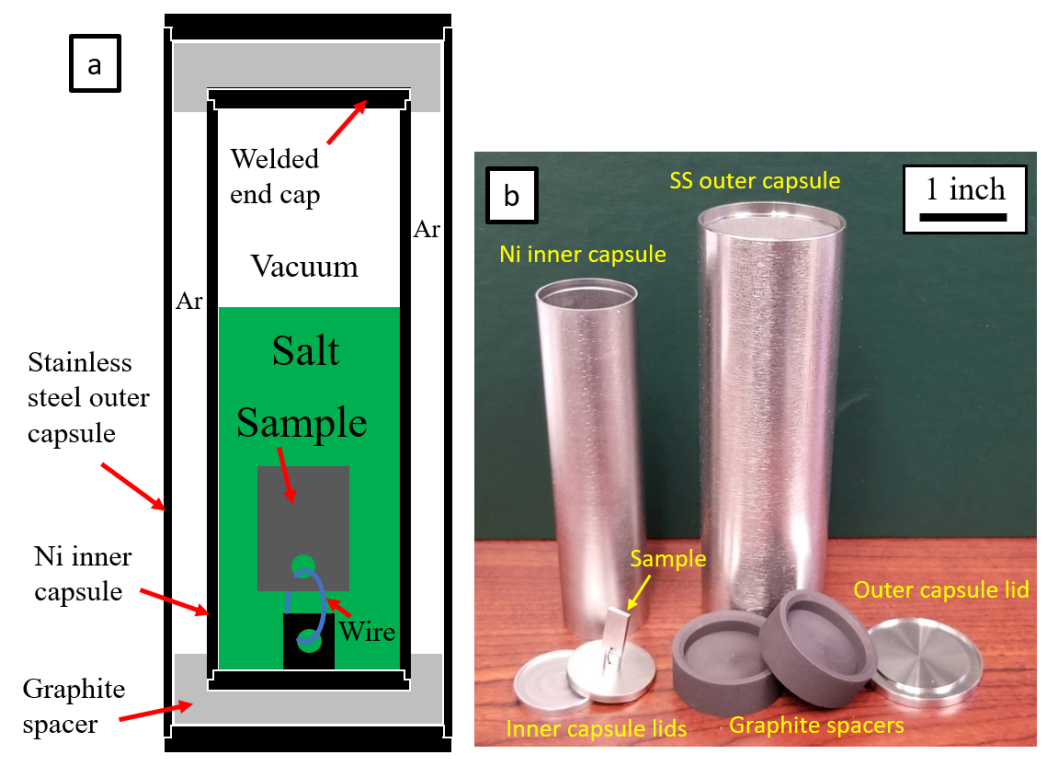

Figure 5. (a) A schematic diagram of a filled capsule (not to scale) and (b) a photograph showing a disassembled capsule with a sample attached to the lid of the inner capsule 
In a second type of experiment, a $250 \mathrm{ml} \mathrm{Ni}$ crucible and lid were purchased per instructions from the Chloride Collective and Savannah River National Laboratory (SRNL). In addition, a stainless steel (SS) "bag" was used to reduce contamination during the experiment. As ORNL does not have a furnace inside a glove box, a SS container was fabricated to hold the bagged crucible during the $100 \mathrm{~h}$ at $800^{\circ} \mathrm{C}$ exposure, Figures $6 \mathrm{a}$ and $6 \mathrm{~b}$. A piece of Ta sheet was added to getter residual $\mathrm{O}$.

\section{Subtask 1.0.2 Accept, characterize, and prepare chloride corrosion salts.}

The standard ORNL process for preparing "laboratory" eutectic $\mathrm{KCl}-\mathrm{MgCl}_{2}$ salt consists of using ACS-grade potassium chloride $(\mathrm{KCl})$ and $98 \%$ pure anhydrous magnesium chloride $\left(\mathrm{MgCl}_{2}\right)$ purchased from Fisher Scientific $(\mathrm{KCl})$ or Milipore-Sigma $\left(\mathrm{MgCl}_{2}\right)$. The water content of the anhydrous $\mathrm{MgCl}_{2}$ is reported as $\leq 0.5 \%$. For purification, carbochlorination via carbon tetrachloride $\left(\mathrm{CCl}_{4}\right)$ is used to remove oxides based on the work of Young and Mamantov [Young 1990, Chen 1993]. The KCl was melted and equilibrated at $850^{\circ} \mathrm{C}$ followed by sparging the molten salt with carbon tetrachloride $\left(\mathrm{CCl}_{4}\right)$ for $3 \mathrm{~h}$, argon for $0.5 \mathrm{~h}$, argon with $4 \%$ hydrogen in argon for $1 \mathrm{~h}$, and argon again for $0.5 \mathrm{~h}$. All gases were Ultra-high Purity (UHP) grade from Airgas and further purified to remove trace moisture with phosphorus pentoxide $\left(\mathrm{P}_{2} \mathrm{O}_{5}\right)$ layered with Drierite ${ }^{\mathrm{TM}}$. The $\mathrm{MgCl}_{2}$ was purified with the carnallite method, in which the salt is physically mixed with ammonium chloride $\left(\mathrm{NH}_{4} \mathrm{Cl}\right)$ in a 2:1 $\mathrm{MgCl}_{2}: \mathrm{NH}_{4} \mathrm{Cl}$ ratio, heated to $450^{\circ} \mathrm{C}$ for $2 \mathrm{~h}$ followed by $1 \mathrm{~h}$ at $750^{\circ} \mathrm{C}$. The mixture was then sparged with $\mathrm{CCl}_{4}$ at $850^{\circ} \mathrm{C}$ for $35-40 \mathrm{~h}$, followed by argon for $0.5 \mathrm{~h}$. The mixture was then sparged with Ar$4 \% \mathrm{H}_{2}$ for $12-15 \mathrm{~h}$, followed by argon for $0.5 \mathrm{~h}$. Lastly, the $\mathrm{KCl}$ and $\mathrm{MgCl}_{2}$ were mixed together in the desired $68 / 32$ eutectic composition, heated to $850^{\circ} \mathrm{C}$, and sparged with Ar for $0.5 \mathrm{~h}$ to effectively mix the salts. In Table 2 , this is salt \#3.

(a)

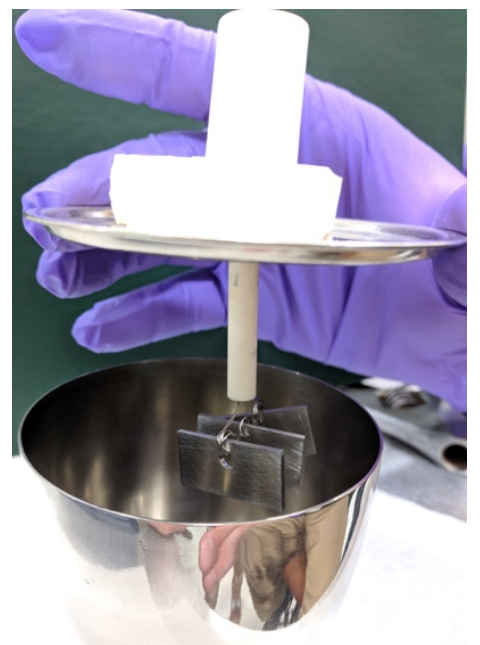

(b)

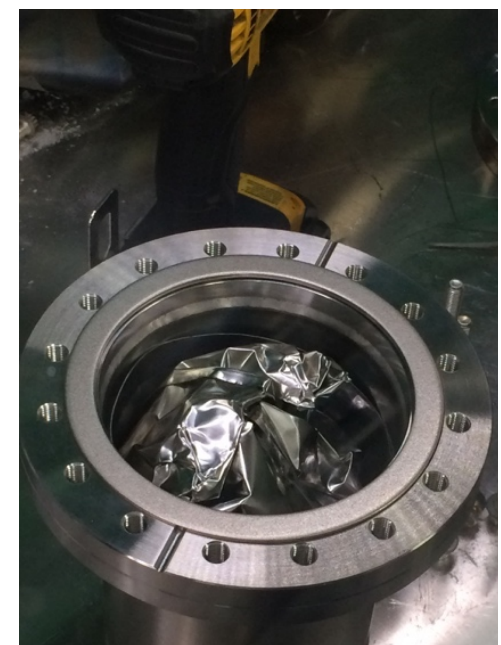

(c)

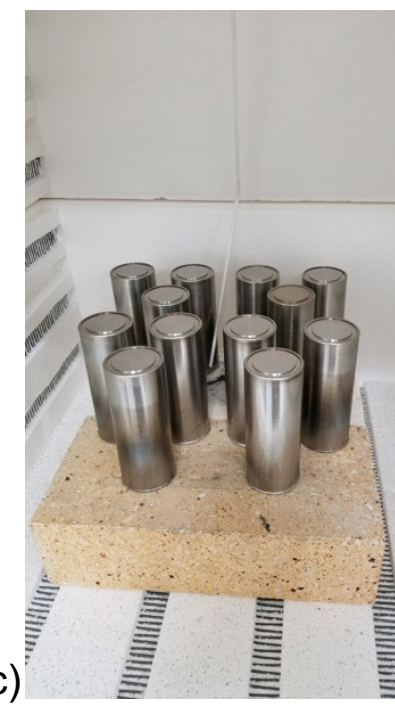

Figure 6. Images of (a) Ni crucible, samples and lid, (b) SS vessel with crucible loaded in SS bag before sealing and (c) loaded capsules before heating in box furnace to $800^{\circ} \mathrm{C}$. 
The "CSP Salt," described as $\mathrm{Na-K}-\mathrm{Mg}-\mathrm{Cl}$, was provided by the program and used herein, the starting composition is show in Table 2. It was dried via the carnallite method due to the $4.5 \%$ water present, as reported by the supplied elemental analysis, followed by carbochlorination via sparging the molten salt with $\mathrm{CCl}_{4}$ as described above for the anhydrous $\mathrm{MgCl}_{2}$ with the exception of time. The as-received salt was analyzed by inductively coupled plasma optical emission spectroscopy (ICP-OES) in the asreceived condition and after the carnallite process (Salt \#2 in Table 2) and after the carnallite and sparging processes (Salt \#1 in Table 2). The laboratory eutectic salt is shown for comparison (Salt \#3). Unfortunately, ICP-OES was not adequate for determining the composition, particularly the $\mathrm{Fe}, \mathrm{Mn}$ and $\mathrm{Zn}$ contents at ppm levels. Inductively coupled plasma mass spectroscopy (ICP-MS) also was attempted to resolve that issue but was not successful. Also, because of the high $\mathrm{Cl}$ content, it was not possible to determine the $\mathrm{SO}_{4}{ }^{2-}$ content.

In order to determine the oxide content of the salt at various processing stages, an acidbase titration process was used. (NREL recently developed a different procedure [Klammer 2020].). A known amount of salt was dissolved in deionized water (18.2 M $\Omega$ resistivity). The $\mathrm{pH}$ and potential $(\mathrm{mV})$ of the solution was measured with a calibrated $\mathrm{pH}$ probe. The solution was titrated with aliquotes of $\mathrm{HCl}$ until neutral $\mathrm{pH}$ was obtained. As this is a strong acid-weak base titration, complex equilibria exist between the magnesium oxide $(\mathrm{MgO})$, magnesium hydroxide $\left(\mathrm{Mg}(\mathrm{OH})_{2}\right)$, and $\mathrm{MgCl}_{2}$ in the solution. Attention to the equilibration time was required and each salt tested required an equilibration study to determine an effective equilibration time that did not result in significant $\mathrm{pH}$ probe signal drift. For these salts, 5-10 min was adequate. After titration, the amount of $\mathrm{HCl}$ consumed was equated to the amount of $\mathrm{MgO}$ present within the salt. The use of $\mathrm{MgO}$ for the calculations was based upon the thermodynamics of the salt wherein at the temperatures used for carbochlorination, $\mathrm{MgO}$ is the thermodynamically preferred species and thus the basicity is assumed to be due to the presence of $\mathrm{MgO}$. While $\mathrm{MgO}$ does precipitate out of the salt, there is reported to be a high solubility of MgO within chloride salts [Ostvold 1972, Boghosian 1991, Mediaas 1997, Vindstad 1997, Ito 2004]. It has not been established if the

Table 2. Chemical composition of the industrial-sourced salt determined by mass spectrometry and acid-base titration for the $\mathrm{O}_{2}$ content for each of the salt variations.

\begin{tabular}{|c|c|c|c|c|c|c|c|c|c|c|c|c|}
\hline Element & $\begin{array}{c}\mathbf{K} \\
(\%)\end{array}$ & $\begin{array}{c}\mathbf{M g} \\
(\%)\end{array}$ & $\begin{array}{c}\mathbf{N a} \\
(\%)\end{array}$ & $\begin{array}{c}\mathbf{B} \\
(\mathbf{p p m})\end{array}$ & $\begin{array}{c}\mathbf{F e} \\
(\mathbf{p p m})\end{array}$ & $\begin{array}{c}\mathbf{M n} \\
(\mathbf{p p m})\end{array}$ & $\begin{array}{c}\mathbf{S O}_{4} \\
(\mathbf{p p m})\end{array}$ & $\begin{array}{c}\mathbf{Z n} \\
(\mathbf{p p m})\end{array}$ & $\begin{array}{c}\mathbf{B r} \\
(\%)\end{array}$ & $\begin{array}{c}\mathbf{C l} \\
(\%)\end{array}$ & $\begin{array}{c}\mathbf{H}_{2} \mathbf{O} \\
(\%)\end{array}$ & $\begin{array}{c}\mathbf{O}_{2} \\
(\mathbf{m m o l} / \mathbf{k g})\end{array}$ \\
\hline Specification $^{1}$ & 21.2 & 12.8 & 1.33 & 2.5 & 4 & 2.8 & 186 & 1 & 0.58 & 58.2 & 5 & \\
\hline As Received & 19.7 & 12.8 & 1.55 & $* *$ & 4.67 & 3.36 & $\wedge$ & 0.3 & 0.61 & 61 & 5 & \\
\hline Salt \#1 & 20.1 & 12.9 & 1.62 & $* *$ & 1.65 & 1.20 & $\wedge$ & 0.04 & n.d. & 65 & $*$ & 197 \\
\hline Salt \#2 & 18.4 & 11.9 & 1.76 & $* *$ & 5.63 & 2.46 & $\wedge$ & 0.31 & 0.39 & n/a & $*$ & 3934 \\
\hline Salt \#3 & 29.3 & 9.1 & n/a & $* *$ & $* *$ & $\star *$ & $\wedge$ & $\star *$ & n/a & n/a & $*$ & 298 \\
\hline
\end{tabular}

${ }^{1}$ as received from industrial salt manufacturer (ICL) documentation

*below detection limits

**below detection limits of ICP-OES \& ICP-MS

${ }^{\wedge}$ Sulfate determination could not be performed on IC due to chloride concentration (resulting in salting out $\mathrm{Cl}$ ); ICP analysis indicated presence of sulfur but was not quantifiable. 
precipitated $\mathrm{MgO}$ contributes to the corrosion of structural alloys in the salt. However, it will influence the $\mathrm{MgO}$ equilibrium within the melt. If $\mathrm{MgO}$ is consumed in the corrosion process, the insoluble $\mathrm{MgO}$ will ensure the maximum solubilized $\mathrm{MgO}$ is present within the melt, perhaps further enhancing the corrosion. To fully understand the influence of oxide content on corrosion, a method to relate the oxide content is required. In the case of the eutectic $\mathrm{KCl}-\mathrm{MgCl}_{2}$ "bottled" salt \#3, a molecular formula can be proposed that allows an oxide measurement as parts per million (24 ppm for salt \#3). However, for the industrial-sourced salts \#1 and \#2, a molecular formula is harder to propose because of the complex composition. Therefore, micro-molal $(\mu \mathrm{m})$, i.e. micromoles of $\mathrm{MgO}$ per kg of salt, was used as the unit of measure for oxide content for the salts studied to date, Table 2 . After only the carnallite process, the oxide content was still $3934 \mu \mathrm{mol} / \mathrm{kg}$. The additional $\mathrm{CCl}_{4}$ sparging process dropped the $\mathrm{O}$ content to 197 $\mu \mathrm{mol} / \mathrm{kg}$, lower than the eutectic laboratory (bottled) salt. A second batch of salt \#1 (\#1A) showed an even lower oxide content that could not be quantified.

For the crucible test, the SRNL procedure was followed to slowly heat the salt with $\mathrm{N}_{2}$ purge to $600^{\circ} \mathrm{C}$ and drive off water. Per instructions, $5.1 \mathrm{~g}$ of Mg was added to $300 \mathrm{~g}$ of salt (>1.7 wt. \%) and slowly heated to $850^{\circ} \mathrm{C}$. After cooling, $170 \mathrm{~g}$ of salt was selected for the corrosion experiment.

\section{Subtask 1.0.3. Accept, characterize, and prepare Haynes 230 control samples.}

Samples were prepared from $\sim 12 \mathrm{~mm}$ thick Haynes ${ }^{\mathrm{TM}} 230^{\mathrm{TM}}$ plate (pieces of the same plate were delivered to all participants), which was cut into specimens measuring $12.5 \mathrm{x}$ $6.2 \times 1.6 \mathrm{~mm}$ with a $0.5 \mathrm{~mm}$-diameter hole for the capsule experiments. The chemical composition of the 230 plate is shown in Table 3. Prior to loading in the capsule, all of the coupons were ground to 120-grit finish, except one sample which was ground to a 600 grit finish for comparison. The specimens were weighed using a Mettler Toledo model XP205 balance with an accuracy of $\sim \pm 0.04 \mathrm{mg}$.

For the crucible experiment, larger alloy 230 specimens measuring $12.8 \times 25.6 \times 1.7 \mathrm{~mm}$ with a $4 \mathrm{~mm}$ diameter hole were used. Figure 6 a shows specimens hung together on $\mathrm{Ni}$ wire with an alumina holder to electrically isolate the specimens from the crucible.

\section{Subtask 1.0.4. Run \& analyze results from $\mathrm{H} 230$ chloride corrosion experiments.}

Each capsule was filled with $48 \mathrm{~g}$ of a mixture of lump and powdered salt, with a volume of $31.9 \mathrm{~cm}^{3}$ at $800^{\circ} \mathrm{C}$, based on a temperature-dependent density of $1.5 \mathrm{~g} / \mathrm{cm}^{2}$ [Williams 2006]. Based on the salt volume, the inner capsule area in contact with the salt was $61 \mathrm{~cm}^{2}$. Using an average sample surface area of $2.2 \mathrm{~cm}^{2}$, Table 4 shows various ratios calculated for the capsule (Figure 5) and crucible (Figure 6) experiments:

Table 3. Alloy chemical composition in weight $\%$ measured using inductively coupled plasma and combustion analyses.

\begin{tabular}{|c|c|c|c|c|c|c|c|c|c|c|c|}
\hline Alloy & $\mathrm{Ni}$ & $\mathrm{Cr}$ & $\mathrm{Fe}$ & Al & $\mathbf{W}$ & Mo & Ti & $\mathrm{Mr}$ & $\mathrm{Si}$ & $S(k$ & ) Other \\
\hline 30 & 58.4 & 23. & 1.5 & 0.3 & 14.0 & 1.3 & 0.01 & 0.49 & 0.3 & $<3$ & $0.11 \mathrm{C}, 0.01$ \\
\hline 00T & 75.5 & 15.3 & 9.4 & 0.2 & 0.01 & 0.01 & 0.15 & 0.60 & 0. & $<3$ & $0.05 \mathrm{C}$ \\
\hline OOS & 77.1 & 14 & 7. & 0.2 & $<0.01$ & $<0.01$ & 0.20 & 0. & 0 & 4 & $0.08 \mathrm{C}$ \\
\hline 244 & 62.2 & 8 & $1 .($ & 0.1 & 5.9 & 22.4 & 0.002 & 0.29 & 0.04 & $<3$ & $0.002 \mathrm{C}$ \\
\hline 24 & 57.7 & 16.0 & 5.7 & 0.2 & 3.5 & 15.3 & 0.005 & 0.57 & 0.06 & $<3$ & $0.002 \mathrm{C}$ \\
\hline
\end{tabular}


Table 4. Various ratios calculated for the capsule and crucible experiments used in these experiments.

\begin{tabular}{|l|c|c|}
\hline & Capsule & Crucible \\
\hline Salt volume / sample area $\left(\mathrm{cc} / \mathrm{cm}^{2}\right):$ & 14.6 & 4.9 \\
\hline Salt volume / container surface contacting salt $\left(\mathrm{cc} / \mathrm{cm}^{2}\right):$ & 0.5 & 1.0 \\
\hline Container surface in contact with the salt / sample area: & 28.1 & 4.7 \\
\hline
\end{tabular}

Both capsules and the crucible were filled in an Ar-filled glovebox with dynamic moisture and oxygen removal. Capsule lids were press fit onto the open end of the capsules. Capsules were then transported under Ar gas in Mason-style jars to an electron-beam (EB) welder where they were removed from the jar, placed in the welding chamber and pumped down to vacuum. The chamber was allowed to pump overnight before welding the lids shut. Subsequently, the Ni and Mo capsules were welded inside a stainless steel outer capsule with graphite spacers to prevent any interaction between the inner and outer capsules during the thermal exposure, Figure $5 b$.

The capsules were heated in a box furnace at $800^{\circ} \mathrm{C}$. Due to an error, the first capsules with CSP salt \#1 (carnallite + sparging in Table 2) were removed after $92 \mathrm{~h}$ instead of $100 \mathrm{~h}$. At the end of the exposure, the capsules were inverted to allow the salt to drain away from the specimen. After cooling, samples were removed from the capsules and cleaned with $40^{\circ} \mathrm{C}$ water to remove any residual salt. The mass loss was measured, and the specific mass loss results are presented in Figure 7 with 5 capsules repeating the same conditions. Subsequently, three capsules were run with CSP salt \#2 (carnallite only) for $100 \mathrm{~h}$ at $800^{\circ} \mathrm{C}$. Given the oxide contents measured in Table 2, it was surprising that mass losses were similar in the two salts. To better understand the other parameters being used for this task, several other capsules also were exposed. Mass losses using a Mo capsule and salt \#1 or a Ni capsule with eutectic laboratory salt both showed slightly lower mass losses but not the order of magnitude decrease needed to meet the $15 \mu \mathrm{m} /$ year task goal. Finally, one coupon was exposed with a 600 grit finish using a Ni capsule and salt \#1, which also showed a similar mass loss as the 120 grit specimens.

To complete the prescribed characterization, each sample was metallographically mounted in epoxy and polished. Figure 8 shows example sections with the dark areas indicating porosity where $\mathrm{Cr}$ was selectively removed from the alloy, particularly along alloy grain boundaries. Figure 9 shows box and whisker plots of $\sim 30$ measurements from each specimen with the median value noted. For the five repeat capsules, the median value was $92 \mu \mathrm{m}$ (larger shaded box). For comparison, alloy 230 samples exposed to eutectic $\mathrm{KCl}-\mathrm{MgCl}_{2}$ at $750^{\circ} \mathrm{C}$ for $300 \mathrm{~h}$ in $\mathrm{Mo}$ capsules also are shown. The correlation between mass loss and median depth of depletion will be discussed below.

The depth of $\geq 2 \% \mathrm{Cr}$ depletion was quantified using electron microprobe analysis (EPMA) with standard-based wavelength dispersive spectroscopy (WDS) or scanning electron microscopy (SEM) with standardless energy dispersive spectroscopy (EDS). Figure 10a shows typical WDS spectra where the Cr content has dropped at the surface to $0-10 \%$ after $92 \mathrm{~h}$ in salt $\# 1$ at $800^{\circ} \mathrm{C}$ and the depth of $\geq 2 \% \mathrm{Cr}$ varied locally depending on the location of grain boundaries. SEM/EDS analysis of each specimen is 


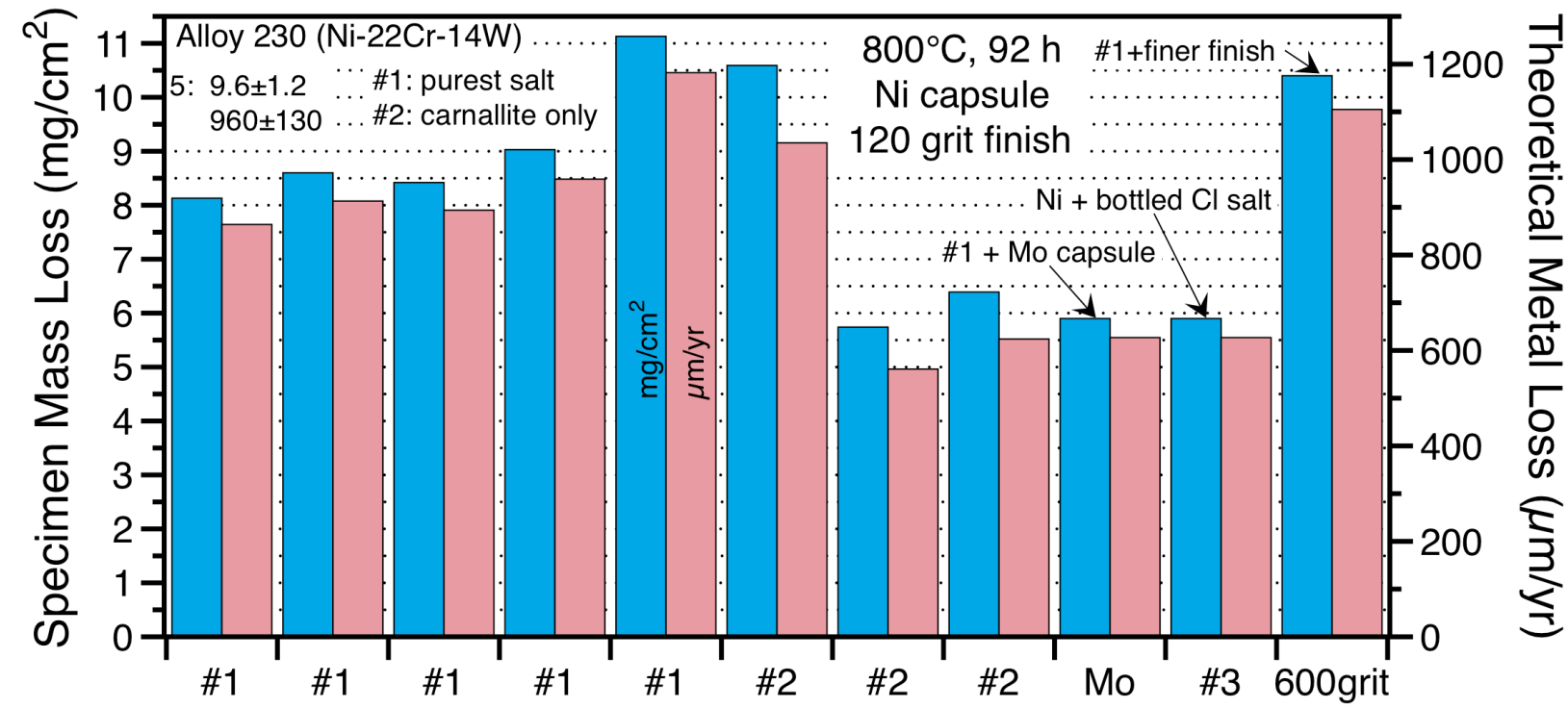

Figure 7. Specimen mass loss and calculated theoretical uniform metal loss converted to $\mu \mathrm{m} / \mathrm{yr}$ assuming a linear rate law. Salt \#2 was purified using only the carnallite process and those capsules ran for $100 \mathrm{~h}$. Salt \#1 used in all of the other capsules used the carnallite plus sparging.

resource intensive. Figure 10b shows the relationship between average void depth and EDS depth where the $\mathrm{Cr}$ level had dropped $\geq 2 \%$ and the results are fairly similar.

Therefore, the median void depth was used for subsequent experiments and SEM/EDS was reserved for the most critical specimens.

After the unexpected high mass losses in the capsule experiments, the crucible experiment was conducted to repeat the results of the other laboratories in the Chloride Collective using the same alloy 230 specimens exposed for $100 \mathrm{~h}$ at $800^{\circ} \mathrm{C}$ in the $\mathrm{Mg}$ modified industrial-sourced salt prepared by the procedure described above. Figure 11 shows the mass loss data from all three national laboratory members of the Chloride Collective. All of the mass changes (gains and losses) are relatively low and similar.

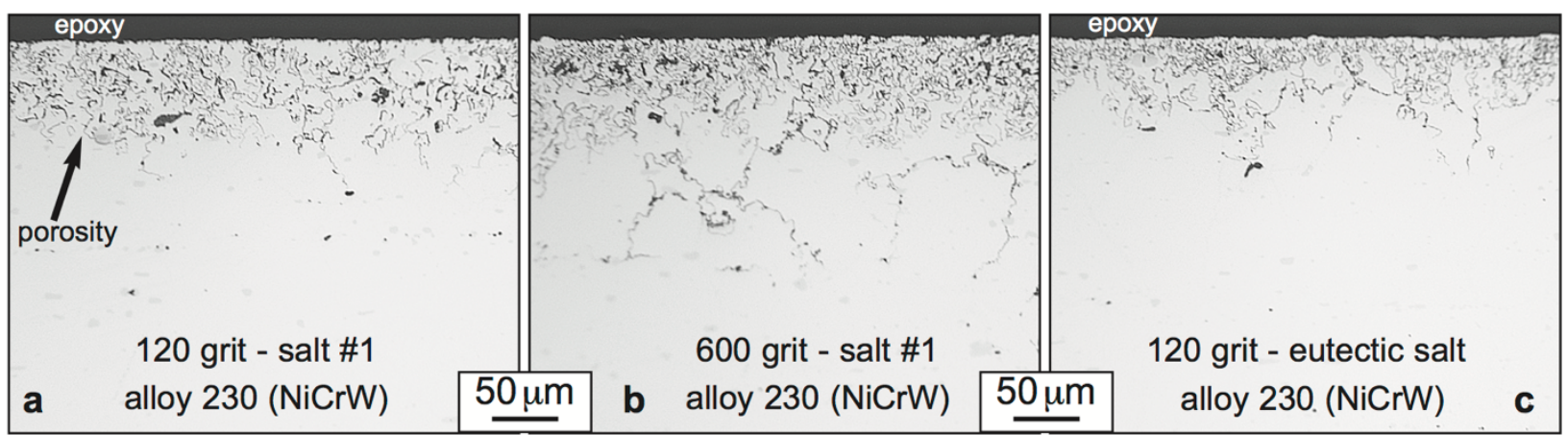

Figure 8. Representative light microscopy of polished sections of alloy 230 after $92 \mathrm{~h}$ at $800^{\circ} \mathrm{C}$ (a) 120 grit, salt \#1, (b) 600 grit, salt \#1, (c) 120 grit, eutectic salt. 
CPS 33873

Progression to Flowing Molten Salts

ORNL Pint

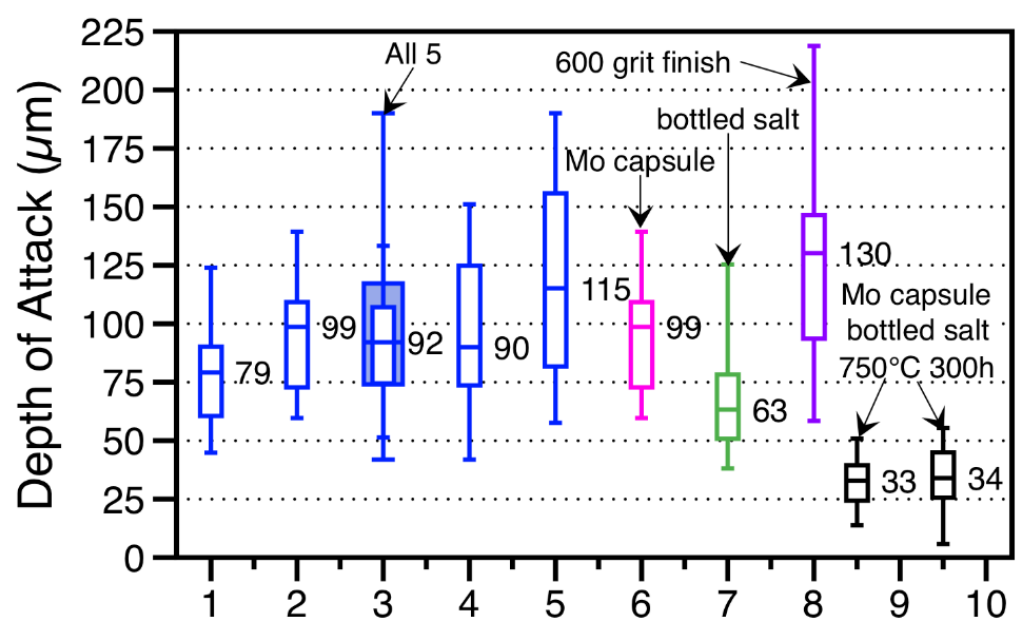

Figure 9. Measured depth of attack for 8 alloy 230 specimens shown in Figure 2 exposed for $92 \mathrm{~h}$ at $800^{\circ} \mathrm{C}$. For comparison, two $750^{\circ} \mathrm{C} / 300 \mathrm{~h}$ exposures of a different alloy 230 heat are shown.

Rather than mass losses in Figure 7, the ORNL experiments showed a mass gain after $100 \mathrm{~h}$ at $800^{\circ} \mathrm{C}$. The standard deviation for the ORNL experiments is similar to that for NREL but the average mass gain was slightly higher. The surface of one specimen was examined by x-ray photoelectron spectroscopy (XPS) prior to mounting. The surface had measurable levels of $\mathrm{Zn}, \mathrm{Cu}$ and $\mathrm{Cl}$ which sputtered away very quickly. An $\mathrm{O}$ signal was gone by $20-30 \mathrm{~nm}$ of sputtering. However, the underlying surface contained $\sim 18 \% \mathrm{Mg}$ and $<1 \% \mathrm{Cr}$ to a depth of $300-500 \mathrm{~nm}$ where the sputtering was stopped. Thus, the mass gain appears to be attributed to $\mathrm{Mg}$ uptake and not oxide formation. Also, the lack of $\mathrm{Cr}$ and $\mathrm{W}$ suggests that $\mathrm{Ni}$ diffused outward to react with the $\mathrm{Mg}$ in the salt. The mass change variations in Figure 11 may be due to the amount of $\mathrm{Mg}$
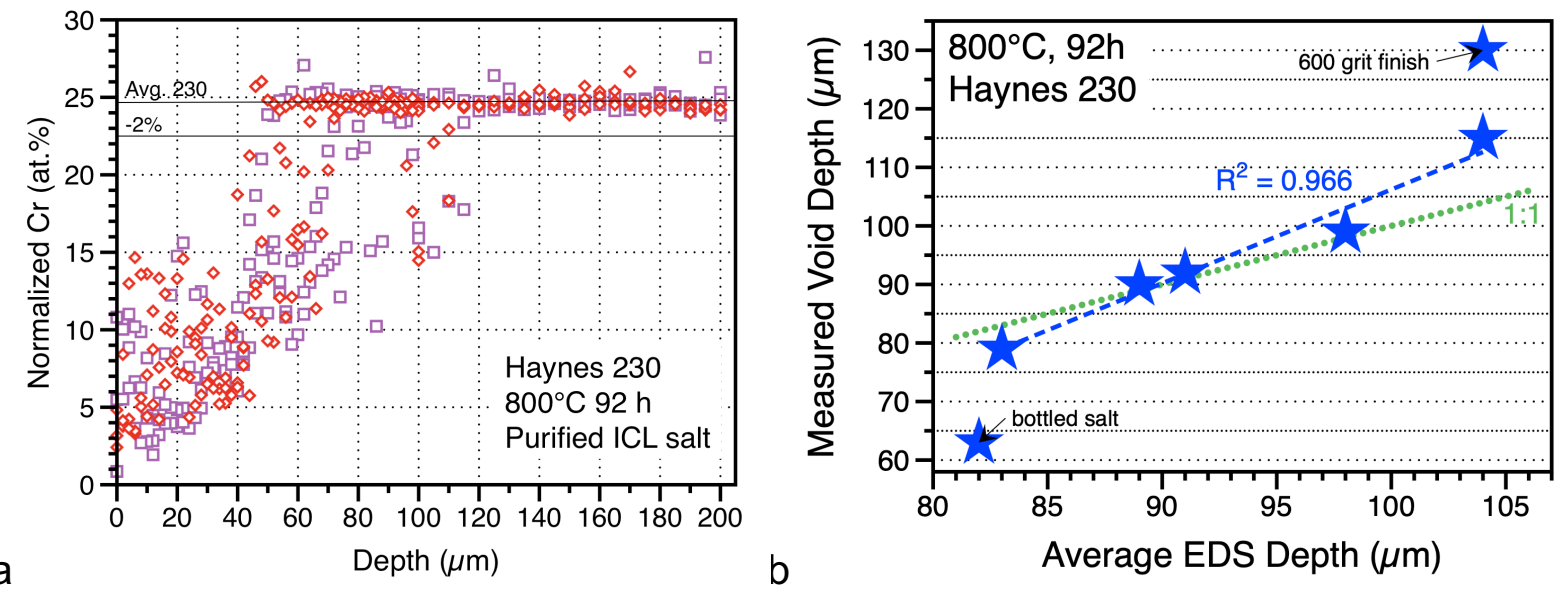

Figure 10. (a) EPMA Cr line profiles from several alloy 230 specimens exposed for $92 \mathrm{~h}$ and (b) comparison between depth of $2 \%$ depletion by WDS/EDS and average measured void depth from image analysis of light microscopy. 


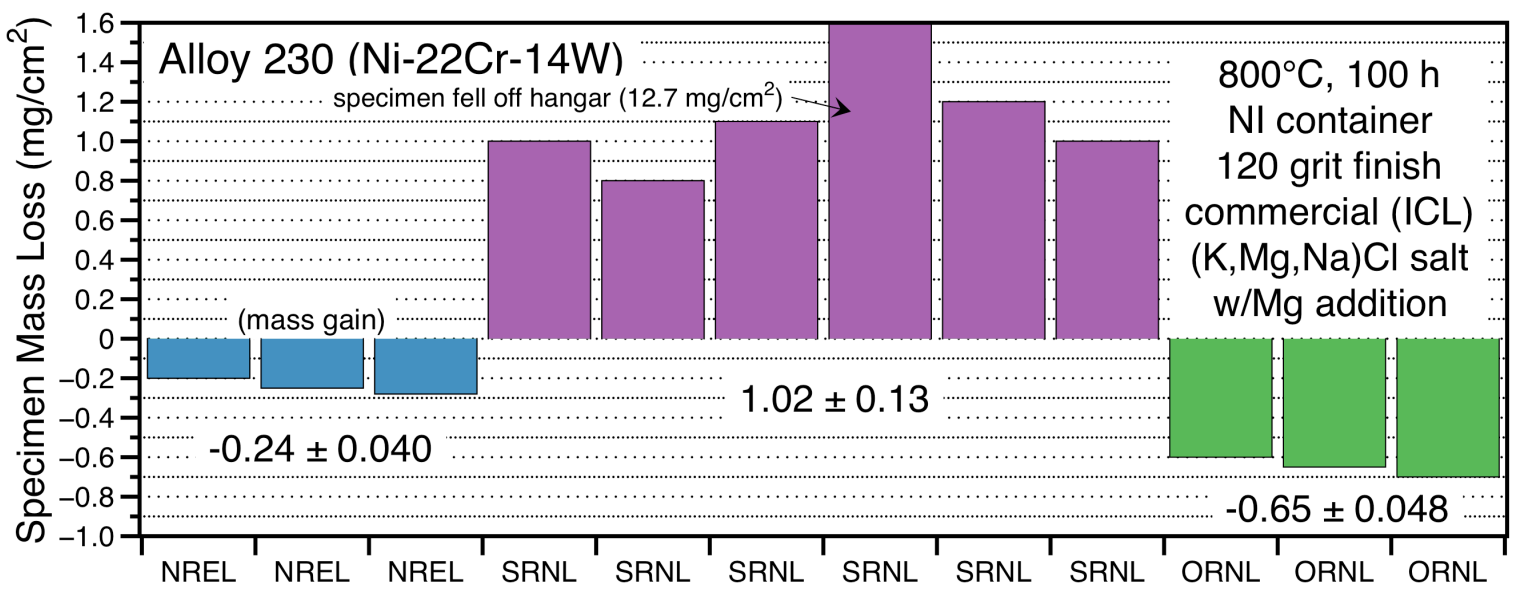

Figure 11. Specimen mass loss for alloy 230 specimens after $100 \mathrm{~h}$ at $800^{\circ} \mathrm{C}$ in industrialsourced salt with a Mg addition. Additional results shown for SRNL and NREL.

retained in the salt for the experiment or the salt volume/specimen surface area (V/SA) in each experiment. SRNL was able to remove excess $\mathrm{Mg}$ from their salt in their process resulting in a small mass loss. However, NREL and ORNL did not remove the Mg and both found mass gains after exposure. Also, since the ORNL procedure did not expose the salt to ambient air, the impurities may have been lower.

Figure $12 \mathrm{~b}$ shows a cross-section of one of the alloy 230 specimens exposed in the crucible with the high $\mathrm{Mg}$ salt for $100 \mathrm{~h}$ at $800^{\circ} \mathrm{C}$. The surface layer appears to be $\sim 10$ $\mu \mathrm{m}$ thick with an intermixed layer beneath it. For comparison, Figure 7 a shows the much deeper attack observed in salt \#1. Figure 13 shows line profiles from one specimen that are representative of the other measurements. The outermost layer appeared to contain only $\mathrm{Ni}$ and $\sim 18 \% \mathrm{Mg}$. Very little $\mathrm{Cr}$ or $\mathrm{W}$ was observed in the outer layer. The inner layer was enriched in $\mathrm{Cr}$, apparently due to the outward diffusion of $\mathrm{Ni}$ and also contained some Mg. Figures 14 and 15 show EDX maps of this region on a second specimen. The maps confirm that the outer layer is rich in $\mathrm{Ni}$ and $\mathrm{Mg}$ and depleted in $\mathrm{Cr}$ and $\mathrm{W}$ compared to the adjacent substrate. The inner layer is enriched in $\mathrm{Cr}, \mathrm{W}$ and Mo. The map in $14 \mathrm{~d}$ also indicates the $\mathrm{Fe}$ is enriched in the inner layer. The alloy contains $1.5 \% \mathrm{Fe}$, Table 3.

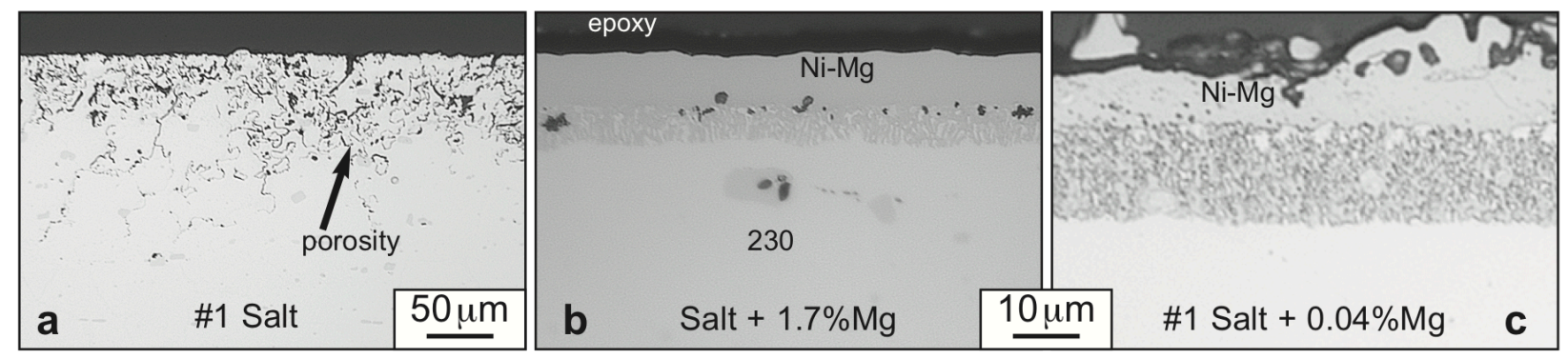

Figure 12. Light microscopy of polished sections of alloy 230 after $100 \mathrm{~h}$ at $800^{\circ} \mathrm{C}$ in (a) salt \#1 (V/SA=14.6) in a Ni capsule, (b) salt $+1.7 \% \mathrm{Mg}(\mathrm{V} / \mathrm{SA}=4.9)$ in a Ni crucible, (c) salt $\# 1+0.04 \% \mathrm{Mg}(\mathrm{V} / \mathrm{SA}=14.6)$ in a Mo capsule. 

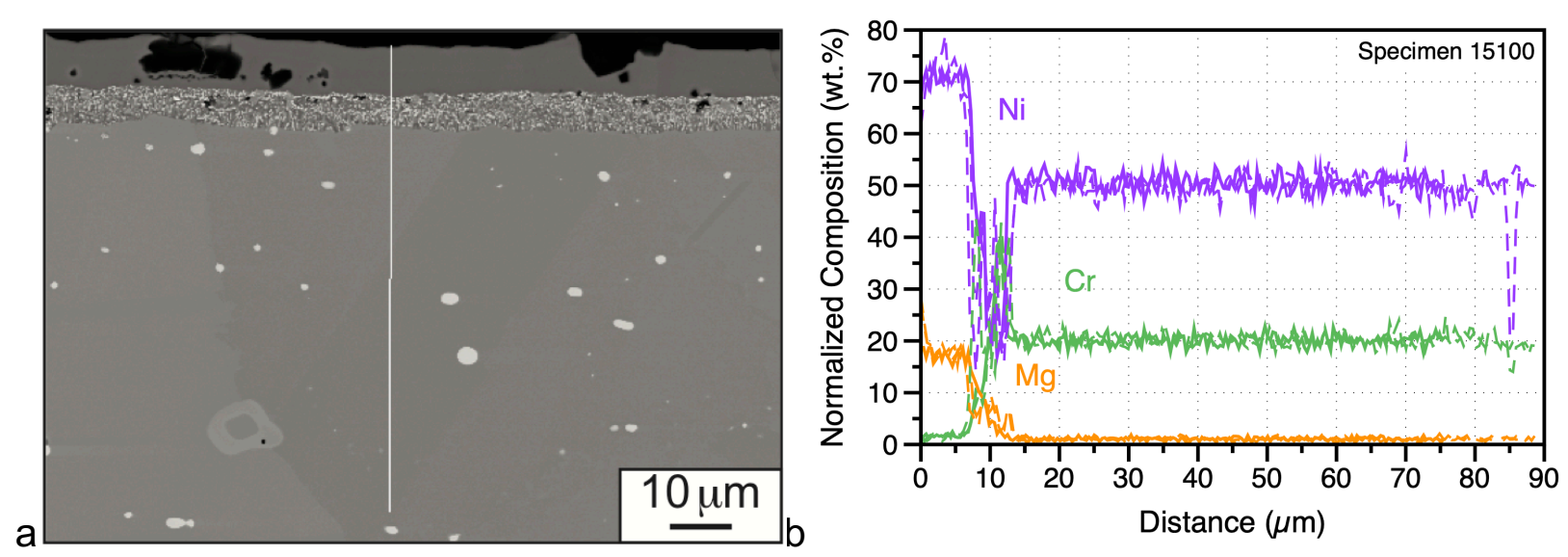

Figure 13. (a) SEM backscattered electron image of a polished section of alloy 230 after $100 \mathrm{~h}$ at $800^{\circ} \mathrm{C}$ in industrial-sourced salt $+1.7 \% \mathrm{Mg}$ and (b) three SEM/EDX profiles from sample, sold line is from line shown in (a) and dashed lines are from other locations.

The map in Figure 14 was selected because it also showed Mg-rich oxide entrapped in the outer layer and oxide in the inner layer. Since the salt in this experiment was not purified like salt \#1, it is likely that Mg-rich oxide was present in the salt and particles could be trapped in the outward growing Ni-Mg layer. However, it is more difficult to explain the $\mathrm{O}$ in the inner layer. Figure 15 includes higher magnification EDX maps of the inner region on the same specimen. Surprisingly, the $\mathrm{O}$ appears to be associated with $\mathrm{Cr}$ in this layer. Additional characterization is needed to resolve the composition and formation of this microstructure. A great deal could be learned from comparing the NREL specimens in Figure 11. It is possible that $\mathrm{Cl}$ was present in this layer but was removed
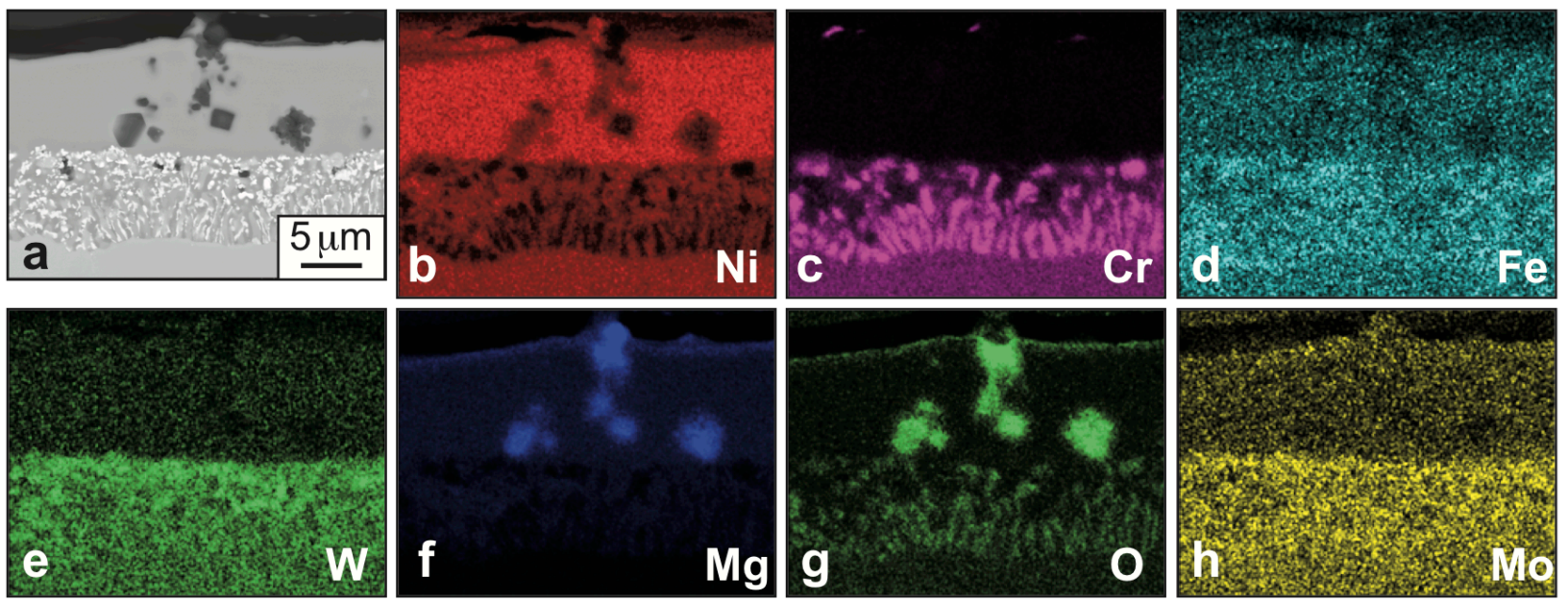

Figure 14. (a) SEM backscattered electron image of a polished section of alloy 230 after $100 \mathrm{~h}$ at $800^{\circ} \mathrm{C}$ in industrial-sourced salt $+1.7 \% \mathrm{Mg}$ and EDX maps of the area in (a): (b) $\mathrm{Ni}$, (c) $\mathrm{Cr}$, (d) $\mathrm{Fe},(\mathrm{e}) \mathrm{W}$, (f) $\mathrm{Mg}$, (g) $\mathrm{O}$ and (h) Mo. 

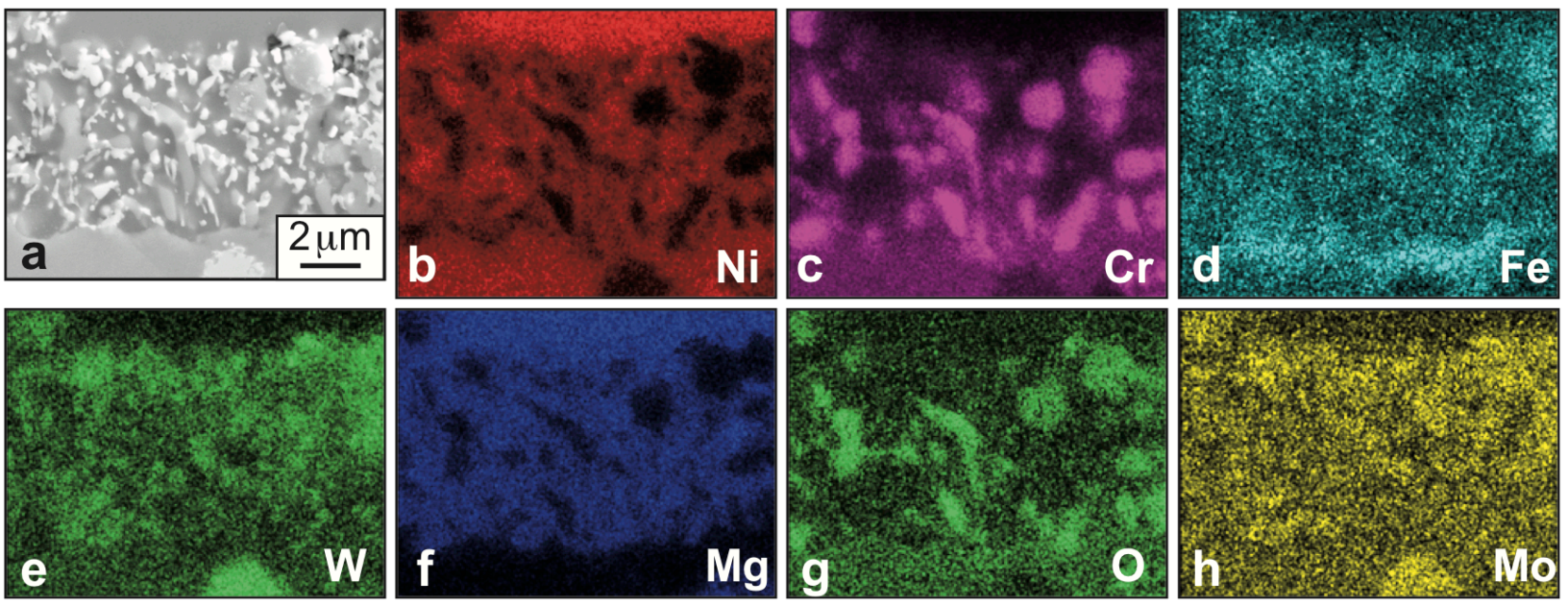

Figure 15. (a) SEM backscattered electron image of polished section of alloy 230 after $100 \mathrm{~h}$ at $800^{\circ} \mathrm{C}$ in industrial-sourced salt $+1.7 \% \mathrm{Mg}$ and EDX maps of the area in (a): (b) $\mathrm{Ni}$, (c) $\mathrm{Cr}$, (d) Fe, (e) W, (f) Mg, (g) O and (h) Mo.

during cleaning or polishing.

Finally, one specimen was analyzed using glow discharge optical emission spectroscopy (GDOES), Figure 16. Qualitatively, the results were similar to those determined by SEM/EDX and are an average of a $\sim 2 \mathrm{~mm}$ diameter sputter crater determined in a $\sim 15$ min analysis. Rather than $\mathrm{Cr}$ depletion, a Ni-Mg surface layer formed, and $\mathrm{Cr}$ and $\mathrm{W}$ were enriched in the inner layer. The concentrations of $\mathrm{Ni}, \mathrm{Cr}$ and $\mathrm{W}$ could be calculated using the measured light intensities deep into the sample as a reference [Lance 2018], but since the base alloy contained no Mg, a similar calculation cannot be made for $\mathrm{Mg}$ and a Ni/Mg ratio in the layer cannot be calculated using GDOES. Based on XPS and SEM/EDS, the Mg content appears to be $\sim 18$ wt. $\%$.

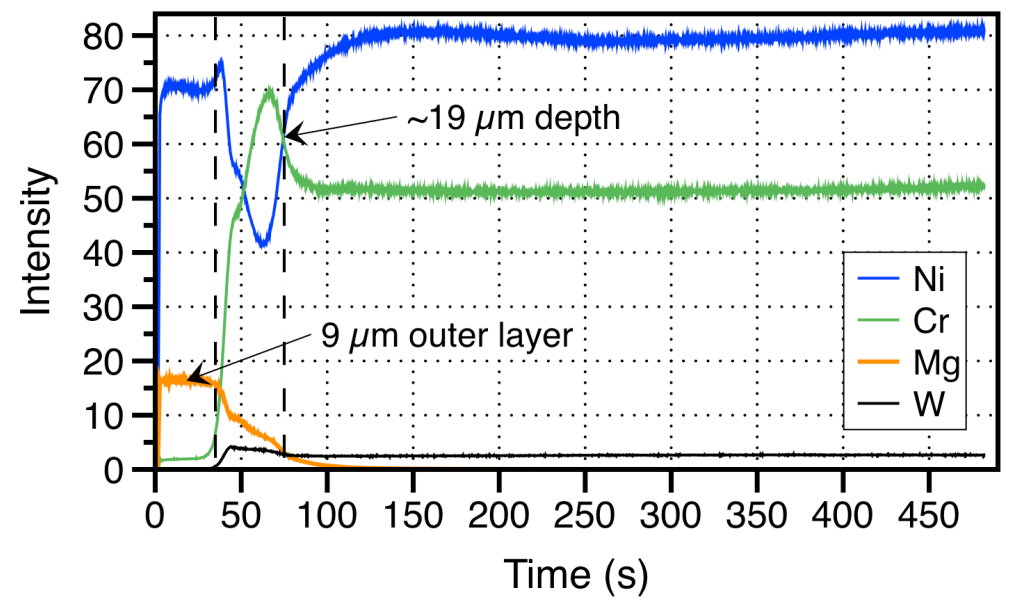

Figure 16. Glow discharge optical emission spectroscopy depth profile of an alloy 230 specimen exposed to $\mathrm{Mg}$-doped salt for $100 \mathrm{~h}$ at $800^{\circ} \mathrm{C}$. 
To further understand these capsule results, a second series of experiments was conducted. Figure 17 summarizes the mass change data from all of the $800^{\circ} \mathrm{C}$ experiments on alloy 230 with results grouped by capsule and salt type. In one experiment, the specimen was inadvertently welded to the Mo wire and no mass change could be measured. Salt \#1B is the batch of salt \#1 used in the first TCL experiment. Without Mg added to any of the salts in Figure 17, all of the mass losses were relatively high compared to the small mass gains in Figure 11. The lowest mass loss was found using salt \#1B in a Mo capsule. However, the scatter in the three experiments was very high. In light of the high mass losses, a thorough review of all procedures was conducted. There was a concern about the purity of $\mathrm{Ar}$ in the glove box during one period and the possibility that the capsules were contaminated when loaded into the EB welder when the lid was in place but not sealed. To avoid this possible source of contamination, the salt \#1B capsules were conventionally welded in an Ar glove box. No dramatic impact of these procedure changes was found. However, tighter procedures were developed to prevent inadvertent contamination in future experiments.

In order to characterize the attack observed in these capsule experiments, specimens were cross-sectioned and typical light microscopy images are shown in Figure 18. As noted above, rather than performing SEM/EDX on each specimen, the average void depth was measured, Figure 19. A simple comparison of the data in Figures 17 and 19 is shown in Figure 20 immediately identifies an interesting result that salt \#2 behaved differently than salts \#1 and \#3. One of the confusing things about the mass loss results in Figures 11 and 17 was that the salt with the lowest purity (\#2) did not show the largest mass loss. Figure 20 suggests a different behavior for salt \#2 in that the average void depth was deeper than expected. Further characterization of two representative specimens suggests that perhaps salt or a reaction product was trapped in the specimen. Whereas the $\mathrm{O}$ and $\mathrm{Mg}$ maps showed very little after exposure in salt \#1 (Figures 21a21d), stronger $\mathrm{O}$ and $\mathrm{Na}$ signals could be seen in the 230 sample exposed to salt \#2.

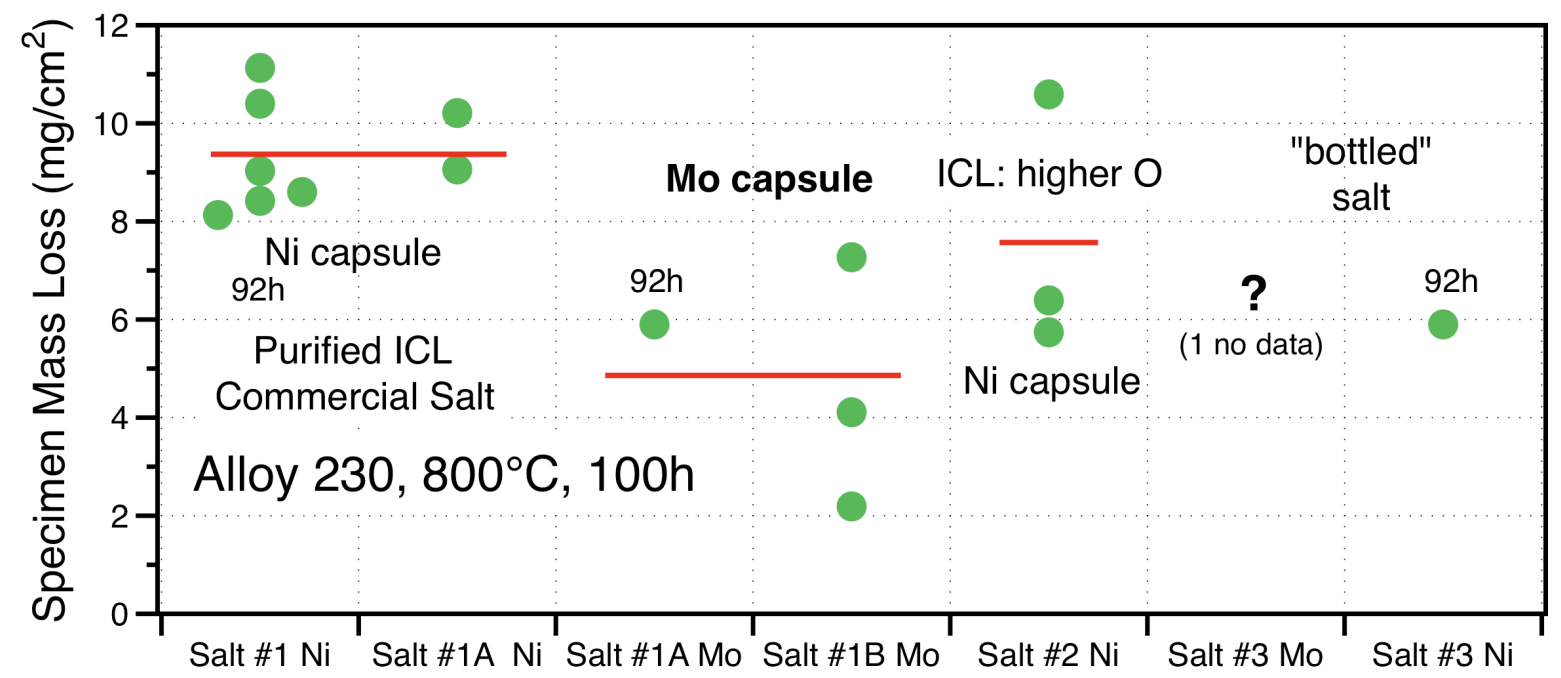

Figure 17. Specimen mass loss results for alloy 230 specimens exposed at $800^{\circ} \mathrm{C}$ to various salts in $\mathrm{Ni}$ or Mo capsules for $92-100 \mathrm{~h}$. 


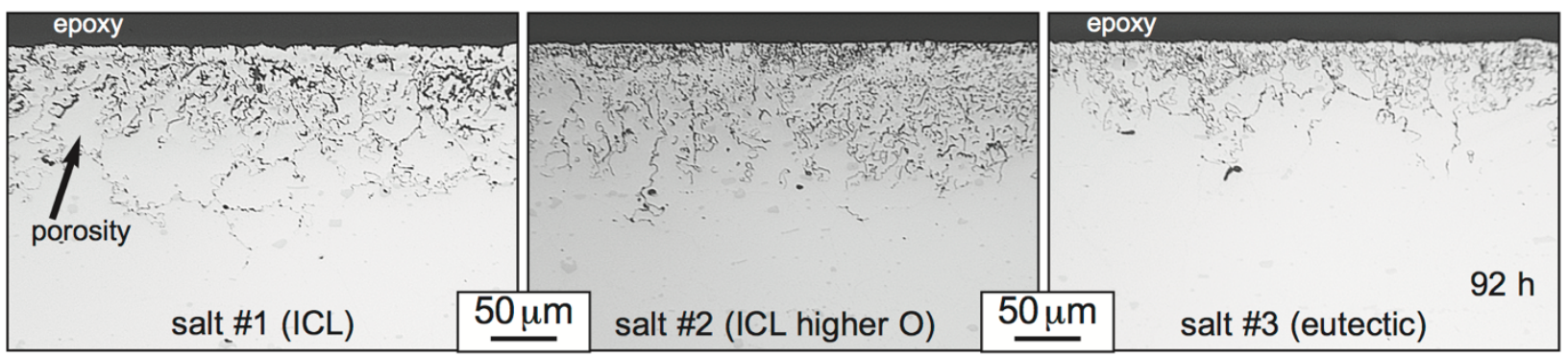

Figure 18. Light microscopy of polished cross-sections of alloy 230 exposed in $\mathrm{Ni}$ capsules at $800^{\circ} \mathrm{C}$ in (a) salt \#1 for $100 \mathrm{~h}$, (b) salt \#2 for $100 \mathrm{~h}$ and (c) salt \#3 for $92 \mathrm{~h}$.

This appears to explain the discrepancy in Figure 20. However, comparing void depths in Figures 18 and 19 for the three salts also may not be an accurate assessment based on the $\mathrm{Cr}$ maps in Figure 21. The $\mathrm{Cr}$ depletion in the maps does not appear to be exactly consistent with void depth in the images. The relationship shown in Figure 10b was only for one salt and $\mathrm{Ni}$ capsules and it may not be applicable to other salts.

A second point about salt composition in Figure 19 is that the lowest void depths were observed for the eutectic $\mathrm{KCl}-\mathrm{MgCl}_{2}$ salt \#3, as indicated in Figure 18. However, only two specimens were exposed to salt \#3 and a wide variation was noted between the $\mathrm{Ni}$ and Mo capsules. A similar relationship was noted for salt \#1 and Figure 22 shows representative images for $\mathrm{Ni}$ and Mo capsules in the two salts. In both cases, the void depth appears to be reduced in the Mo capsule. During the Collective meeting, SRNL staff mentioned that $\mathrm{Cr}$ can react with the $\mathrm{Ni}$ capsule. Based on Equation \#1, if the reaction product ( $\mathrm{Cr}$ in the salt) is being removed from the salt during the exposure then

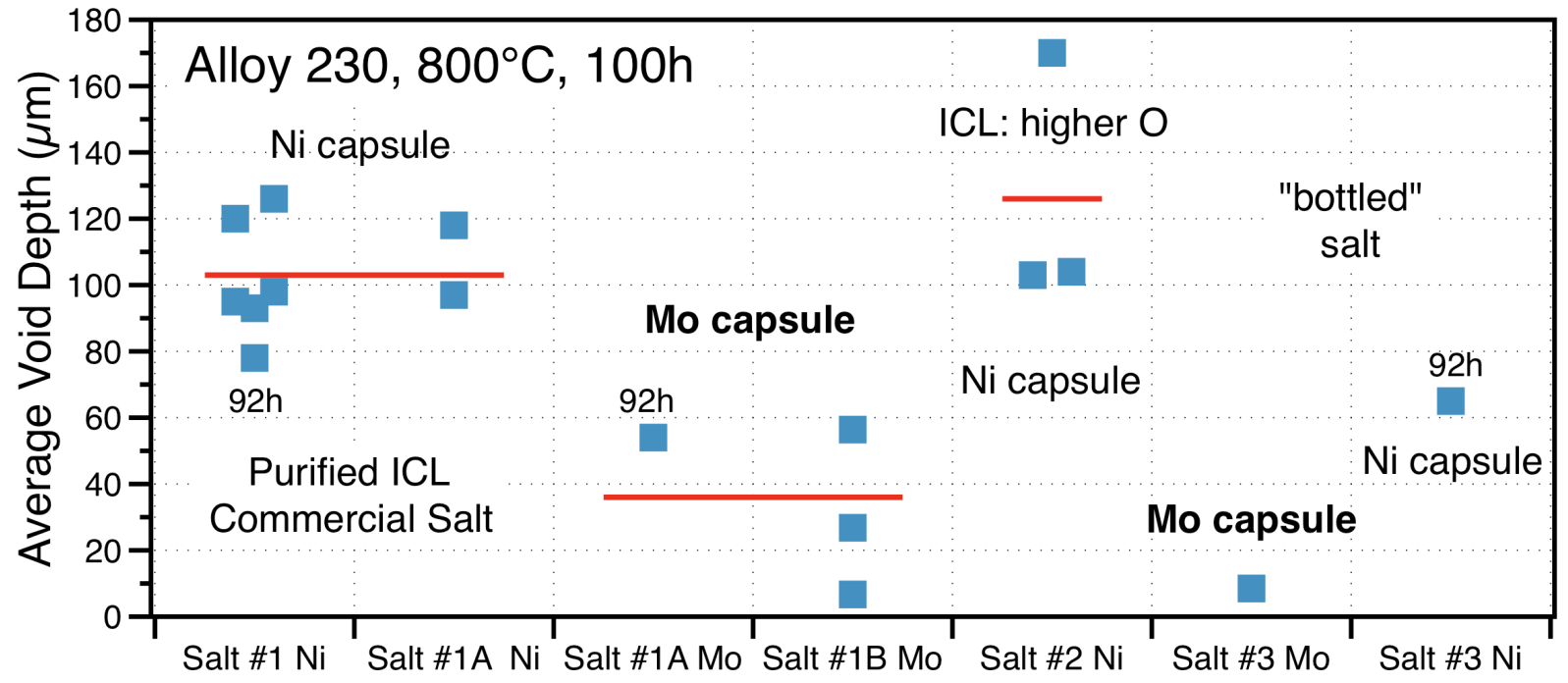

Figure 19. Summary of alloy 230 average void depth measurements after various salt and capsule exposures for $92-100 \mathrm{~h}$ at $800^{\circ} \mathrm{C}$. 


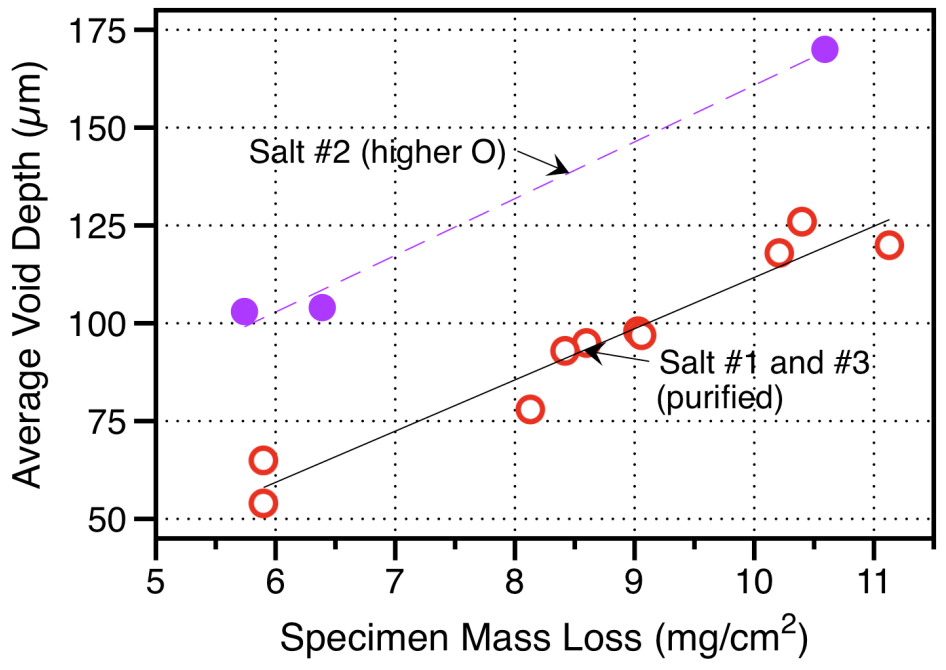

Figure 20. Specimen mass loss plotted versus measured average void depth for alloy 230 specimens exposed for $92-100 \mathrm{~h}$ at $800^{\circ} \mathrm{C}$ in salts \#1-\#3.

the salt will never reach saturation and the flux of $\mathrm{Cr}$ loss will continue at a higher rate. Alternatively, if the container is inert (i.e. Mo) and the $\mathrm{Cr}$ reaction product ( $\mathrm{Cr}$ ions in solution or $\mathrm{Cr}-\mathrm{Cl}-\mathrm{X}$ compounds in the liquid) remains in solution then the liquid will become more saturated with time and the reaction will slow or stop. To test the hypothesis that $\mathrm{Cr}$ reacted with the Ni crucible, a $100 \mathrm{~h}$ capsule was analyzed, however, the $\mathrm{Cr}$ level in the capsule wall was difficult to detect by SEM/EDS. Figure $23 \mathrm{~b}$ shows the result of a $500 \mathrm{~h}$ exposure in salt \#1 with a Ni capsule. The sustained attack indicated that the salt did not appear to saturate during a longer exposure as might be expected from Equation \#1. The capsule material was characterized after the $500 \mathrm{~h}$
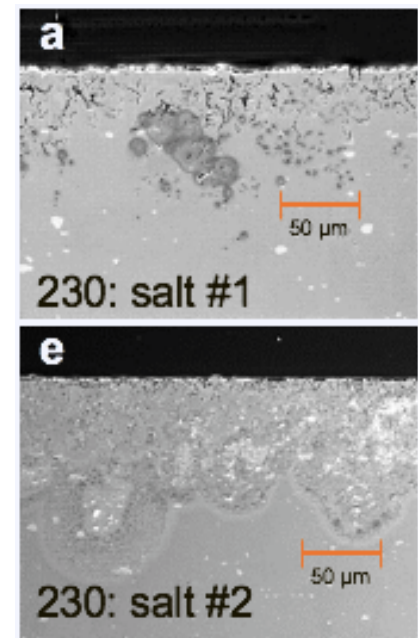
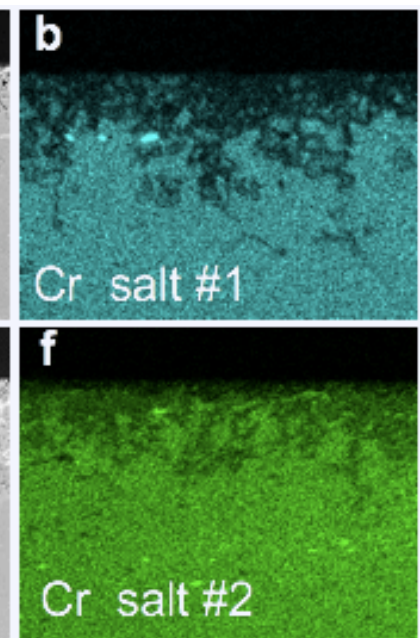
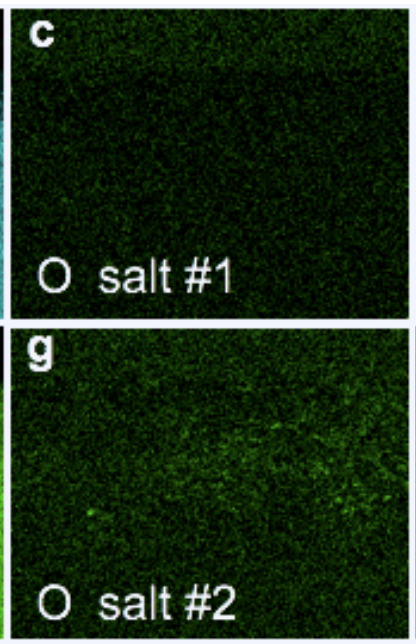

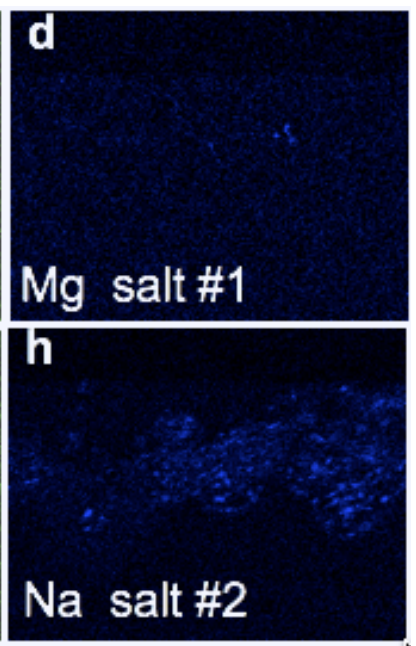

Figure 21. (a,e) SEM images and associated EDS maps of alloy 230 specimen crosssections after exposure for $100 \mathrm{~h}$ at $800^{\circ} \mathrm{C}$ in Ni capsules to purified industrial-sourced salt (a-d) \#1 and (e-h) \#2. 


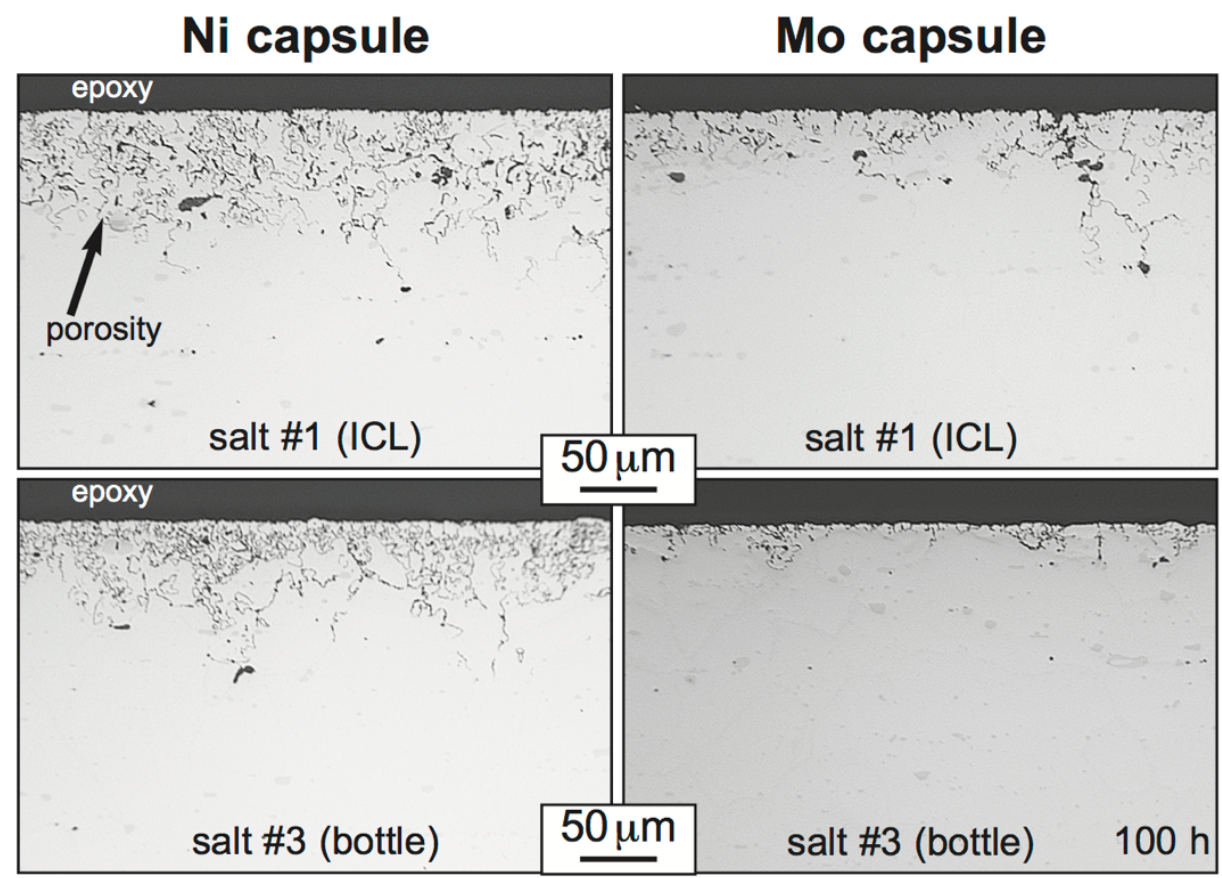

Figure 22. Light microscopy of polished cross-sections of alloy 230 exposed for $92 \mathrm{~h}$ at $800^{\circ} \mathrm{C}$ in $(\mathrm{a}, \mathrm{b})$ purified industrial-sourced salt $\# 1$ and $(\mathrm{c}, \mathrm{d})$ purified laboratory $\mathrm{K}-\mathrm{Mg}-\mathrm{Cl}$ salt \#3 and (a,c) Ni capsule and (b,d) Mo capsule.

exposure and the surface adjacent to the salt was enriched in $\mathrm{Cr}$, Figure 23c, indicating that $\mathrm{Cr}$ in the salt became incorporated into the Ni capsule wall. The amount of $\mathrm{Cr}$ uptake can be estimated based on the EDS data. The areal concentration of the inner surface of the Ni capsule in contact with the salt was estimated at $1.05 \mathrm{mg} / \mathrm{cm}^{2}$. The 48 $\mathrm{g}$ of salt with a density of $1.66 \mathrm{~g} / \mathrm{cm}^{3}$ at $700^{\circ} \mathrm{C}$ [Williams 2006] had a volume of $28.9 \mathrm{~cm}^{3}$ corresponding to $55 \mathrm{~cm}^{2}$ of capsule surface representing a total uptake of $58 \mathrm{mg} \mathrm{of} \mathrm{Cr}$ by the capsule compared to a measured total specimen mass loss at $800^{\circ} \mathrm{C}$ of $20 \mathrm{mg}$ after $100 \mathrm{~h}$ and $69.8 \mathrm{mg}$ after $500 \mathrm{~h}$. No similar $\mathrm{Cr}$ enrichment was noted for a Mo
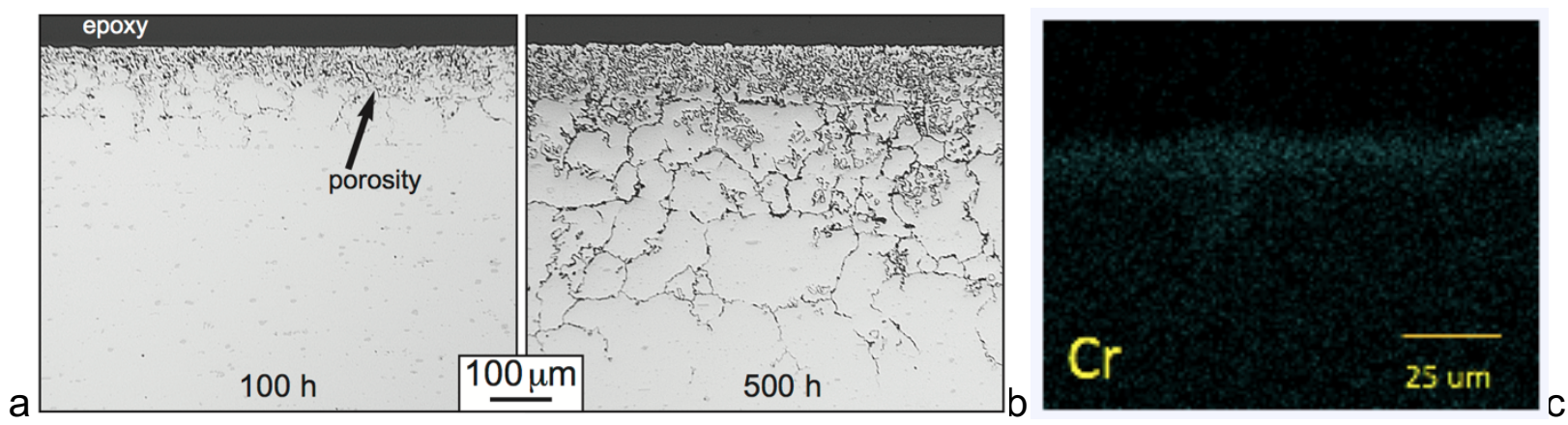

Figure 23. Light microscopy of alloy 230 specimens exposed to purified industrialsourced salt \#1 in Ni crucibles for (a) $100 \mathrm{~h}$ and (b) $500 \mathrm{~h}$. In (c), a Cr EDS map shows $\mathrm{Cr}$ enrichment at the surface of the $\mathrm{Ni}$ crucible after the $500 \mathrm{~h}$ exposure. 
crucible after $100 \mathrm{~h}$ but no longer experiments have been conducted in Mo crucibles for comparison. Thus, it appears that the Ni capsule is accelerating the reaction by not allowing the salt to saturate with the $\mathrm{Cr}$ reaction product. Therefore, future capsule/crucible experiments should be performed in an inert container that does not remove or add reaction products to the salt during the exposure.

Finally, to test the prior ORNL assumption that lowering alloy $\mathrm{Cr}$ content is beneficial to halide salt compatibility, Figure 24a shows the effect of alloy $\mathrm{Cr}$ content on mass loss in salt \#1 after $100 \mathrm{~h}$ at $800^{\circ} \mathrm{C}$. Similar to the prior results with fluoride salts and Hastelloy $\mathrm{N}$, the low Cr alloy 244 (Table 3) showed a small mass gain rather than a mass loss. These results are contrasted to those in the literature [Sun 2018], where very little effect of alloy $\mathrm{Cr}$ content was observed after $100 \mathrm{~h}$ at $700^{\circ} \mathrm{C}$, Figure $2 \mathrm{~b}$. Figure $25 \mathrm{a}$ shows no porosity and very little $\mathrm{Cr}$ depletion in this specimen in comparison to the alloy 230 specimens in Figure 8. It is not clear why this specimen showed a mass gain. XPS analysis of the surface showed a Ni-Mo rich layer that was enriched in $\mathrm{O}$ and $\mathrm{C}$, but the $O$ uptake did not appear sufficient to explain the mass gain.

Reducing the temperature also significantly reduced the mass loss, Figure $24 \mathrm{~b}$. After exposure at $700^{\circ} \mathrm{C}$, the $\mathrm{Cr}$ depleted region was $\sim 10 \mu \mathrm{m}$, Figure $25 \mathrm{f}$. By the understanding in Equation 1, the decrease in mass loss with decreasing temperature in Figure $24 \mathrm{~b}$ may be attributed to a decrease in the $\mathrm{Cr}$ solubility with temperature (Figure 1b) and the small $\mathrm{Cr}$ depletion at $700^{\circ} \mathrm{C}$ should not be interpreted as proof of compatibility. Instead, it could reflect a rapid saturation of the salt at this temperature. Actual solubility values for this salt were not determined but Equation 1 suggests an increase in the $\mathrm{Cr}$ content of the salt will decrease the dissolution rate.
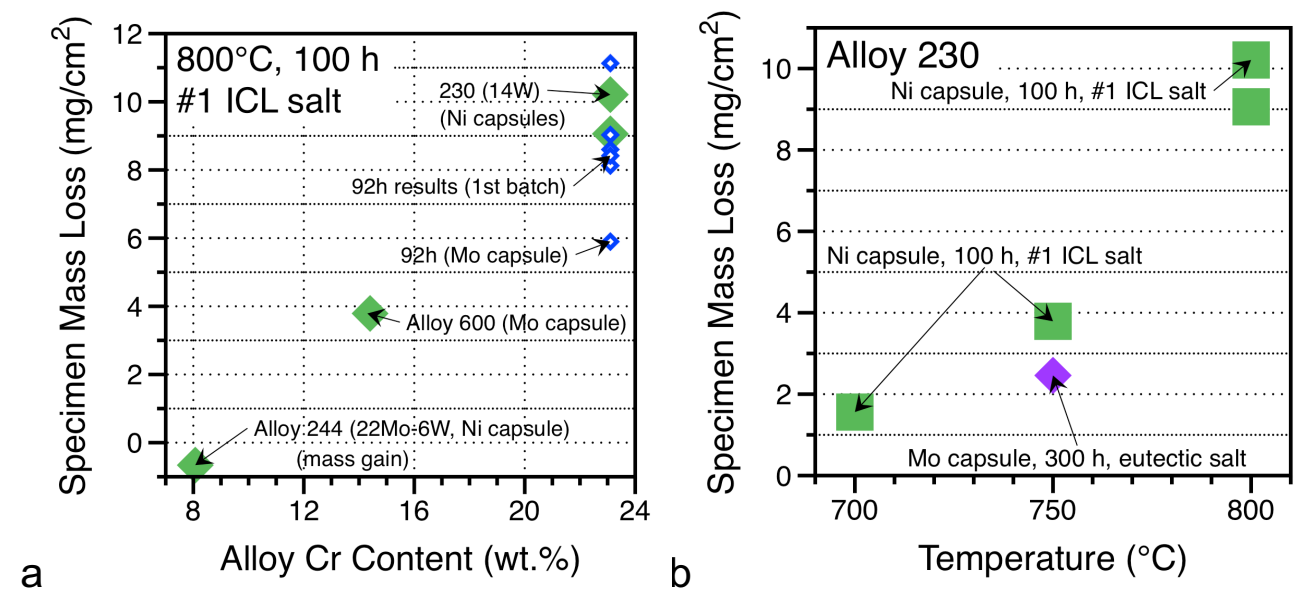

Figure 24. Specimen mass loss after $100 \mathrm{~h}$ isothermal salt exposures (a) at $800^{\circ} \mathrm{C}$ as a function of alloy $\mathrm{Cr}$ content in salt \#1 and (b) alloy 230 as a function of temperature in salt \#1. 

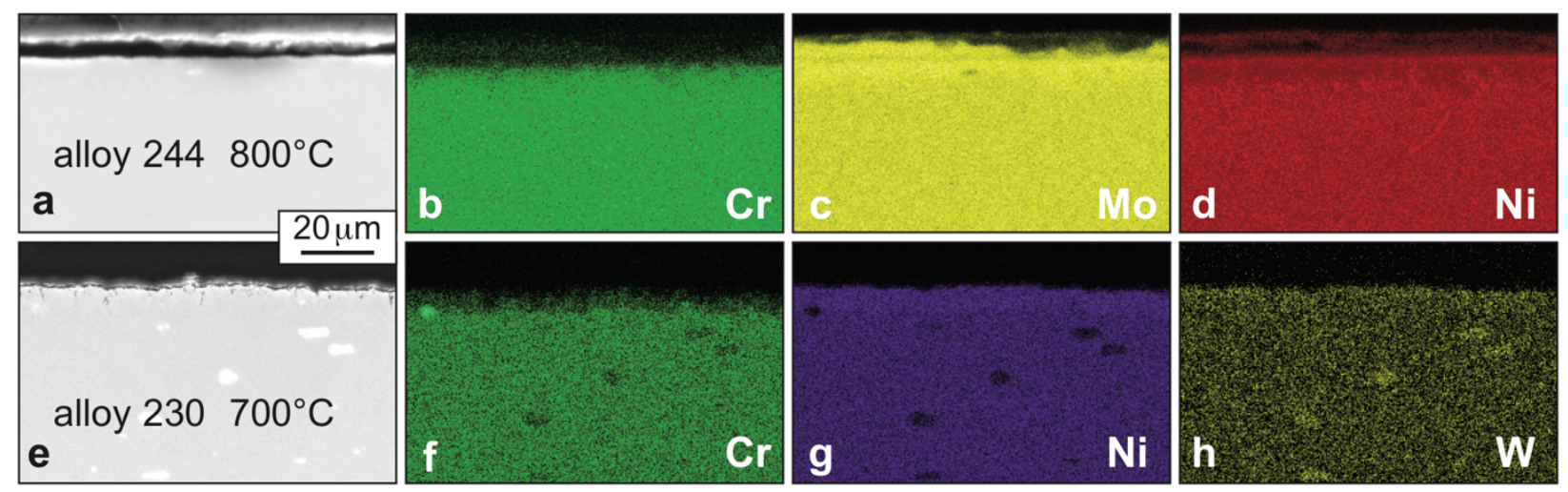

Figure 25 SEM secondary electron images and associated EDS composition maps of polished cross-sections after $100 \mathrm{~h}$ exposure in purified industrial-sourced salt \#1 in $\mathrm{Ni}$ capsules: (a-d) alloy 244 at $800^{\circ} \mathrm{C}$ and (e-h) alloy 230 at $700^{\circ} \mathrm{C}$.

Task 1.1 Capsule testing to support loop experiment

Table 5. Project Evaluation Criteria for Task 1.1

\begin{tabular}{|c|l|l|l|c|c|}
\hline Task & Description & Criteria & $\begin{array}{l}\text { Measured } \\
\text { values }\end{array}$ & Goal Met? & $\begin{array}{c}\text { Supporting } \\
\text { data }\end{array}$ \\
\hline 1.1 & $\begin{array}{l}\text { Identify time, temperature, } \\
\text { salt and alloys that result in } \\
\text { suitably low reaction rates } \\
\text { and depth of attack in } \\
\text { candidate alloys }\end{array}$ & $\begin{array}{l}\text { 1. Depth of } \\
\text { attack } \\
2 .<100 \mu \mathrm{m} \\
\text { at } 1000 \mathrm{~h}\end{array}$ & Figure 27 & Yes & Figure 28 \\
\hline
\end{tabular}

In preparation for the first TCL experiment, alloy 600 was selected as a likely TCL material because of its availability. One reason for choosing alloy 600 is its lower $\mathrm{Cr}$ content, Table 3 shows values for tube (600T) and sheet (600S) material used in all of the TCL experiments. Figure 1a shows the $\mathrm{Cl}$ potential for a number of different salt and alloying elements. Since $\mathrm{Cr}$ is a more stable chloride than $\mathrm{Ni}$ or $\mathrm{Mo}$, one would expect selective attack of $\mathrm{Cr}$ in the salt. Thus, the results in Figure 24a are not surprising that the mass loss after $\sim 100 \mathrm{~h}$ for an alloy 600 specimen was much lower than alloy 230 (with the added complication that alloy 600 was exposed in a Mo capsule). None of the low $\mathrm{Cr}$ alloys, such as Hastelloy $\mathrm{N}$ or alloy 244 are readily available in tube form. However, Hastelloy $\mathrm{N}$ tubing was recently ordered for the ORNL Office of Nuclear Energy molten salt reactor program and could be obtained if future $\mathrm{TCL}$ testing is needed, particularly at $800^{\circ} \mathrm{C}$.

To reduce risk for the first TCL experiment, three alloy 600 specimens were exposed at $600^{\circ}, 650^{\circ}$ and $700^{\circ} \mathrm{C}$ in Mo capsules for $1000 \mathrm{~h}$ to cover the temperature range and operation time of the first TCL. Figure 26 summarizes the mass loss data after exposure, which were unexpected. The highest mass loss was observed for the specimen exposed at $600^{\circ} \mathrm{C}$. However, Figure 27 shows that the depth of attack was relatively minor but unlike the void formation for alloy 230 at $800^{\circ} \mathrm{C}$, a pitting type of 


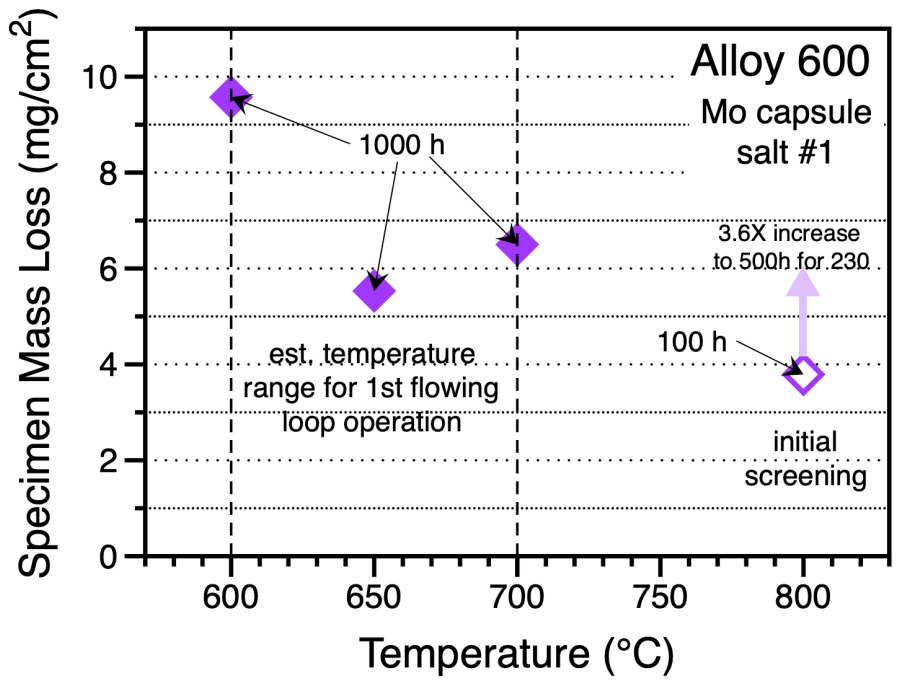

Figure 26. Specimen mass loss for alloy 600 specimens exposed in industrial-sourced salt (\#1) in Mo capsules. The $800^{\circ} \mathrm{C}$ specimen was exposed for only $100 \mathrm{~h}$ for comparison to alloy 230 .

attack was observed at $600^{\circ} \mathrm{C}$ different than the observations at $650^{\circ}$ and $700^{\circ} \mathrm{C}$. Figure 28 shows SEM/EDS analysis of the alloy 600 specimens including the $100 \mathrm{~h}$ at $800^{\circ} \mathrm{C}$ exposure in Figure $24 \mathrm{a}$. Similar to alloy 230 at $800^{\circ} \mathrm{C}$, the voids at $800^{\circ} \mathrm{C}$ appear to be associated with $\mathrm{Cr}$ depletion and there appears to be $\mathrm{Cr}$ depletion at $650^{\circ} \mathrm{C}$. However, very little $\mathrm{Cr}$ depletion appears to have occurred for the $600^{\circ} \mathrm{C}$ specimen. Based on the previously observed effect of salt composition on compatibility in Figure 18 and 19, a question arises about the industrial-sourced salt and particularly its minor impurities of $\mathrm{S}, \mathrm{Zn}, \mathrm{Br}$, etc.. Figure 29 shows that the purified eutectic "bottle" salt \#3 showed considerably less attack for alloy 600 at $600^{\circ} \mathrm{C}$ and for alloy 230 at $800^{\circ} \mathrm{C}$ than the purified industrial-sourced salt \#1. Nevertheless, the results in Figure 27 provided some confidence that the TCL would operate without issue at a peak temperature of $700^{\circ} \mathrm{C}$ for $1000 \mathrm{~h}$.

In retrospect, additional capsule experiments for alloy 600 and C276 should have been run at $750^{\circ} \mathrm{C}$ in anticipation of the second TCL experiment at higher temperatures but the limited $800^{\circ} \mathrm{C}$ results suggested reasonable compatibility.

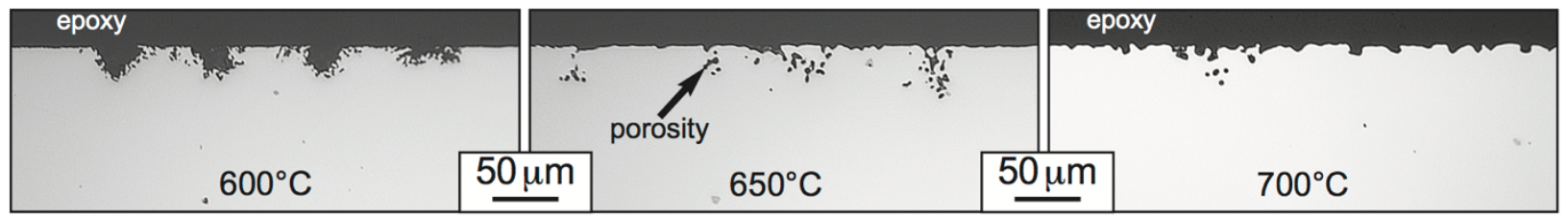

Figure 27. Light microscopy of polished cross-sections of alloy 600 specimens after 1,000 $\mathrm{h}$ exposures at $600^{\circ}-700^{\circ} \mathrm{C}$ in individual Mo capsules. 
CPS 33873

Progression to Flowing Molten Salts

ORNL Pint

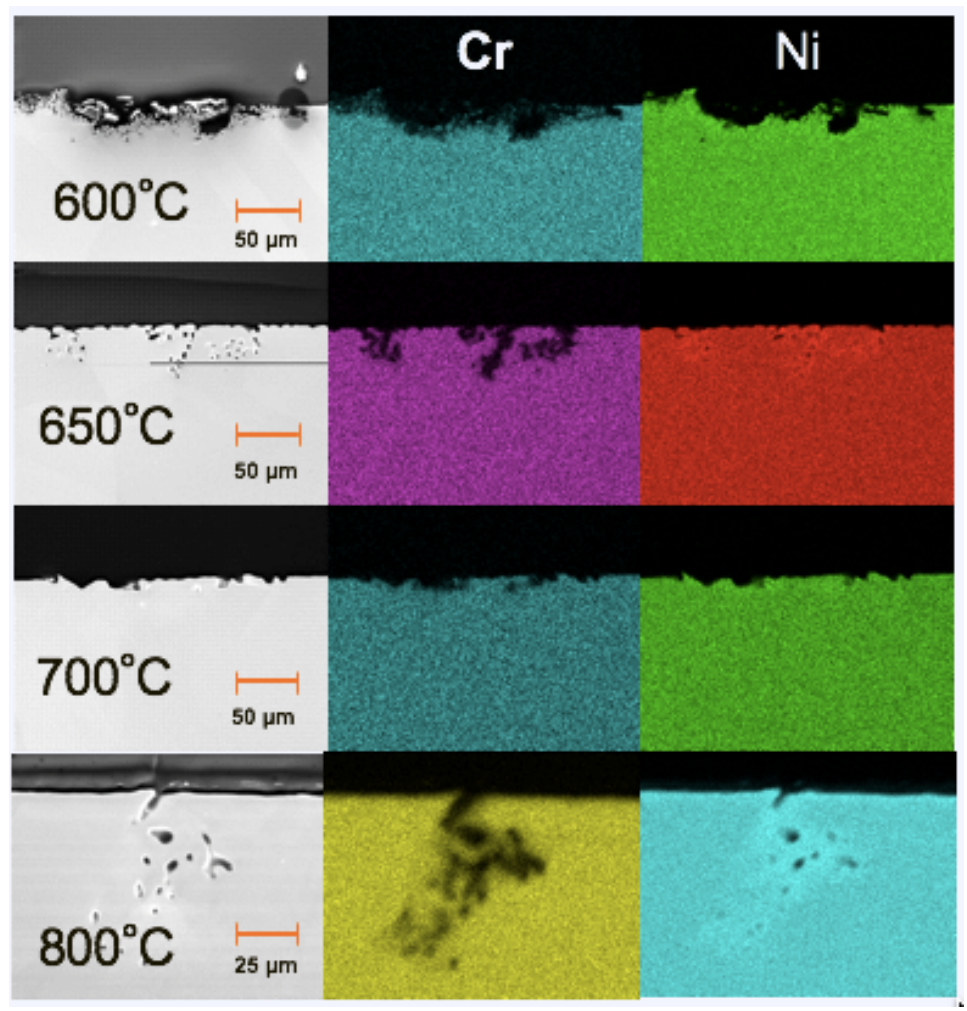

Figure 28. SEM images of alloy 600 specimens after exposures in Mo capsules at $600^{\circ}$ $800^{\circ} \mathrm{C}$ in purified industrial-sourced salt \#1 and associated $\mathrm{Cr}$ and Ni EDS maps.
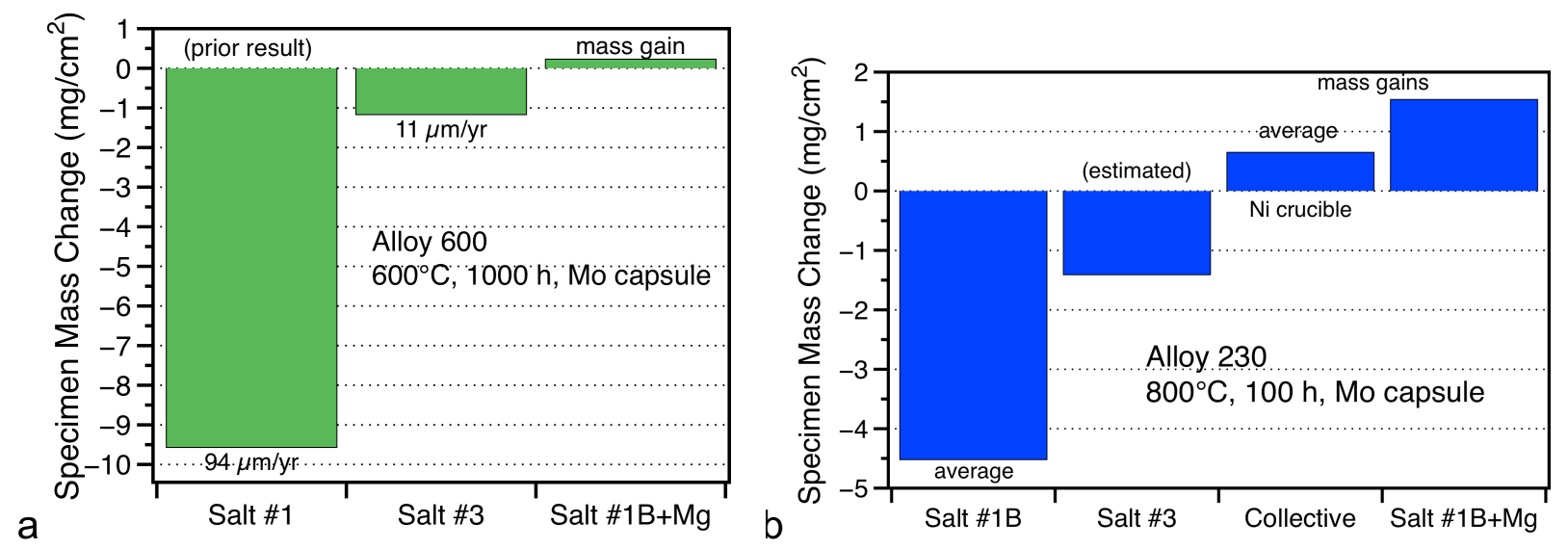

Figure 29. Specimen mass change data from Mo capsule experiments (a) alloy 600 specimens at $600^{\circ} \mathrm{C}$ for $1000 \mathrm{~h}$ and (b) alloy 230 specimens at $800^{\circ} \mathrm{C}$ for $100 \mathrm{~h}$. Two batches of purified industrial-sourced salt (\#1 and \#1B) were compared to purified eutectic "bottled" salt (\#3). The \#1B+0.05\%Mg was the salt added to the 1 st TCL experiment where the surface area/volume ratio was much different than in a Mo capsule. 
Task 1.2 First thermal convection loop test

Table 6. Project Evaluation Criteria for Task 1.2

\begin{tabular}{|c|l|l|l|c|c|}
\hline Task & Description & Criteria & $\begin{array}{l}\text { Measured } \\
\text { values }\end{array}$ & Goal Met? & $\begin{array}{c}\text { Supporting } \\
\text { data }\end{array}$ \\
\hline 1.2 & $\begin{array}{c}\text { Complete first loop test of } \\
1000 \mathrm{~h}\end{array}$ & $\begin{array}{l}1 . \text { Specimen } \\
\text { mass loss } \\
2 .<15 \mu \mathrm{m} / \mathrm{yr} \\
3 .>30 \\
\text { specimens } \\
\text { exposed }\end{array}$ & Figure 32 & Yes & $\begin{array}{c}\text { Figures } \\
\text { (n)-40 }\end{array}$ \\
\hline
\end{tabular}

Figure 30a shows the hood and associated control systems that was built to house the TCL experiments for this project and used for all TCL tasks. To save floor space, the control cabinet with data acquisition and controllers (three furnaces and 10 heat tapes) was built into the hood. Exhaust and power upgrades were completed, and all of the ancillary equipment procured. All TCLs were fabricated from seamless alloy 600 tubing (25 mm outer diameter (OD) and $1.2 \mathrm{~mm}$ wall) and sheet (600T and 600S in Table 3) and was $\sim 0.75 \mathrm{~m}$ tall by $0.5 \mathrm{~m}$ wide. A similar design has been used in other recent liquid metal studies [Pint 2009, Pawel 2012, Pawel 2017]. The first TCL is shown schematically in Figure $30 \mathrm{~b}$ with the overflow tank above the hot leg. An extension was added to the cold leg to prevent the salt from contacting the stainless steel fitting. Figure 30c shows the loop with the furnaces and insulation in place inside the hood. Prior to loading, the loop was internally cleaned with water plus $20 \%$ nitric acid to remove any residual oxide from the tubing inner diameter (ID), followed by water and then acetone prior to evacuation with a turbo pump and pre-heating with heat tape
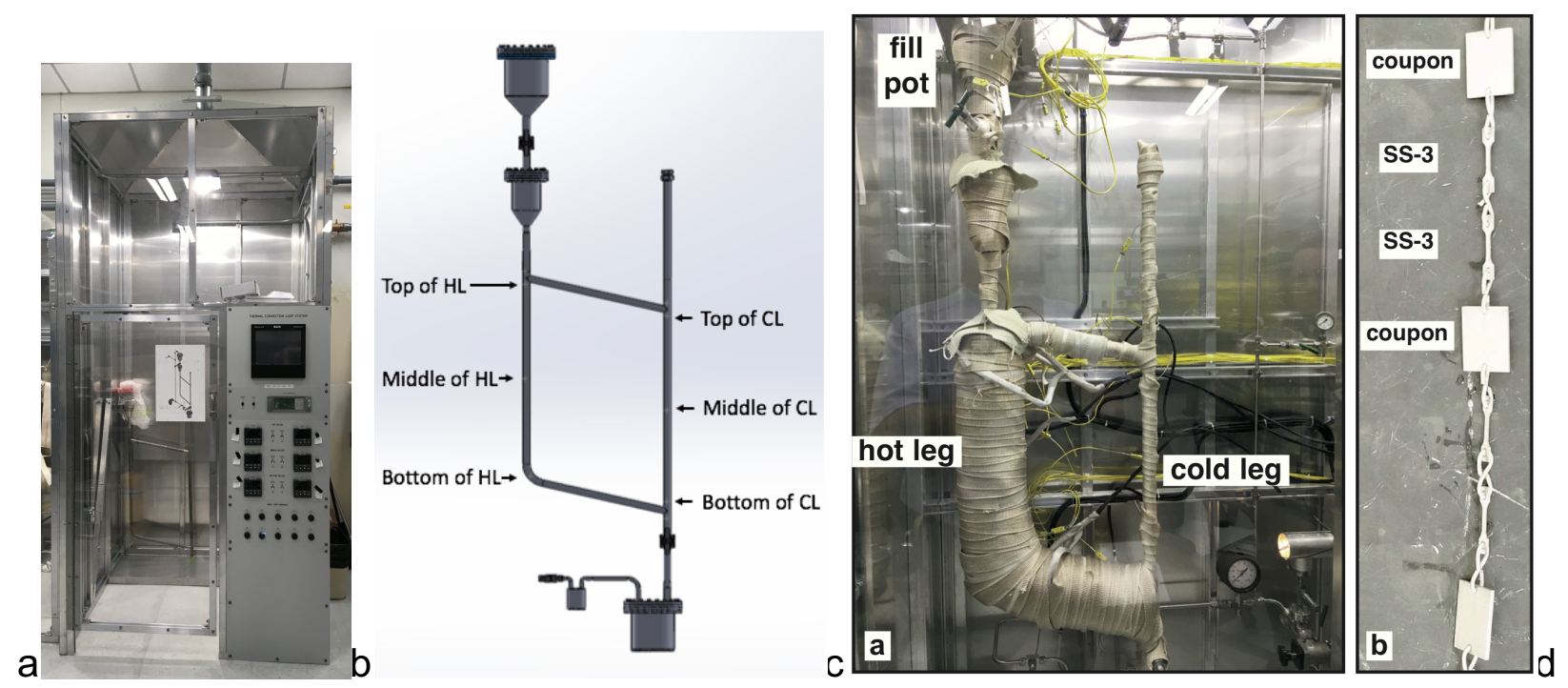

Figure 30. (a) New ORNL molten salt TCL hood, (b) TCL schematic showing location of thermowells (c) TCL during operation with furnaces on hot leg and (d) segment of alloy 600 specimen chain showing coupons and type SS-3 tensile specimens. 
to $>100^{\circ} \mathrm{C}$ to drive off any residual water. Evacuation also allows for any leak detection and repair before the salt is loaded in the melt tank.

The alloy 600S specimens in the hot and cold legs consisted of type SS-3 dogbone tensile specimens $(25 \mathrm{~mm}$ long with a $1.5 \times 0.76 \mathrm{~mm}$ gage) and coupons $(1.8 \times 19 \times 25$ $\mathrm{mm}$ ), Figure $30 \mathrm{~d}$. Identical chains of 20 specimens were suspended in the hot and cold legs using alloy 600 wire $(1.6 \mathrm{~mm}$ diameter) and spanned the distance between the thermowells shown in Figure 30b. At the middle and bottom of each chain an alloy 600 interlocked spacer kept the chain centered in the flow path.

The loop required $\sim 2.3 \mathrm{~kg}$ of purified industrial-sourced salt \#1 (designated \#1B) prepared in 4 batches. Excess salt was used for additional capsule testing, e.g. Figures 17 and 29. Based on the high mass losses observed for alloy 600 specimens in capsules with salt \#1, Figure 26, it appeared that the salt had a high $\mathrm{Cl}$ potential after purification, Figure $1 \mathrm{a}$. Therefore, $1 \mathrm{~g}$ of $\mathrm{Mg}$ shavings $(0.04 \mathrm{wt} . \% \mathrm{Mg})$ was added to the salt to lower the $\mathrm{Cl}$ potential for the first TCL experiment. Figure 30c shows the loop with resistively heated furnaces on the hot and bottom legs and heat tape in place as well as 24 thermocouples (TCs). The loop was pre-heated to $\sim 500^{\circ} \mathrm{C}$ prior to filling. The salt was melted using heat tape in a $316 \mathrm{~L}$ SS pot above the hot leg (Figure 30b) prior to its introduction into the TCL using a SS valve. This composition of industrialsourced salt melted at $\sim 475^{\circ} \mathrm{C}$ unlike the eutectic temperature of closer to $425^{\circ} \mathrm{C}$. The temperature of the flowing salt in the TCL was monitored primarily by type $\mathrm{K}$ thermocouples in 6 thermowells at the top, middle and bottom of the hot and cold legs that were inserted $\sim 3 \mathrm{~mm}$ into the flow path, Figure $30 \mathrm{~b}$. The loop temperature was controlled at the top of the hot leg to $700 \pm 1^{\circ} \mathrm{C}$ for $1000 \mathrm{~h}$ and the bottom of the cold leg was $575-590^{\circ} \mathrm{C}$ with an average temperature of $580^{\circ} \mathrm{C}$, Figure 31 . The top leg and cold leg were lightly insulted and not actively cooled or heated. The temperature difference created a density gradient resulting in flow of $\sim 2.4 \mathrm{~cm} / \mathrm{s}$ determined by monitoring a "hot spot" created by a torch applied for $60 \mathrm{~s}$ to the bottom of the cold leg. At the end of the experiment, the salt was dumped

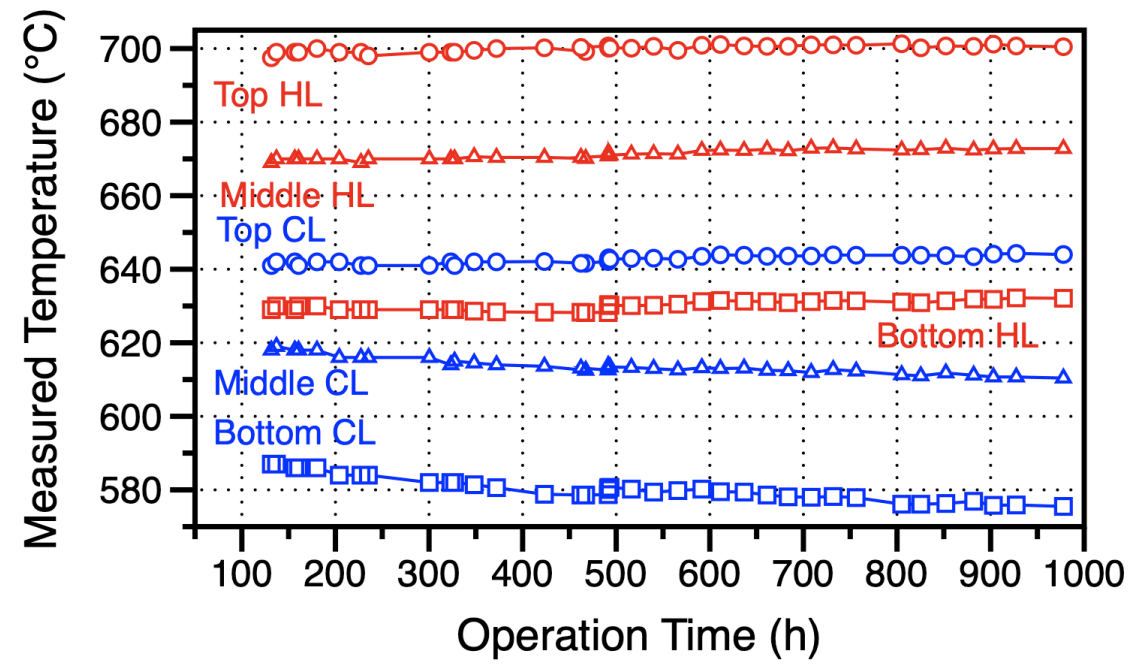

Figure 31. Measured temperatures at six thermocouples around the TCL in the hot leg $(\mathrm{HL})$ and cold leg $(\mathrm{CL})$ during the $1000 \mathrm{~h}$ experiment. 
CPS 33873

Progression to Flowing Molten Salts

ORNL Pint

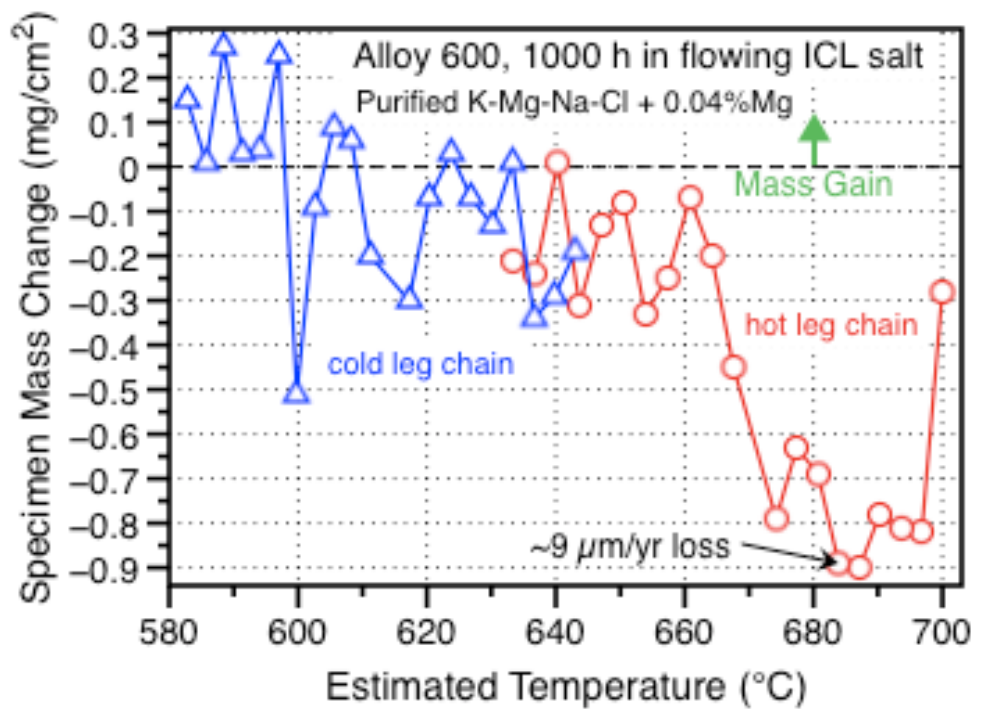

Figure 32. Specimen mass change as a function of estimated temperature for alloy 600 specimens exposed in flowing purified salt.

into a similar SS pot by opening a SS valve below the cold leg, Figure 30b. The specimens were cleaned prior to exposure using acetone and methanol and after exposure by using deionized water at $40^{\circ} \mathrm{C}$. Before and after exposure, the specimens were weighed using a Mettler Toledo XP205 balance with an accuracy of $\sim \pm 0.04 \mathrm{mg}$.

Figure 32 shows the mass change data obtained from the specimens in the hot leg $(\mathrm{HL})$ and cold leg $(\mathrm{CL})$. The individual specimen temperatures are estimated based on the temperature data from the six thermowells in the TCL. The purified salt with $0.04 \% \mathrm{Mg}$ appeared to be relatively inert as only small mass losses were observed in the specimens exposed for $1000 \mathrm{~h}$ in flowing salt. The data show classic dissolutionprecipitation behavior with the largest mass loss at the highest temperatures and mass gain at the coldest temperatures. In stark contrast to the recent literature, Figure 2, this result indicates that $\mathrm{Cl}$ salts can be compatible with a structural alloy like alloy 600 . To compare these results to the recent literature [Ding 2018, Sun 2018], the mass change was converted to metal loss using the alloy density and linear kinetics were assumed (which may be a worst case scenario). The largest mass loss amounts in the TCL correspond to a $\sim 9 \mu \mathrm{m} / \mathrm{yr}$ corrosion rate, which suggests that this industrial-sourced salt can be compatible with alloy 600 at up to $700^{\circ} \mathrm{C}$.

Post-exposure characterization focused on the coupon specimens, which had a larger surface area. As shown in Figure $30 \mathrm{~d}$, the coupons were interspersed between the tensile specimens with 6 in each specimen chain. The specimens can be identified based on their estimated exposure temperature as in Figure 32. Figure 33 shows SEM secondary electron images of four specimens from different locations in the loop. The highest temperature specimen that experienced a mass loss at $\sim 690^{\circ} \mathrm{C}$ showed indication of material removal, Figure 33a. The lowest temperature specimen appeared to show material deposited on the surface, Figure 33d. The other two specimens showed less change. 


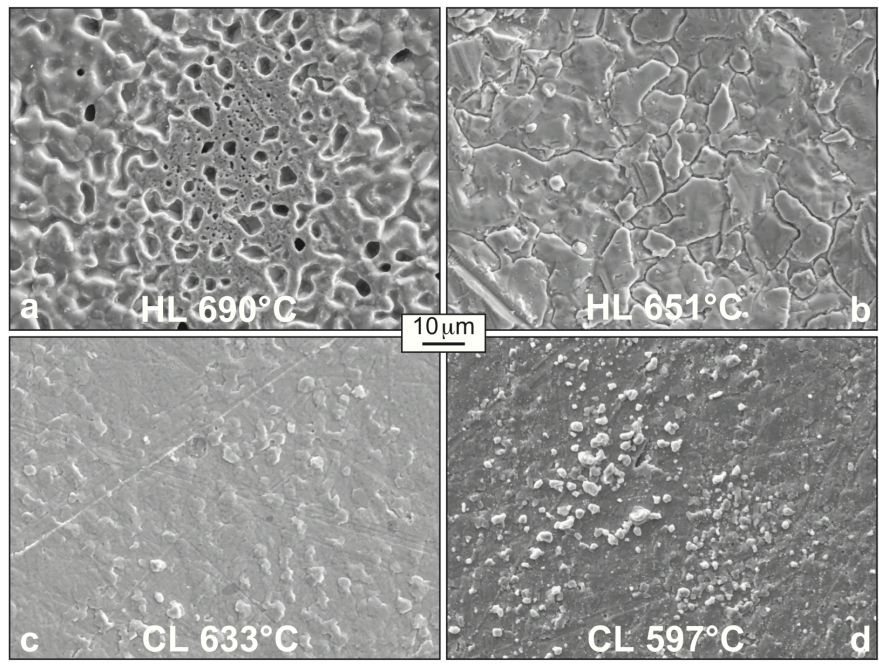

Figure 33. SEM secondary electron plan view images of alloy 600 specimens after 1,000 $\mathrm{h}$ exposures in flowing salt $+0.04 \% \mathrm{Mg}$ identified by their estimated temperature in the hot leg $(\mathrm{HL})$ or cold leg $(\mathrm{CL})$. In (c), observed polishing marks suggested little corrosion.

Figure 34 shows cross sections of the coupons from the HL and CL. Consistent with the mass change data, the highest temperature specimen from the top of the HL (Figure 34a) showed less attack than specimens at slightly lower temperature, Figures 34b and 34c. This may be due to the $700^{\circ} \mathrm{C}$ specimen being at the very top of the $\mathrm{HL}$ perhaps not in a uniform flow region. Consistent with the plan view image in Figure 33a, the cross-section of the specimen exposed at $\sim 690^{\circ} \mathrm{C}$ showed material removal. However, the pits are $\leq$ $10 \mu \mathrm{m}$ in depth. The three specimens from the bottom of the $\mathrm{CL}$ all showed small nodules consistent with mass gain, Figures $34 \mathrm{j}, 34 \mathrm{k}$ and $34 \mathrm{l}$. The intermediate temperature specimens showed very little attack.

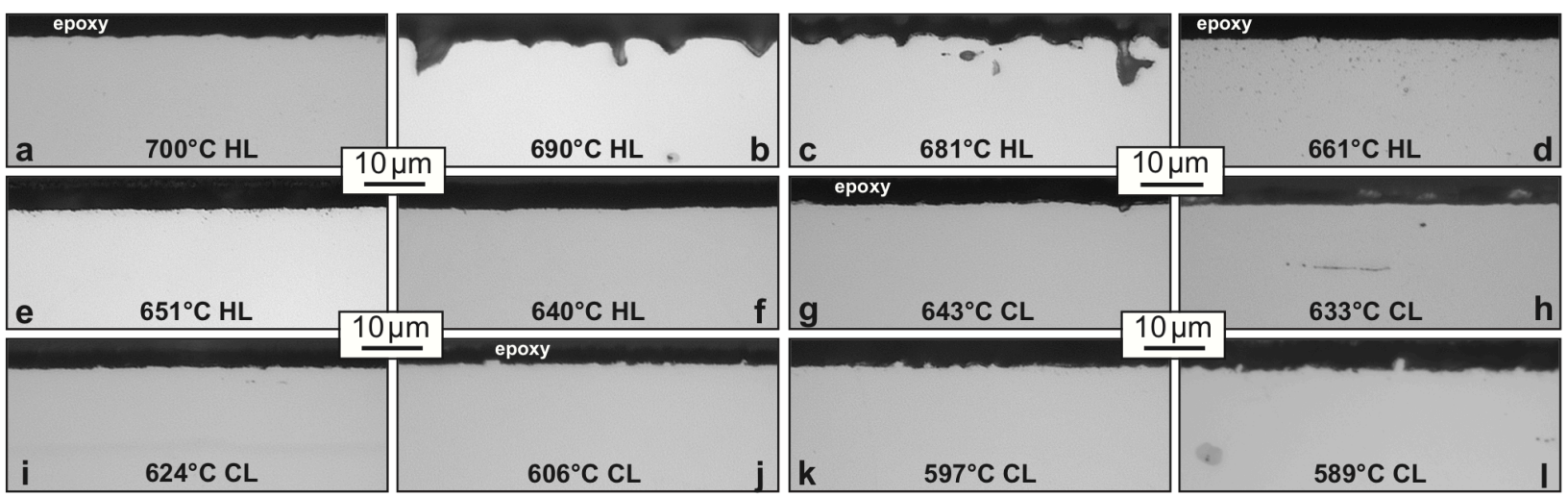

Figure 34. Light microscopy of polished cross-sections of alloy 600 specimens after 1,000 $\mathrm{h}$ exposures in flowing purified industrial-sourced salt $+0.04 \% \mathrm{Mg}$ identified by their estimated temperature in the hot leg $(\mathrm{HL})$ or cold leg $(\mathrm{CL})$. Consistent with the mass change data in Figure 32, $(b, c)$ show material removal at the surface, while $(j, k, l)$ show nodules at the surface. 

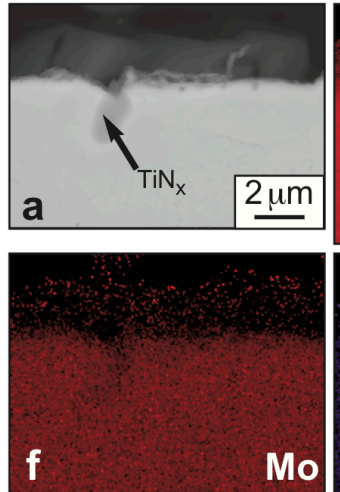
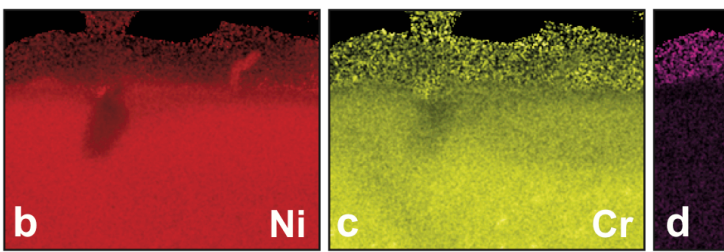

C

$\mathrm{Mg} h$
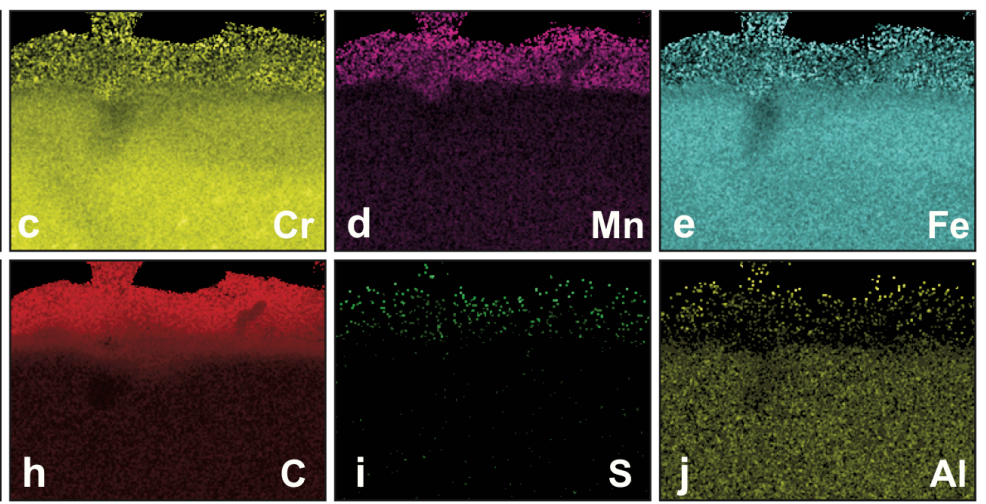

Figure 35. (a) SEM backscattered electron image of polished section of alloy 600 after $1000 \mathrm{~h}$ in the hot leg at $\sim 700^{\circ} \mathrm{C}$ in flowing purified industrial-sourced salt $+0.04 \% \mathrm{Mg}$ and EDX maps of the area in (a): (b) Ni, (c) Cr, (d) Mn, (e) Fe, (f) Mo, (g) Mg, (h) C, (i) S and (j) Al.

Figures 35,37 and 38 show SEM/EDX analysis of selected specimens. Figure 35a shows a $\sim 2 \mu \mathrm{m}$ layer on the surface of the specimen exposed at $700^{\circ} \mathrm{C}$ at the top of the $\mathrm{HL}$. This layer may explain the different mass change behavior of this specimen compared to the $\sim 690^{\circ} \mathrm{C}$ specimen. The precipitate in the image is representative of similar Ti-rich precipitates seen throughout all of these alloy 600 specimens. It appeared to be rich in $\mathrm{N}$ but could also contain $\mathrm{O}$ and $\mathrm{C}$. The outer layer is difficult to identify and may not be metallic. It appears to be depleted in $\mathrm{Ni}$ and $\mathrm{Mo}$, although the $0.01 \% \mathrm{Mo}$ content in alloy 600 (Table 3) makes the Mo map questionable. The layer appears to be enriched in C and $\mathrm{Mn}$ and have particles rich in $\mathrm{S}, \mathrm{Fe}$ and $\mathrm{Al}$ (S is present in the industrial-sourced salt, Table 2). No Mg enrichment was detected. An EDX line profile indicated that the $\mathrm{Cr}$ was depleted to $10 \%$ at the surface, Figure $36 \mathrm{a}$. Consistent with the map in Figure $35 \mathrm{c}$, the depletion was only to a depth of $\sim 5 \mu \mathrm{m}$. The area of interest is so small in these specimens that SEM/EDX quantification is somewhat unreliable due to the electron beam exciting a volume in the specimen of $\sim 1 \mu \mathrm{m}$ diameter. The maps provide qualitative
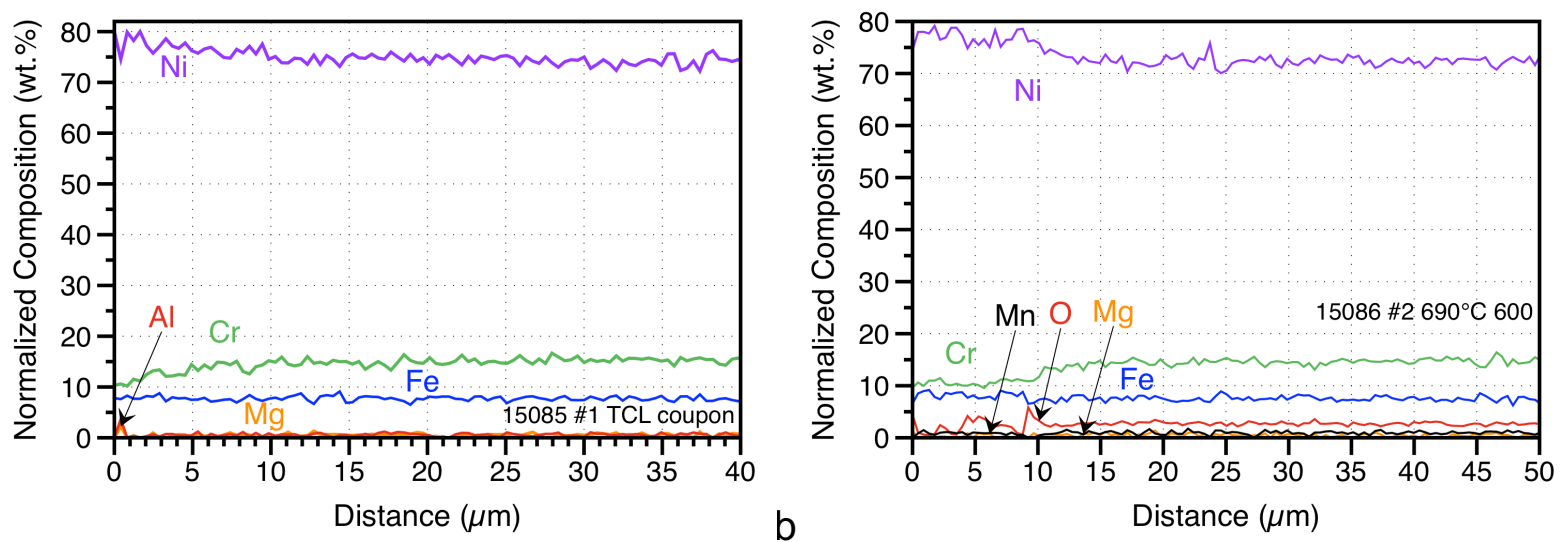

Figure 36. SEM/EDX line profiles from polished sections of alloy 600 after $1000 \mathrm{~h}$ in the hot leg in flowing purified industrial-sourced salt $+0.04 \% \mathrm{Mg}$ at (a) at $700^{\circ} \mathrm{C}$ and (b) $\sim 690^{\circ} \mathrm{C}$. 


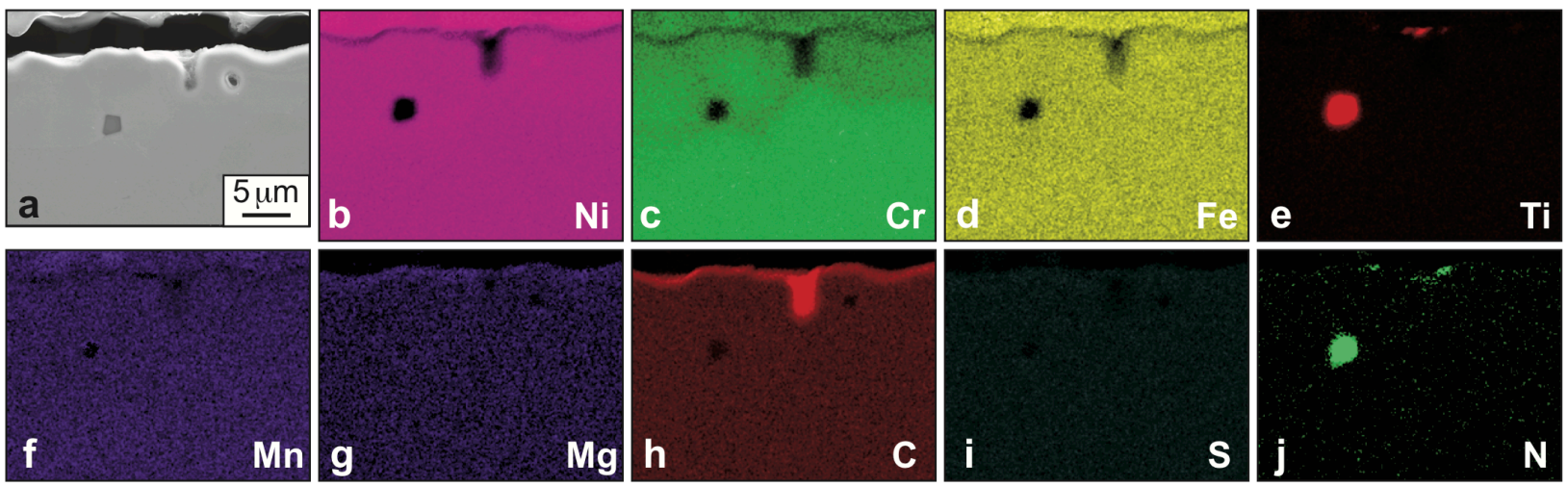

Figure 37. (a) SEM secondary electron image of polished section of alloy 600 after 1000 $\mathrm{h}$ in the hot leg at $\sim 690^{\circ} \mathrm{C}$ in flowing purified industrial-sourced salt $+0.04 \% \mathrm{Mg}$ and EDX maps of the area in (a): (b) Ni, (c) Cr, (d) Fe, (e) Ti, (f) Mn, (g) Mg, (h) C, (i) S and (j) N.

information but higher magnification or more surface sensitive characterization (e.g. XPS) would be needed to further characterize the surface of this specimen.

Figure 37 shows similar maps from the specimen exposed at $\sim 690^{\circ} \mathrm{C}$. In this case the $\mathrm{Ti}$ and $\mathrm{N}$ maps (Figures $37 \mathrm{e}$ and $37 \mathrm{j}$ ) identify the $\mathrm{TiN}_{\mathrm{x}}$ precipitate in Figure $37 \mathrm{a}$. In these maps, the surface also appears to be enriched in $\mathrm{C}$ and perhaps a weak $\mathrm{Mg}$ signal was observed, Figures $37 \mathrm{~h}$ and $37 \mathrm{~g}$. No S was detected in this specimen, Figure $37 \mathrm{i}$. A line profile indicated that the $\mathrm{Cr}$ was depleted to $\sim 10 \mathrm{wt} \%$ at the surface but the depletion was $\leq 10 \mu \mathrm{m}$, Figure 36b, consistent with the map in Figure 37c.

Figure 38 shows similar EDX maps for the coupon from the bottom of the CL exposed at $\sim 589^{\circ} \mathrm{C}$. A thin outer layer appears to be rich in $\mathrm{C}$ and $\mathrm{O}$ and depleted in $\mathrm{Ni}$ and a deeper region of $\sim 5 \mu \mathrm{m}$ is rich in Fe and slightly depleted in $\mathrm{Cr}$, Figures $37 \mathrm{~d}$ and $37 \mathrm{c}$, respectively. A line profile indicated the Fe enrichment was to $13-14 \%$, higher than the $7.3 \%$ in the bulk alloy, Table 3 . The $\mathrm{Cr}$ map shows Cr-rich precipitates that may be oxides in the Fe-rich layer. This specimen gained $0.27 \mathrm{mg} / \mathrm{cm}^{2}$ and this would

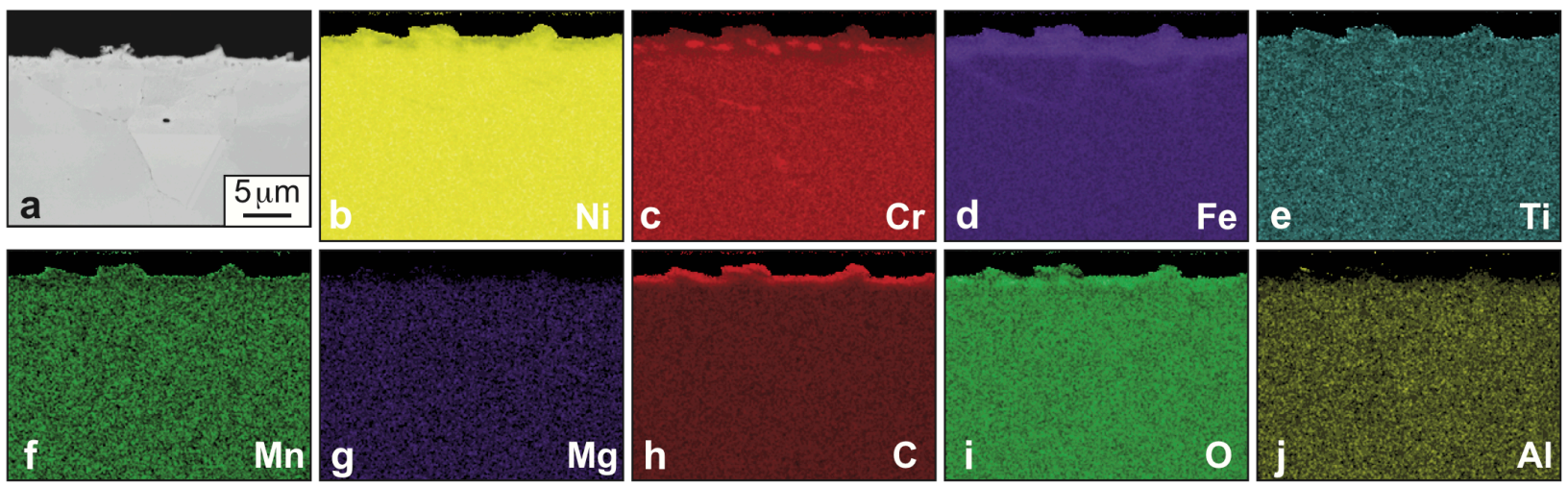

Figure 38. (a) SEM backscattered electron image of polished alloy 600 section after 1000 $\mathrm{h}$ in the cold leg at $\sim 589^{\circ} \mathrm{C}$ in flowing purified industrial-sourced salt $+0.04 \% \mathrm{Mg}$ and EDX maps of the area in (a): (b) Ni, (c) $\mathrm{Cr}$, (d) Fe, (e) Ti, (f) Mn, (g) Mg, (h) C, (i) O and (j) Al. 
correspond to $<0.5 \mu \mathrm{m}$ layer on the surface. Perhaps if $\mathrm{Fe}$ is being transported, it is diffusing into the surface of this specimen.

Several specimens also were analyzed by GDOES, which is difficult to quantify without standards. One of the key questions was about Mg alloying, based on the results for alloy 230 in Figure 12b. Figure 39 shows just the Mg intensity from four TCL specimens compared to an unexposed alloy 600 specimen. Almost no Mg was detected in the hot leg specimens except for a slight bump below the surface for the $681^{\circ} \mathrm{C}$ specimen. Based on the microstructure of this specimen in Figure 34c, this could be residual $\mathrm{Mg}$ trapped in the pores. The highest Mg content was observed for the coldest specimen examined, Figure 39. This could be from the material deposited on this specimen. Based on a Mg alloy specimen with an intensity of 222, the 0.55 intensity in Figure 39 would indicate the amount detected at the surface was $<<1 \%$.

Half of the 28 tensile specimens exposed were broken at room temperature using a strain rate of $10^{-3} \mathrm{~s}^{-1}$. Figure 40 summarizes the results with data shown as a function of estimated exposure temperature in the $\mathrm{HL}$ and $\mathrm{CL}$. The shaded areas show the range of data measured for two as-received alloy 600 specimens. Almost no change in the ultimate tensile strength was observed and a slight reduction in the $0.2 \%$ yield stress, Figure 40a. Likewise, almost no change in the uniform or total elongation was observed, Figure 40b.

Thus, the mass change, microstructure characterization and post-exposure tensile properties all indicate that alloy 600 was compatible with purified industrial-sourced salt at $580^{\circ}-700^{\circ} \mathrm{C}$ for $1000 \mathrm{~h}$. No Mg-rich layer was formed with a $0.04 \% \mathrm{Mg}$ addition and very little mass transfer occurred.

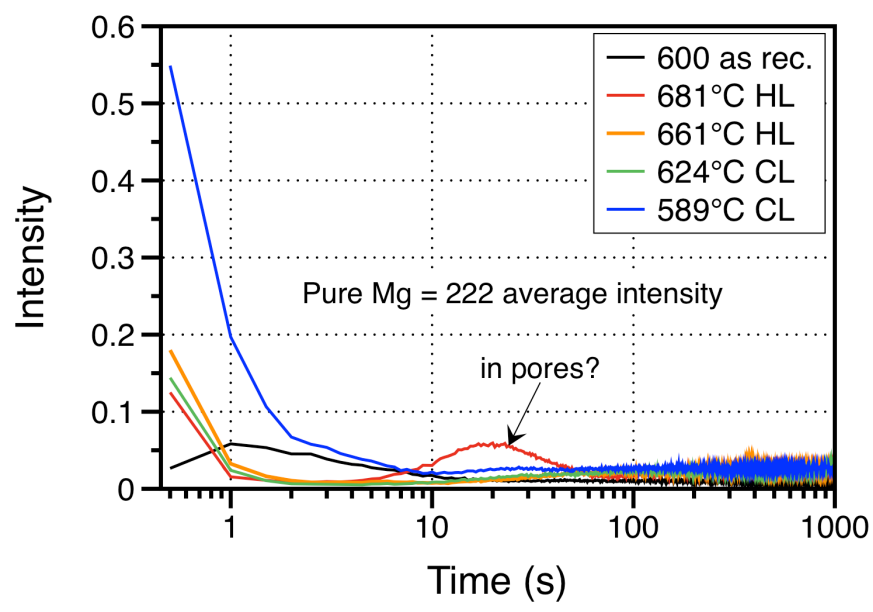

Figure 39. Glow discharge optical emission spectroscopy Mg depth profiles of alloy 600 specimens after $1,000 \mathrm{~h}$ exposures in flowing purified industrial-sourced salt $+0.04 \% \mathrm{Mg}$ identified by their estimated temperature in the hot leg $(\mathrm{HL})$ or cold leg $(\mathrm{CL})$. An unexposed (as received) alloy 600 specimen is shown for reference. The highest $\mathrm{Mg}$ signal was observed for the specimen at the lowest temperature. 
CPS 33873

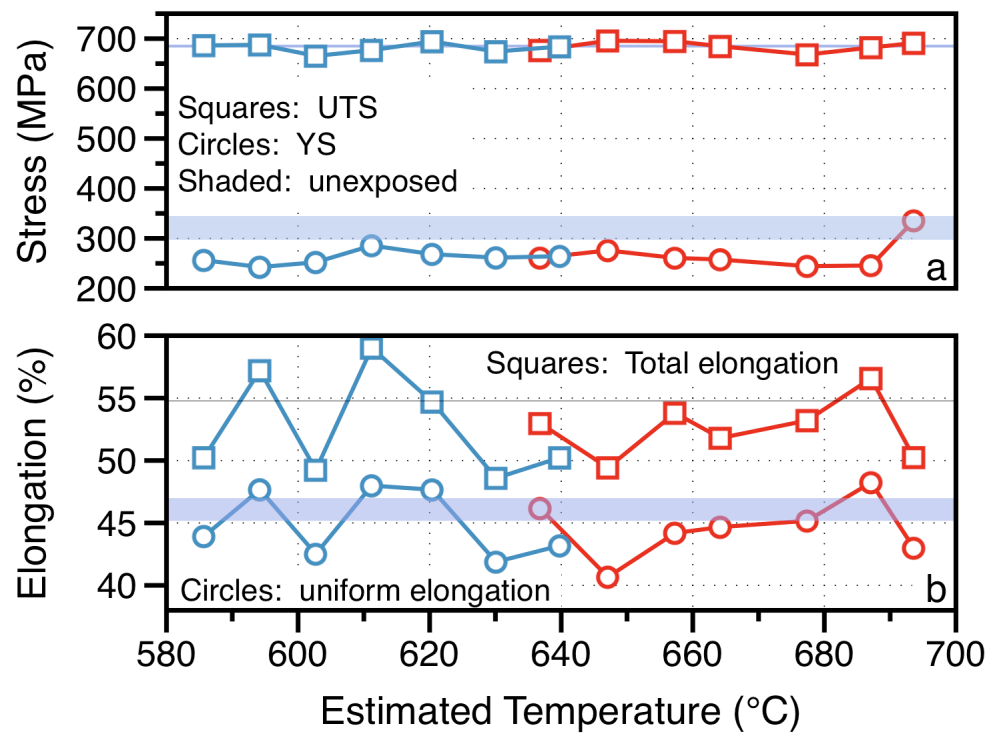

Figure 40. Room temperature tensile properties with a $10^{-3} \mathrm{~s}^{-1}$ strain rate for alloy 600 specimens after $1,000 \mathrm{~h}$ exposures in flowing purified industrial-sourced salt $+0.04 \% \mathrm{Mg}$ identified by their estimated temperature in the hot leg $(\mathrm{HL})$ or cold leg $(\mathrm{CL})$. (a) $0.2 \%$ yield stress (YS) and ultimate tensile stress (UTS) and (b) uniform and total elongation. The shaded region shows the range of values for unexposed specimens. Minimal degradation in properties was observed.

Task 1.3: Second thermal convection loop test.

Table 7. Project Evaluation Criteria for Task 1.3

\begin{tabular}{|c|c|c|c|c|c|}
\hline Task & Description & Criteria & $\begin{array}{c}\text { Measured } \\
\text { values }\end{array}$ & Goal Met? & $\begin{array}{c}\text { Supporting } \\
\text { data }\end{array}$ \\
\hline 1.3 & $\begin{array}{l}\text { Complete second loop test } \\
\text { of } 1000 \mathrm{~h} \text { (goal changed } \\
\text { from adding mitigation to } \\
\text { increased peak } \\
\text { temperature) }\end{array}$ & $\begin{array}{l}\text { 1. Specimen } \\
\text { mass loss } \\
\text { 2. }<15 \mu \mathrm{m} / \mathrm{yr} \\
\text { 3. }>30 \\
\text { specimens } \\
\text { exposed }\end{array}$ & Figure 42 & $\begin{array}{l}\text { No. Only } \\
\sim 110 \mathrm{~h} \\
\text { operation }\end{array}$ & Figure 43 \\
\hline
\end{tabular}

This task was originally planned to deploy a getter can from SRNL and a sensor developed by ANL. In late September 2018, SRNL notified ORNL that instead of a getter can, corrosion mitigation would be achieved via a retractable $\mathrm{Zr}$ rod into the salt. However, based on the low mass change in the first TCL, it was decided at the end of November 2018 to change the second experiment parameters. Since the mass change in the first TCL met the $<15 \mu \mathrm{m} / \mathrm{yr}$ metric, the effect of a getter could not be adequately demonstrated. Instead, the peak temperature was increased to $750^{\circ} \mathrm{C}$ and alternating specimens of alloys 600 and $\mathrm{C} 276$ (Ni-16\%Cr-16\%Mo-4\%W) were exposed in the specimen chains, Table 3. To expedite the second TCL, it was decided to use the same alloy $600 \mathrm{TCL}$ from the first experiment with the ANL sensor added to the overfill tank 
above the hot leg (Figure 30b) so that experience could be gained on the sensor operation.

The sensor was received at ORNL in December 2018. Approximately $2.5 \mathrm{~kg}$ of salt \#1 was purified using the same ORNL two stage process as described before with a $0.04 \% \mathrm{Mg}$ addition. The loop was assembled for operation in January 2019 using the same procedure as described for Task 1.2. The SS valves were replaced but the same TCL and fill and dump pots were used. In this case, the top of the hot leg was controlled at $749 \pm 1^{\circ} \mathrm{C}$. After $\sim 110 \mathrm{~h}$ of operation, one furnace failed during holiday weekend operation. Because of the added load to keep the TCL at the temperature setpoint, a second furnace failed about $24 \mathrm{~h}$ later followed by the third furnace. By the time staff returned to work, the salt had frozen. The temperature profiles during operation are shown in Figure 41 and indicated a $\sim 175^{\circ} \mathrm{C}$ temperature gradient. After furnace repairs, the TCL was reheated for $\sim 24 \mathrm{~h}$ but flow was not restored and the experiment was terminated. After opening the TCL, there was an empty region in the cold leg that formed during solidification. This area likely had poor thermal conductivity and may have prevented the adjacent salt from re-melting. Some of the salt was drained into the dump attack but most had to be dissolved with warm water to retrieve the specimens.

The mass change for the 40 specimens is shown in Figure 42 and compared to the results for the first TCL experiment (dashed lines). The maximum mass losses and gains were similar in both experiments because of the shorter time but higher temperature in the second experiment. Because the mass change was similar in both experiments, a limited amount of attack was expected for the second set of specimens.

A limited amount of characterization was conducted on this set of specimens for several reasons. The experiment ended near the end of Phase 1 (Year 1) of the project and it was decided to not continue studying the two stage purified salt. Also, the salt composition was changed for Year 2, increasing the $\mathrm{NaCl}$ content. Thus, Figures 43 and 44 show light microscopy images of coupon specimens from the hot and cold legs for

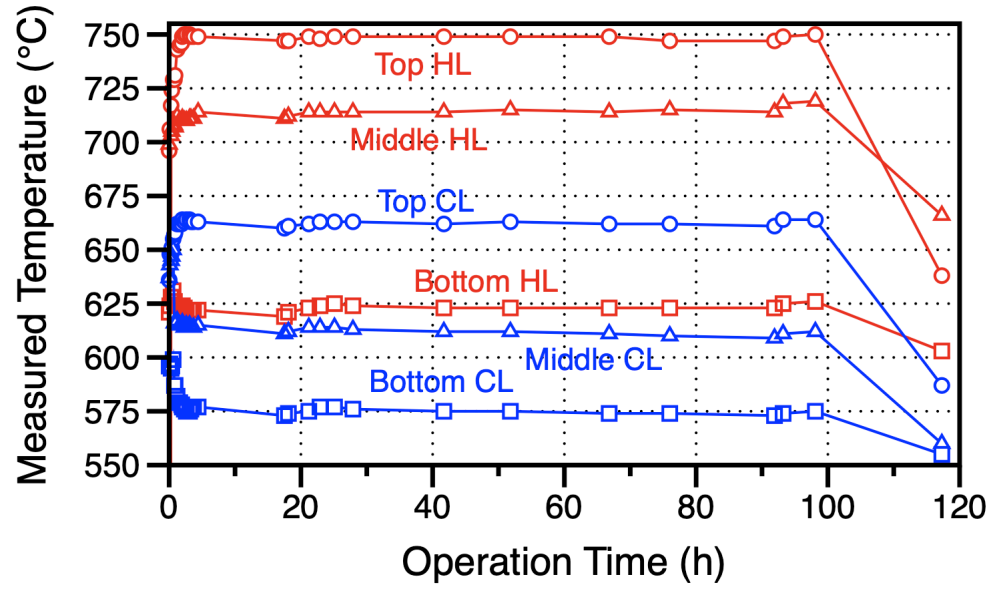

Figure 41. Measured temperatures at six thermocouples around the second TCL in the hot leg $(\mathrm{HL})$ and cold leg $(\mathrm{CL})$ during the experiment, which ended prematurely due to a furnace failure. 
CPS 33873

Progression to Flowing Molten Salts

ORNL Pint

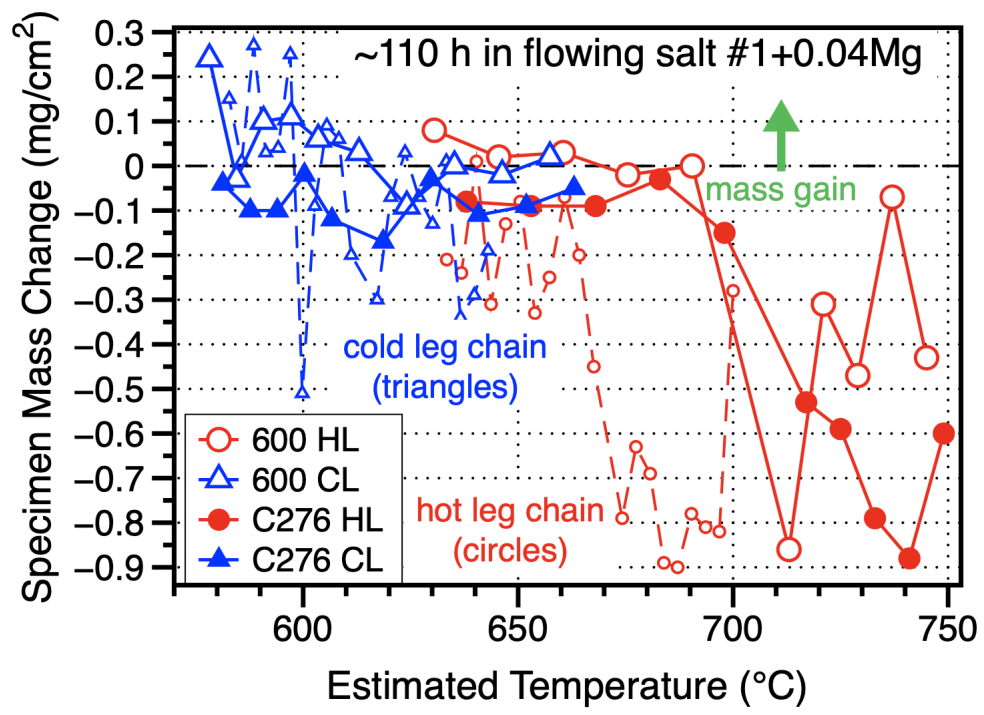

Figure 42. Specimen mass change as a function of estimated temperature for alloy 600 (open symbols) and C276 (closed symbols) specimens exposed in flowing purified salt in the first TCL experiment (dashed lines all alloy 600) and the second TCL experiment (solid lines).

C276 and alloy 600 specimens, respectively. The images are consistent with the mass change data. All of the $\mathrm{C} 276$ specimens exposed above $650^{\circ} \mathrm{C}$ show signs of surface pitting. However, none of the specimens showed a mass gain in the cold leg. Instead all but the $581^{\circ} \mathrm{C}$ specimen showed a $\sim 5 \mu \mathrm{m}$ deep surface affected zone, Figure 43. Similarly for the alloy 600 specimens, pitting was observed on the hottest specimens from the cold leg. Four alloy 600 coupons exhibited a mass gain after the exposure. The two coldest specimens in the cold leg clearly showed a layer on the surface, perhaps suggesting material deposition.

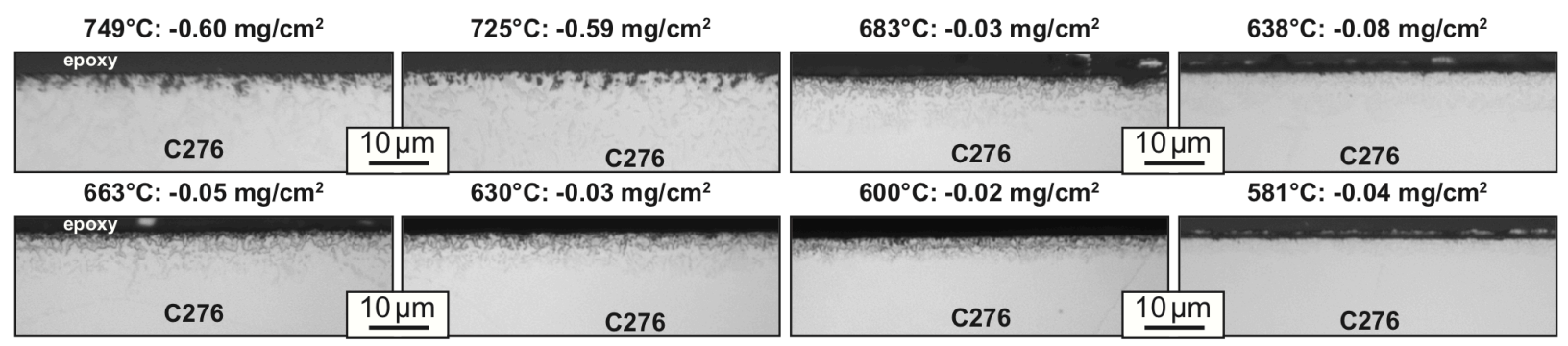

Figure 43. Light microscopy of polished cross-sections of alloy C276 coupons after 110 $\mathrm{h}$ exposures in flowing purified industrial-sourced salt $+0.04 \% \mathrm{Mg}$ identified by their estimated temperature in the hot (top row) and cold leg (bottom row). 


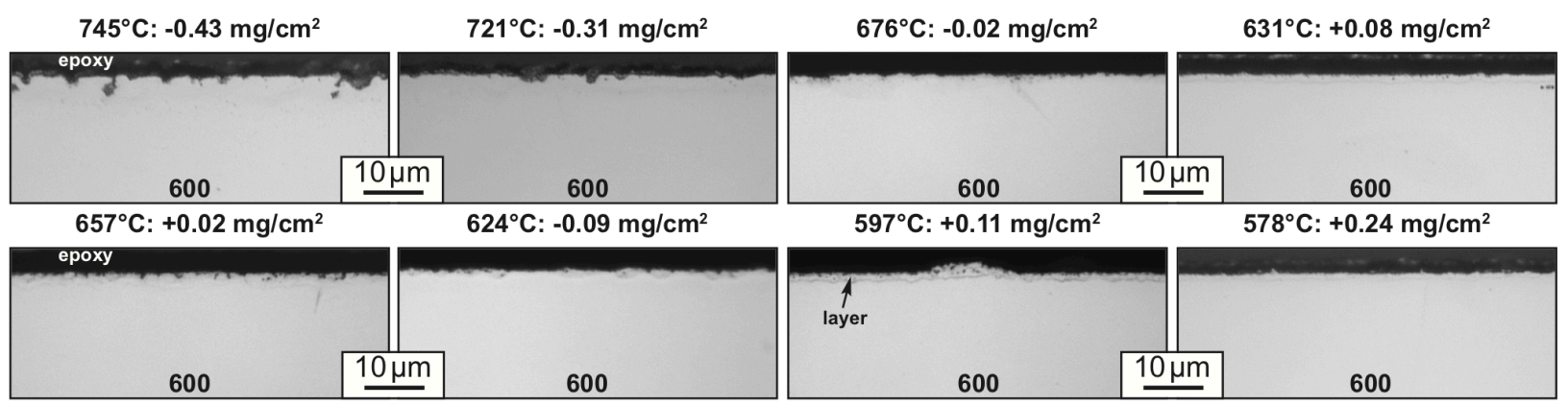

Figure 44. Light microscopy of polished cross-sections of alloy 600 coupons after $110 \mathrm{~h}$ exposures in flowing purified industrial-sourced salt $+0.04 \% \mathrm{Mg}$ identified by their estimated temperature in the hot (top row) and cold leg (bottom row).

Task 2.0: Chloride corrosion facilities qualification

Table 8. Project Evaluation Criteria for Task 2.0

\begin{tabular}{|c|l|l|l|l|c|}
\hline Task & Description & Criteria & $\begin{array}{l}\text { Measured } \\
\text { values }\end{array}$ & Goal Met? & $\begin{array}{c}\text { Supporting } \\
\text { data }\end{array}$ \\
\hline 2.0 & $\begin{array}{l}\text { Conduct crucible test and } \\
\text { characterize alloy } \\
\text { specimens after exposure } \\
\text { per instructions on salt } \\
\text { preparation, test conditions } \\
\text { and characterization }\end{array}$ & $\begin{array}{l}1 . \text { Specimen } \\
\text { mass loss } \\
2 .<15 \mu \mathrm{m} / \mathrm{yr} \\
3 . \text { Repeat } \geq 3\end{array}$ & Figure 45 & $\begin{array}{l}\text { Yes, no mass } \\
\text { loss observed }\end{array}$ & Figure 47 \\
\hline
\end{tabular}

Similar to Task 1.0, Task 2.0 sought to statistically compare Chloride Collective participant results using a modified procedure (see Appendix A). A quartz crucible was used rather than a $\mathrm{Ni}$ crucible as well as a new salt composition and preparation procedure. The anhydrous ICL salt was mixed with halite to make a 40:40:20 K:Mg:Na composition. Per the procedure, the salt was heated to $650^{\circ} \mathrm{C}$ and $0.25 \% \mathrm{Mg}$ was added. However, most of the added Mg appeared to float to the top or sink to the bottom and was not used in the experiment. Chunks of salt were loaded into the crucible and the three alloy 230 specimens were hung from the Ni lid, similar to what was shown in Figure 6a. The measured composition for alloy 230 is shown in Table 3 . The crucible was then placed in a stainless steel bag and the bag was placed in a stainless steel container (Figure 6b) that was bolted shut inside the glove box. The stainless steel container was then removed from the glove box and heated in a box furnace at $800^{\circ} \mathrm{C}$ for $100 \mathrm{~h}$.

After the exposure was complete, the container was opened, and the specimens were removed and cleaned in water. The mass change data is shown in Figure 45. A mass gain was observed for each of the three specimens. This mass change was higher than the $0.65 \pm 0.05 \mathrm{mg} / \mathrm{cm}^{2}$ observed in Task 1.0. In that case, a Ni-Mg layer formed on the specimens [Pint 2019]. The mass gain was similar to a $800^{\circ} \mathrm{C} / 100 \mathrm{~h}$ capsule experiment conducted in a Mo capsule $\left(1.54 \mathrm{mg} / \mathrm{cm}^{2}\right)$, Figure $29 \mathrm{~b}$. Figure 46 shows SEM/EDX maps from one of the alloy 230 specimens. In this case, no $\mathrm{Mg}$ rich layer formed. Instead there was clear $\mathrm{Cr}$ depletion (observed in all of the specimens) and a surprising Fe-enrichment 


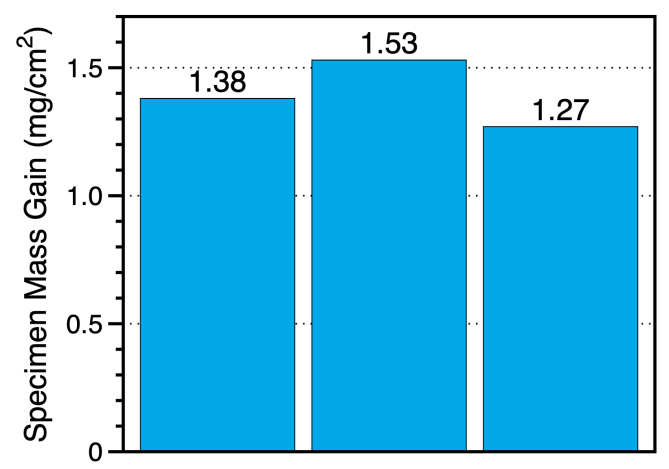

Figure 45. Specimen mass gain for alloy 230 specimens after $100 \mathrm{~h}$ at $800^{\circ} \mathrm{C}$ in industrialsourced salt with a $0.25 \% \mathrm{Mg}$ addition.

observed in the outer layer of the reaction product. As shown in Table 3, alloy 230 contains $1.5 \% \mathrm{Fe}$ so it is unlikely that Fe from the alloy enriched the surface. The only source of $\mathrm{Fe}$ in the experiment was the stainless steel bag surrounding the quartz capsule. With the Ni lid, it seems unlikely that the bag contaminated the specimen. Previously, the salt was only found to have $4 \mathrm{ppm}$ Fe, Table 2. ICP analysis of the new salt shows $90 \mathrm{ppm} \mathrm{Fe}$ (Table 9) after drying the mixture of the as-received salt and halite. Figure 46 also shows that the inner layer contains $\mathrm{MgO}$ particles and some Al-rich areas, which is likely Al from the alloy.

Figure 47 shows EDS $\mathrm{Cr}$ line profiles from one specimen. The three profiles were taken at roughly $1 / 4$ increments along the length of the specimen. The average depletion depth was $16 \pm 7 \mu \mathrm{m}$ in this specimen. The other two specimens had $\mathrm{Cr}$ depletions depths of $10 \pm 7$ and $6 \pm 2 \mu \mathrm{m}$. Based on the $\mathrm{Cr}$ map in Figure $46 \mathrm{~b}$, the variability stems from the deeper $\mathrm{Cr}$ depletion encountered at alloy grain boundaries. For clarity, only one Fe line profile is shown in Figure 47, which corresponds to the lowest $\mathrm{Cr}$ depletion. This shows the $\mathrm{Fe}$ enrichment in the outer layer of the reaction product. About $40 \% \mathrm{Fe}$ and $40 \% \mathrm{Ni}$
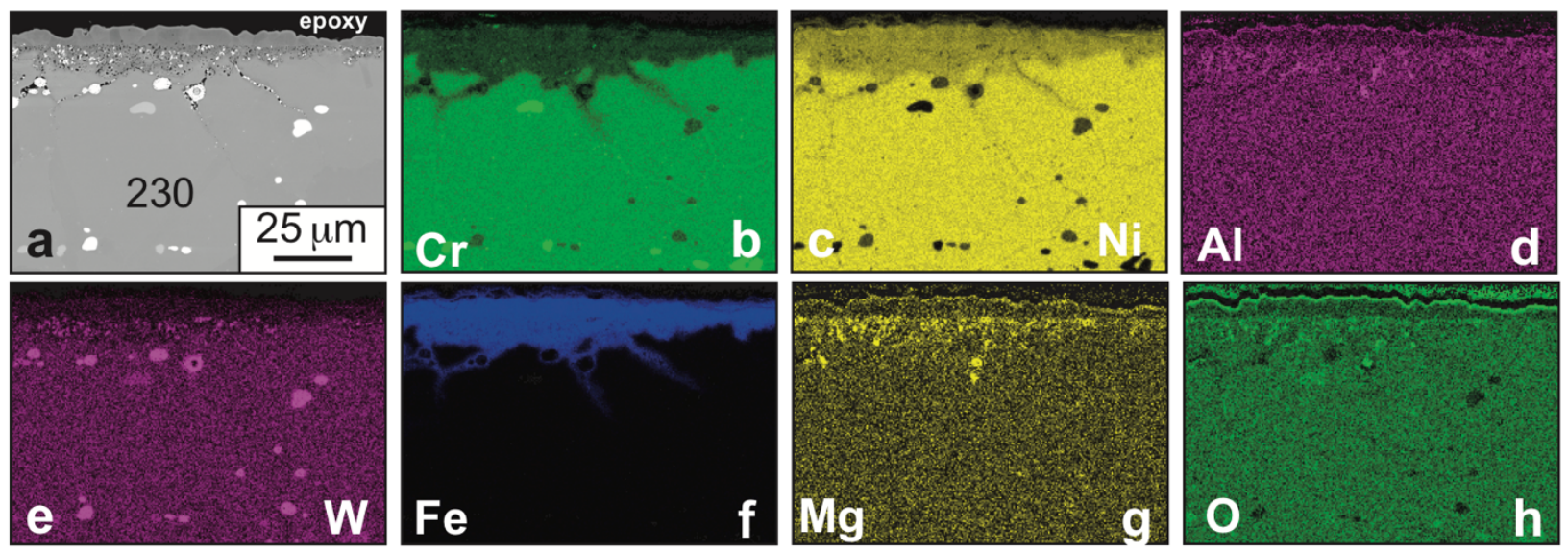

Figure 46. (a) SEM backscattered electron image of a polished section of alloy 230 after exposure to ICL salt for $100 \mathrm{~h}$ at $800^{\circ} \mathrm{C}$, (b-h) EDX maps of the same region. 
Table 9. Chemical composition of the industrial-sourced salt determined by ICP for each of the salt variations and acid-base titration of the $\mathrm{O}^{2-}$ content of the dried salt.

\begin{tabular}{|c|c|c|c|c|c|c|c|c|c|c|c|c|c|}
\hline & $\begin{array}{c}\mathrm{K} \\
(\%)\end{array}$ & $\begin{array}{c}\mathrm{Mg} \\
(\%)\end{array}$ & $\begin{array}{c}\mathrm{Na} \\
(\%)\end{array}$ & $\begin{array}{c}\mathrm{Ca} \\
(\%)\end{array}$ & $\begin{array}{c}\mathrm{Br} \\
(\%)\end{array}$ & $\begin{array}{c}\mathrm{S} \\
(\mathrm{ppm})\end{array}$ & $\begin{array}{c}\mathrm{Ni} \\
(\mathrm{ppm})\end{array}$ & $\begin{array}{c}\mathrm{Fe} \\
(\mathrm{ppm})\end{array}$ & $\begin{array}{c}\mathrm{Cr} \\
(\mathrm{ppm})\end{array}$ & $\begin{array}{c}\mathrm{Mn} \\
(\mathrm{ppm})\end{array}$ & $\begin{array}{c}\mathrm{W} \\
(\mathrm{ppm})\end{array}$ & $\begin{array}{c}\mathrm{Al} \\
(\mathrm{ppm})\end{array}$ & $\begin{array}{c}\mathrm{O}^{2-} \\
(\mu \mathrm{mol} / \mathrm{kg})\end{array}$ \\
\hline As-rec. & 20.6 & 12.2 & 4.8 & 0.09 & 0.14 & 79 & 0.3 & 67 & 0.2 & 4 & 0 & 2 & \\
\hline Halite & 7.9 & 0.02 & 31.9 & 0.26 & 0.01 & 6618 & 0.1 & 82 & 0.1 & 5 & 0 & 104 & \\
\hline Dried & 18.5 & 11.2 & 7.1 & 0.12 & 0.14 & 344 & 0.4 & 90 & 0.04 & 5 & 0 & 4 & $>20,000$ \\
\hline After loop & 19.2 & 11.5 & 6.8 & 0.13 & 0.14 & 15 & $\mathbf{5 6}$ & 94 & $\mathbf{2 2 9}$ & 37 & 44 & 1 & \\
\hline
\end{tabular}

was detected in the outer layer. However, the outer layer was not uniform on the surface. In some areas, this layer was minimal. It is not clear how such a large amount of $\mathrm{Fe}$ formed but NREL and SRNL also observed Fe enrichment after similar exposures.

ORNL was not able to conduct ICP analysis in-house nor the NREL-developed $\mathrm{MgOHCl}$ titration without significant investment in standards and equipment. Therefore, specimens were sent to NREL and an outside laboratory generated the results in Table 9. The ORNL acid-base titration was used to determine that a very large $\mathrm{O}$ content remained in the salt after drying, very different from the purified salt in Phase 1, Table 2.

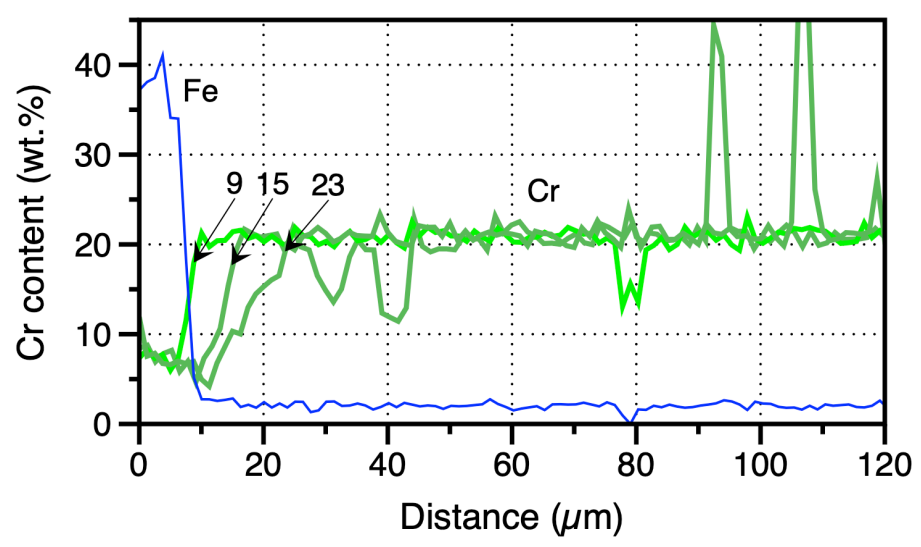

Figure 47. Three EDS line profiles from one of the 230 specimens exposed to ICL salt for $100 \mathrm{~h}$ at $800^{\circ} \mathrm{C}$. The $\mathrm{Cr}$ profiles came from three different parts of the specimen. For clarity, only one Fe profile is shown. The $\mathrm{Cr}$ peaks are from the W-rich carbides. 
Task 2.1: Capsule testing to support loop experiment

Table 10. Project Evaluation Criteria for Task 2.1

\begin{tabular}{|c|l|l|l|c|c|}
\hline Task & Description & Criteria & $\begin{array}{l}\text { Measured } \\
\text { values }\end{array}$ & Goal Met? & $\begin{array}{c}\text { Supporting } \\
\text { data }\end{array}$ \\
\hline 2.1 & $\begin{array}{l}10 \text { capsule experiments: } \\
\text { Investigate } 3 \text { different } \mathrm{Mg} \\
\text { additions in } 500-1000 \mathrm{~h} \\
\text { exposures at } 600^{\circ}-800^{\circ} \mathrm{C} \\
\text { in alloy } 600 \text { capsules; } \\
\text { select Mg level for Task } \\
\text { 2.2, process } 5 \mathrm{~kg} \text { and } \\
\text { determine chemistry }\end{array}$ & $\begin{array}{l}\text { attack } \\
2 .<100 \mu \mathrm{m} \\
\text { at } 1000 \mathrm{~h}\end{array}$ & Figure 53 & Yes & Figure 52 \\
Table 9
\end{tabular}

This task had two objectives. First, to help identify an optimal Mg content in the starting salt and second, as a safety requirement to demonstrate reasonable salt-structural alloy compatibility prior to the flowing salt test for Task 2.2. Since the salt composition (higher $\mathrm{Na}$ content) and preparation process were changed compared to Phase 1, it was necessary to reconfirm compatibility. The capsule test results also created a baseline for comparison with the flowing experiment results.

Task 2.1 was planned to include at least 10 capsule experiments. The first set of experiments explored $3 \mathrm{Mg}$ addition levels with $500 \mathrm{~h}$ exposures at $600^{\circ}$ and $700^{\circ} \mathrm{C}$ with alloy 600 specimens (600S in Table 3). Based on Phase 1 results (Figure 29), the use of a Mo capsule can cause excess reaction of $\mathrm{Mg}$ in the salt with the specimen because the Mo container is relatively inert to reaction with $\mathrm{Mg}$. Therefore, $25 \mathrm{~mm}$ diameter by 100 $\mathrm{mm}$ tall alloy 600 capsules were fabricated for this task made from the same tubing material used to construct the loop (600T in Table 3). In order to create additional Mg levels for this task, a new batch of commercially-sourced dried salt was made with no $\mathrm{Mg}$ addition and 0.05 or $0.1 \% \mathrm{Mg}$ was added to those capsules with the Mg-free salt. Salt from Task 2.0 was used for the experiments with $0.25 \% \mathrm{Mg}$ in the salt.

Typical capsules with the outer stainless steel capsule are shown in Figure 5 . In each case, chunks of salt were loaded into the capsules in an Ar-filled glove box. The alloy 600 capsules were then welded inside outer stainless steels capsules and these were then placed in a box furnace for $500 \mathrm{~h}$ at $600^{\circ}$ or $700^{\circ} \mathrm{C}$. At the conclusion of the experiment, the capsules were inverted to allow the salt to drain away. The capsules were then opened and the specimens cleaned ultrasonically in $40^{\circ} \mathrm{C}$ de-ionized water. The capsule procedure has been described previously in Tasks 1.0/1.1 [Pint 2019].

The mass change results for these first 6 experiments are shown in Figure 48. One specimen showed a mass gain while the others showed mass losses. These values correspond to $\sim 0-20 \mu \mathrm{m} / \mathrm{yr}$ losses. The mass losses were different from the Task 2.0 result where a mass gain was observed for alloy 230 specimens at $800^{\circ} \mathrm{C}$, Figure 45 . 


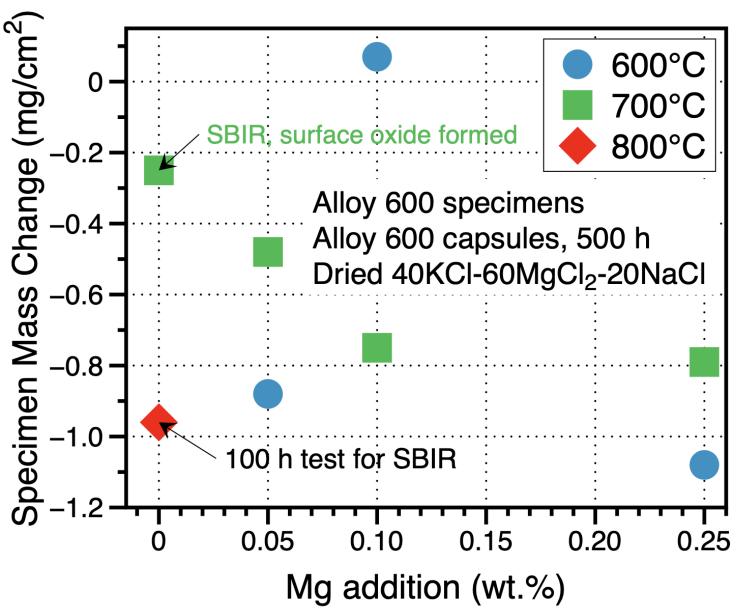

Figure 48. Specimen mass change for alloy 600 specimens after $500 \mathrm{~h}$ at $600^{\circ}-800^{\circ} \mathrm{C}$ in industrial-sourced dried salt with a Mg addition in an alloy 600 capsule. Additional results are shown for an SBIR project.

Figure 48 also shows results from two capsule experiments funded by a DOE Nuclear Energy SBIR project. Since the goal of the SBIR was to non-destructively characterize tube materials, no $\mathrm{Mg}$ addition was added with the goal of maximizing attack. A higher mass loss was observed after $100 \mathrm{~h}$ at $800^{\circ} \mathrm{C}$ in one experiment. However, a much lower mass loss was observed after $500 \mathrm{~h}$ at $700^{\circ} \mathrm{C}$. In the latter case, the specimen had a green appearance after testing and XPS analysis indicated an oxide layer was present which may account for the lower mass loss with no Mg addition in Figure 48.

Polished cross-sections of the 6 specimens are shown in Figure 49 in addition to a similar alloy 600 specimen exposed for $500 \mathrm{~h}$ at $700^{\circ} \mathrm{C}$ with salt with $0 \% \mathrm{Mg}$ from the SBIR project. All of the specimens at $600^{\circ} \mathrm{C}$ looked similar as did the $700^{\circ} \mathrm{C}$ specimens. Figure 2 quantifies the depth of internal attack in these specimens using box and whisker plots of $\sim 30$ measurements from each specimen. Very little effect of $\mathrm{Mg}$ content was observed.

The lack of a consistently different behavior in depth of attack among the three Mg levels did not help with the down selection process. However, to scale up to larger salt quantities, it was decided to use the $0.05 \% \mathrm{Mg}$ addition for the second round of experiments and Task 2.2. A batch of this salt was prepared for the $2^{\text {nd }}$ round of
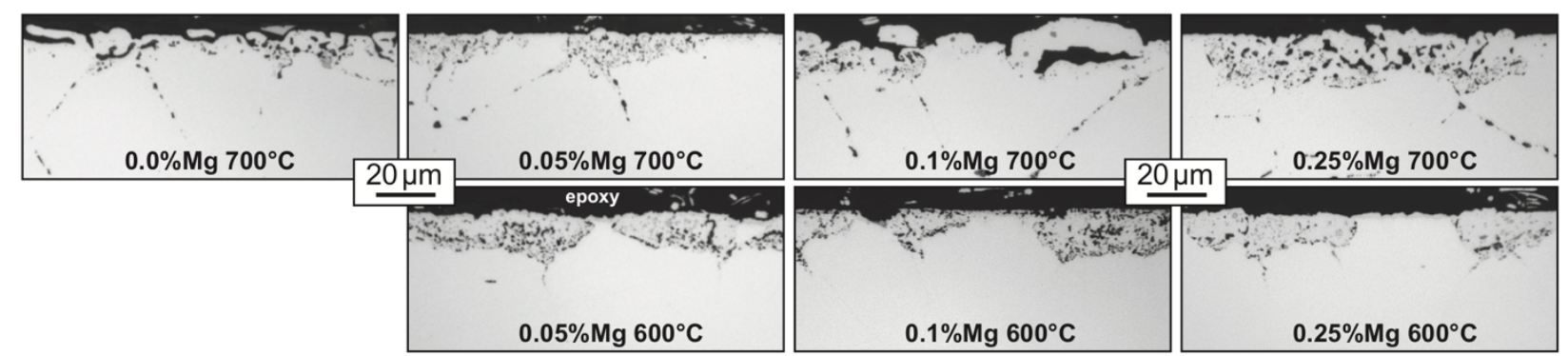

Figure 49. Light microscopy of alloy 600 specimens exposed to dried industrial-sourced molten salt for $500 \mathrm{~h}$ at $600^{\circ}$ and $700^{\circ} \mathrm{C}$ with different levels of $\mathrm{Mg}$ additions. 


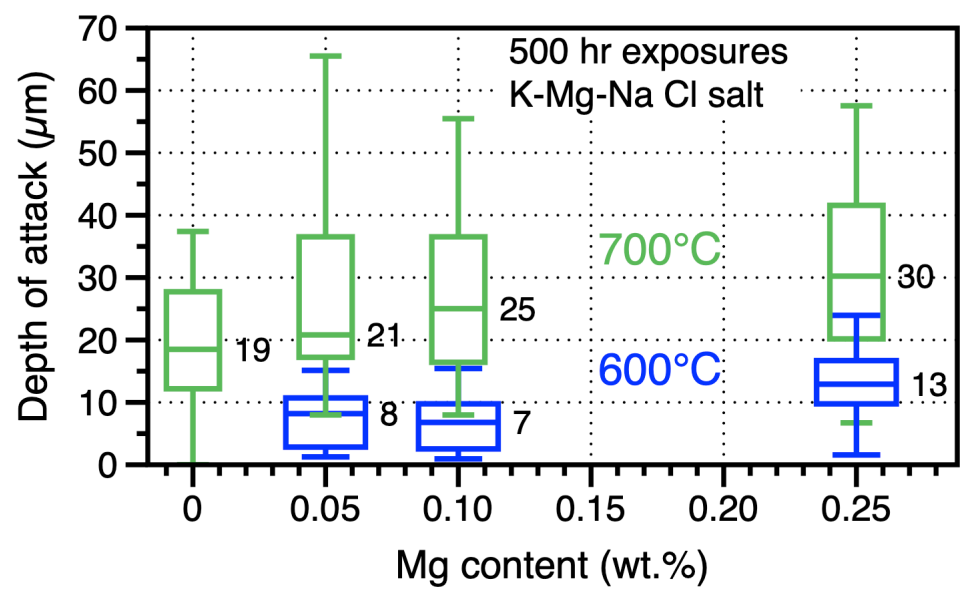

Figure 50. Box and whisker plots of the depth of attack measured for alloy 600 specimens exposed for $500 \mathrm{~h}$ at $600^{\circ}$ and $700^{\circ} \mathrm{C}$ in dried industrial-sourced salt as a function of the $\mathrm{Mg}$ addition in the salt. The whiskers show the maximum and minimum values measured and the boxes mark the $25 \%$ and $75 \%$ values with the median value noted.

capsule experiments (Table 9), which were exposed for $1000 \mathrm{~h}$ at $600^{\circ}, 700^{\circ}$ and $800^{\circ} \mathrm{C}$, again using alloy 600 capsules. No C276 capsules were fabricated since the C276 loop fabricated during Phase 1 was not used for this project. Figure 51 shows the mass change results for alloy 600 and C276 specimens. The composition of this heat of C276 is shown in Table 3. Not unlike the $500 \mathrm{~h}$ results, the mass loss was greater at $600^{\circ} \mathrm{C}$ than at $700^{\circ} \mathrm{C}$. The $\mathrm{C} 276$ specimen exposed at $800^{\circ} \mathrm{C}$ exhibited a mass gain similar to the alloy 230 specimens in Task 2.0.

Figure 52 shows metallographic cross-sections of the specimens after the $1000 \mathrm{~h}$ exposures. A higher magnification was used for the $\mathrm{C} 276$ specimens, which showed

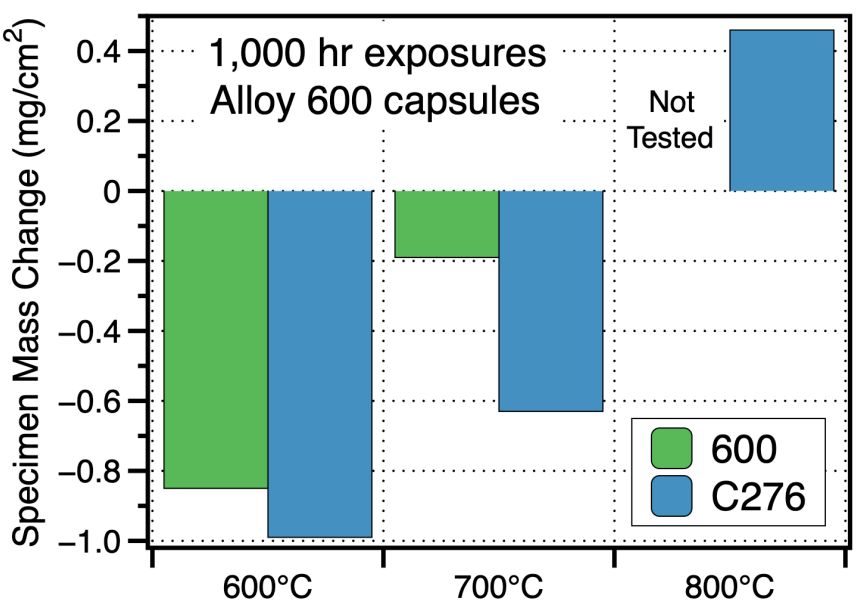

Figure 51. Specimen mass change for alloy 600 and C276 specimens after $100 \mathrm{~h}$ at $800^{\circ} \mathrm{C}$ in dried industrial-sourced salt with $0.05 \% \mathrm{Mg}$. Specimens were exposed in individual alloy 600 capsules. 

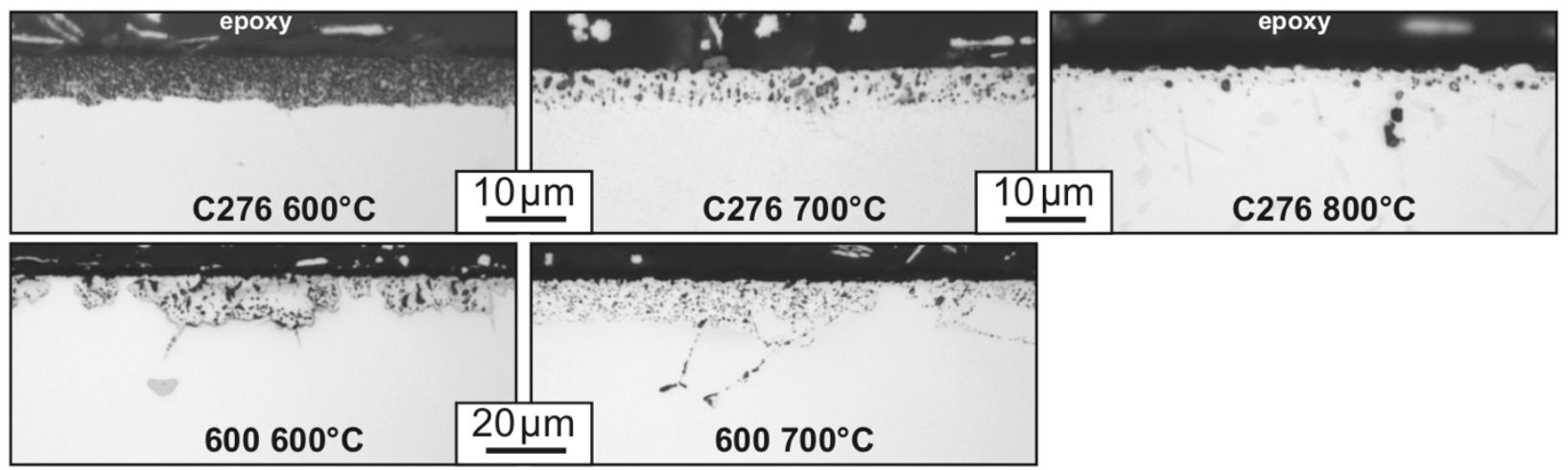

Figure 52. Light microscopy of alloy 600 and C276 specimens exposed to dried industrialsourced molten salt with $0.05 \% \mathrm{Mg}$ for $1,000 \mathrm{~h}$ at $600^{\circ}-800^{\circ} \mathrm{C}$. A higher magnification was used for the C276 specimens.

higher mass losses at $600^{\circ}$ and $700^{\circ} \mathrm{C}$ than the alloy 600 specimens but showed more uniform attack. Figure 53 quantifies the differences observed with less attack and smaller boxes for the $\mathrm{C} 276$ specimens. For the alloy 600 specimens, the attack at $600^{\circ} \mathrm{C}$ was somewhat consistent with the median depth of attack increasing from $8 \mu \mathrm{m}$ at $500 \mathrm{~h}$ in Figure 50 to $10 \mu \mathrm{m}$ after $1000 \mathrm{~h}$. However, at $700^{\circ} \mathrm{C}$, the median attack depth dropped from $21 \mu \mathrm{m}$ at $500 \mathrm{~h}$ to $11 \mu \mathrm{m}$ at $1000 \mathrm{~h}$. Nevertheless, the attack was relatively low for all of the specimens and provides confidence for Task 2.2 and baseline results for comparison.

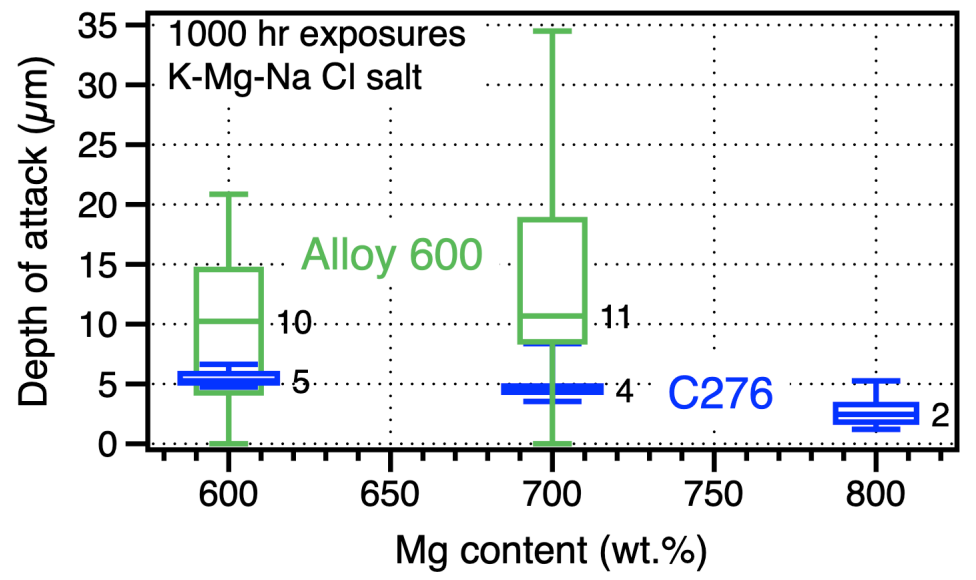

Figure 53. Box and whisker plots of the depth of attack measured for the alloy 600 specimens exposed for $1000 \mathrm{~h}$ in dried industrial-sourced salt with $0.05 \% \mathrm{Mg}$ as a function of exposure temperature. The whiskers show the maximum and minimum values measured and the boxes mark the $25 \%$ and $75 \%$ values with the median value noted. 
Task 2.2: Third thermal convection loop test

Table 11. Project Evaluation Criteria for Task 2.2

\begin{tabular}{|c|c|c|c|c|c|}
\hline Task & Description & Criteria & $\begin{array}{c}\text { Measured } \\
\text { values }\end{array}$ & Goal Met? & $\begin{array}{c}\text { Supporting } \\
\text { data }\end{array}$ \\
\hline 2.2 & $\begin{array}{l}\text { Run alloy } 600 \text { loop using } \\
\text { salt parameters developed } \\
\text { in Task } 2.1 \text { and include } \\
\text { sensor and } \mathrm{Mg} \text { in melt } \\
\text { tank and } \mathrm{Mg} \text { in cold leg. } \\
\text { Peak temperature of } \\
700^{\circ} \mathrm{C} \text { and } 40 \text { specimens } \\
\text { exposed. }\end{array}$ & $\begin{array}{l}\text { 1. Specimen } \\
\text { mass change } \\
2 .<15 \mu \mathrm{m} / \mathrm{yr} \\
\text { 3. }>30 \\
\text { specimens } \\
\text { exposed } \\
\text { 4. Include } \mathrm{Mg} \\
\text { metal at cold } \\
\text { leg bottom }\end{array}$ & Figure 56 & Yes & $\begin{array}{c}\text { Figure } 54 \\
\text { Figures 58- } \\
59\end{array}$ \\
\hline
\end{tabular}

This TCL experiment followed a similar procedure as Task 1.2 [Pint 2019] with a peak temperature of $700^{\circ} \mathrm{C}$ but used the $40: 40: 20$ dried salt with a $0.05 \% \mathrm{Mg}$ addition. A similar set of specimens was used as Task 1.3 with chains of 20 alternating alloy 600 and C276 specimens hanging in both the hot and cold legs. The majority of specimens were 25 $\mathrm{mm}$ long SS-3 type tensile specimens with a few coupons $(25 \times 19 \times 1.8 \mathrm{~mm})$. In addition to the specimens, alloy 600 spacers were added to keep the chain centered in the tube (immediately above the $\mathrm{Mg}$ coupon in Figure 54b). The loop design was changed to include a tank at the top of the hot leg to better integrate the ANL sensor into the flowing salt, compare Figures 30 and 54a. Two ports were used to insert 8 tungsten rods for the ANL sensor (the sensor performance will be reported by ANL). A piece of $\mathrm{Mg}$ metal was machined to hang at the bottom of the cold leg chain, arrow in Figure 54b. A vacuum throughput was added to the top of the tank so that a Mg rod could be inserted into the tank if the salt potential increased during the $1000 \mathrm{~h}$ experiment. (It was not deployed in this experiment.). Because of the larger tank, $5 \mathrm{~kg}$ of salt was dried for the experiment.

Similar to the previous procedure, the alloy $600 \mathrm{TCL}$ was cleaned with nitric acid and then rinsed with alcohol and evacuated to ensure a lack of leaks. As before, the temperature of the flowing salt in the TCL was monitored using type K thermocouples in 6 thermowells at the top, middle and bottom of the hot and cold legs that were inserted $\sim 3 \mathrm{~mm}$ into the flow path, Figure 30b. The loop temperature was controlled at the top of the hot leg to $700 \pm 2^{\circ} \mathrm{C}$ for $1000 \mathrm{~h}$ and the bottom of the cold leg was $550-570^{\circ} \mathrm{C}$ with an average temperature of $565^{\circ} \mathrm{C}$, Figure 55. Several events occurred during the experiment: (1) at $\sim 196 \mathrm{~h}$ the temperature dropped inside the pot, (2) at $\sim 230 \mathrm{~h}$, the sensor began to detect an increasing $\mathrm{Cr}$ signal in the salt and (3) at $\sim 590 \mathrm{~h}$ the top furnace failed and it was repaired the next day (shaded area in Figure 55) such that the experiment was continued for an extra $27 \mathrm{~h}$ to make up for the time when the peak temperature was below $\sim 700^{\circ} \mathrm{C}$. After removing the insulation, it was discovered that the Ni gasket of the pot above the hot leg leaked and shorted out the heat tape around the pot at $\sim 196 \mathrm{~h}$. The increase in the $\mathrm{Cr}$ signal at $230 \mathrm{~h}$ may have coincided with the dissolution of the $\mathrm{Mg}$ coupon, which was not found after the experiment. It is possible that the two events are related. It is also possible that the leak contributed to the furnace failure. After the experience with 

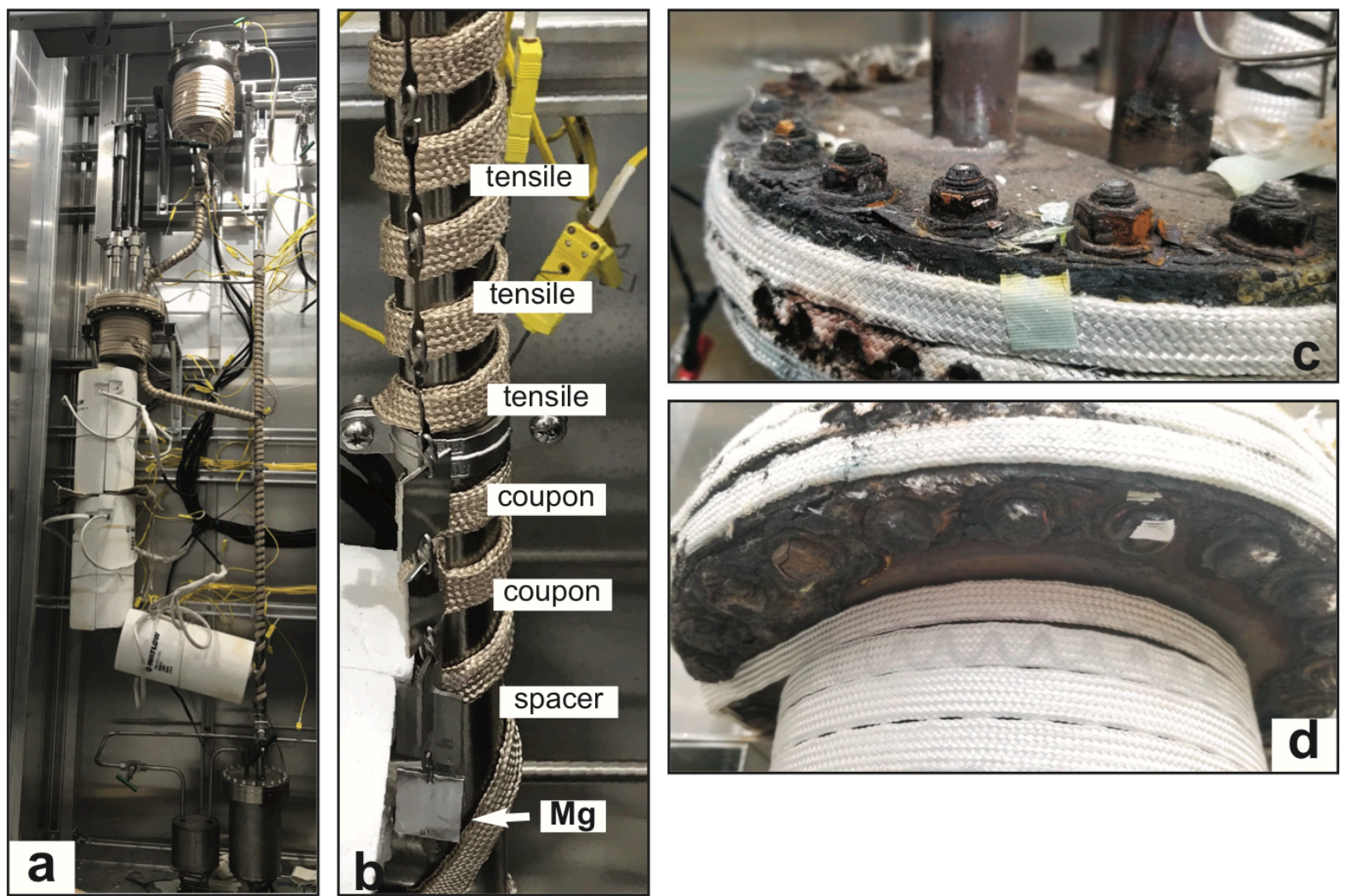

Figure 54. (a) Image of the thermal convection loop (TCL) before operation, without heat tape or insulation including fill tank at top and dump tank at the bottom and intermediate tank at the top of the hot leg. (b) cold leg chain hanging outside loop showing $\mathrm{Mg}$ specimen at the bottom of the chain (arrow). (c,d) Flange of top leg pot after operation.

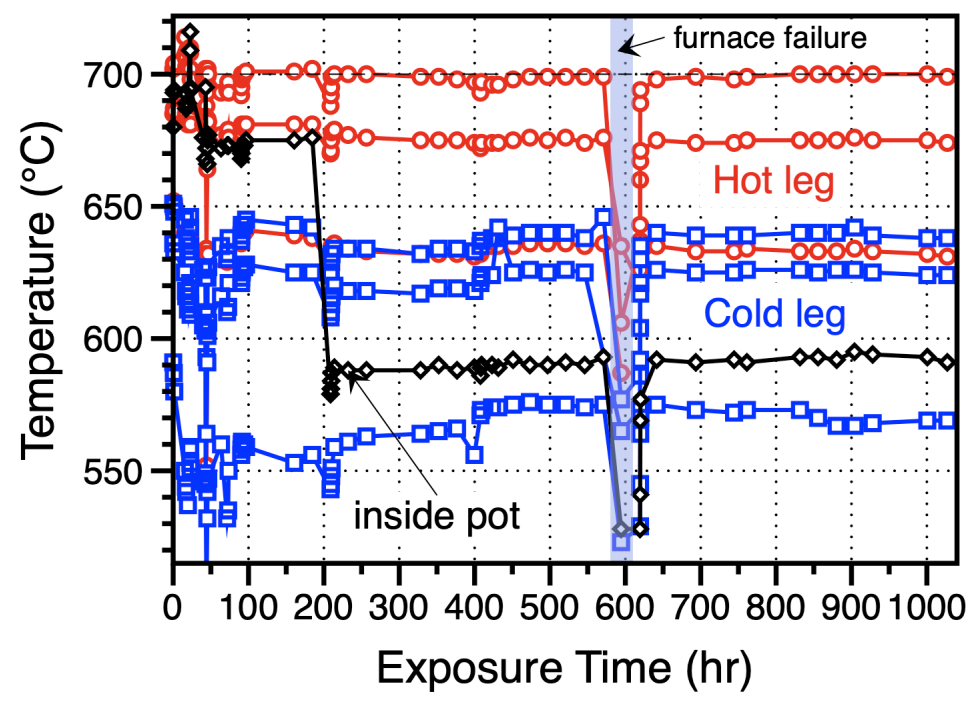

Figure 55. Measured temperatures at six thermocouples around the TCL in the hot leg $(\mathrm{HL})$ and cold leg $(\mathrm{CL})$ during the $1000 \mathrm{~h}$ experiment. A furnace failure caused a drop in the peak temperature at $\sim 590^{\circ} \mathrm{C}$ and required $\sim 27 \mathrm{~h}$ to repair and return to temperature. 
the second loop furnace failures, all of the furnace controllers were set to prevent the other furnaces from overheating when one failed.

Similar to the procedure reported for tasks 1.2 and 1.3, a similar flow rate was measured for $2.4 \mathrm{~cm} / \mathrm{s}$. At the end of the experiment, the salt was dumped and the loop was cleaned using deionized water at $40^{\circ} \mathrm{C}$. Figure 56 compares the mass change of the alternating C276 and alloy 600 specimens to the mass change measured in the Task 1.2 loop with purified salt. In general, all of the measured masses were slightly higher than the previous experiment with more specimens experiencing a mass gain in this experiment. Both the alloy 600 and C276 specimens experienced a mass loss at the highest temperatures, $>670^{\circ} \mathrm{C}$. Unlike the Task 1.2 specimens, the highest temperature specimen did not show obvious porosity on the surface. However, many of the specimens showed indications of surface deposits. For example, Figure 57a shows a plan view SEM image of the alloy 600 specimen exposed at $\sim 639^{\circ} \mathrm{C}$. The figure also includes SEM/EDX maps from the same region which indicate that the surface deposit is rich in $\mathrm{Mg}, \mathrm{O}$ and Cl.

All of the coupons were cross-sectioned for analysis and the alloy 600 and C276 specimens from the $\mathrm{HL}$ and $\mathrm{CL}$ are shown in Figures 58 and 59, respectively. While the depth of attack was small in all cases, it was surprising to see in the cold leg evidence of both deposits and internal attack. In Figures 34, 43 and 44, the CL specimens tended to have minimal attack and only evidence of deposits. In Figures 58 and 59, only the specimens exposed below $\sim 600^{\circ} \mathrm{C}$ showed no internal attack. Also, regarding the surface deposits, both metallic and non-metallic deposits were evident on the CL specimens. Figure 60 is a box and whisker plot where an attempt was made to quantify the deposit thickness and depth of internal attack for all of the coupon specimens of C276 and alloy 600 . All of the median depths were $<16 \mu \mathrm{m}$ but attack was as deep as $20-28 \mu \mathrm{m}$.

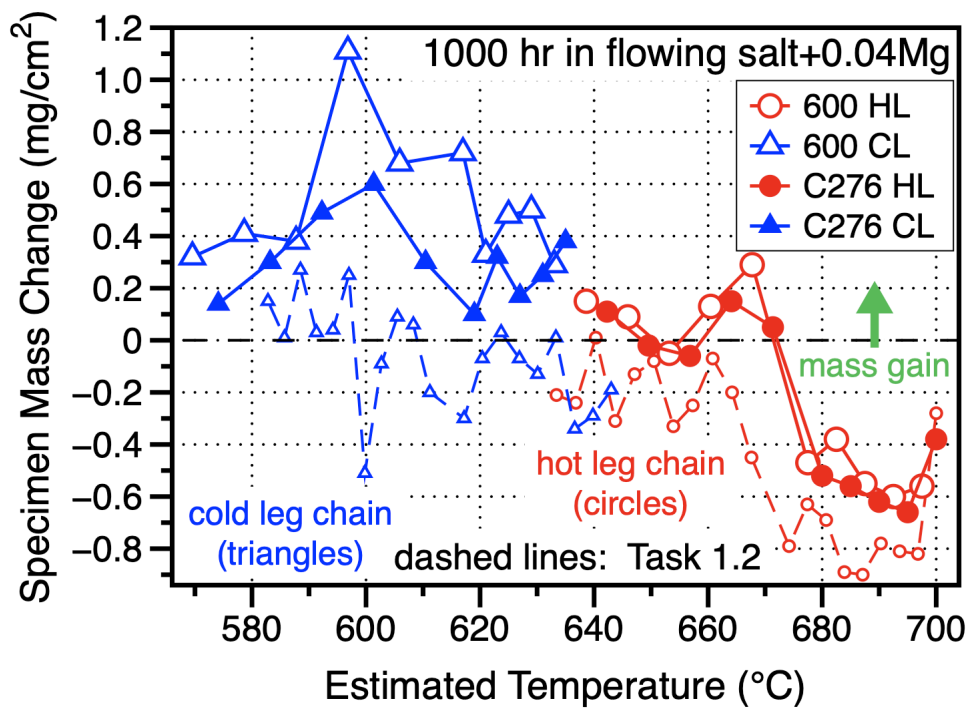

Figure 56. Specimen mass change as a function of estimated temperature for alloy 600 and C276 specimens exposed in flowing purified salt. Solid lines for Task 2.2, dashed lines for Task 1.2. 

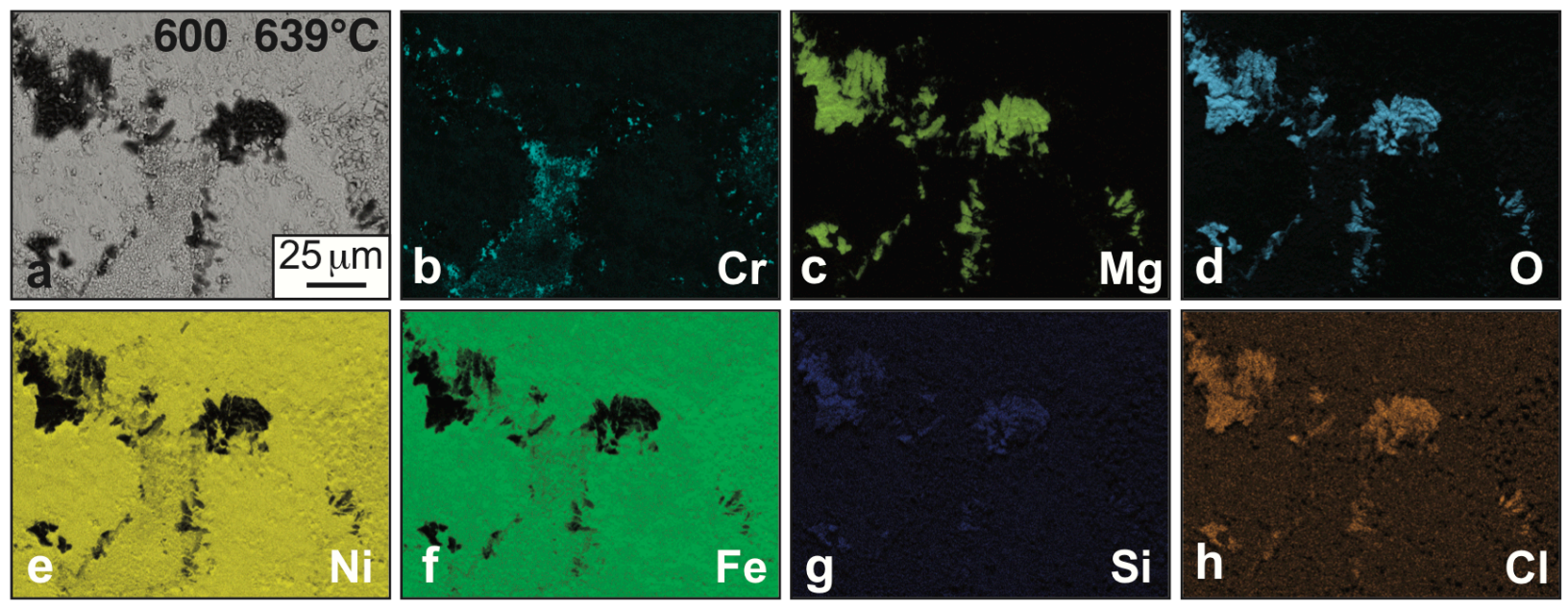

Figure 57. (a) SEM secondary electron plan view image of alloy 600 specimen after 1,000 $\mathrm{h}$ exposure in flowing dried industrial-sourced salt $+0.04 \% \mathrm{Mg}$ at $\sim 639^{\circ} \mathrm{C}$. Associated SEM EDX maps of (a): (b) Cr, (c) Mg, (d) O, (e) Ni, (f) Fe, (g) Si and (h) Cl.

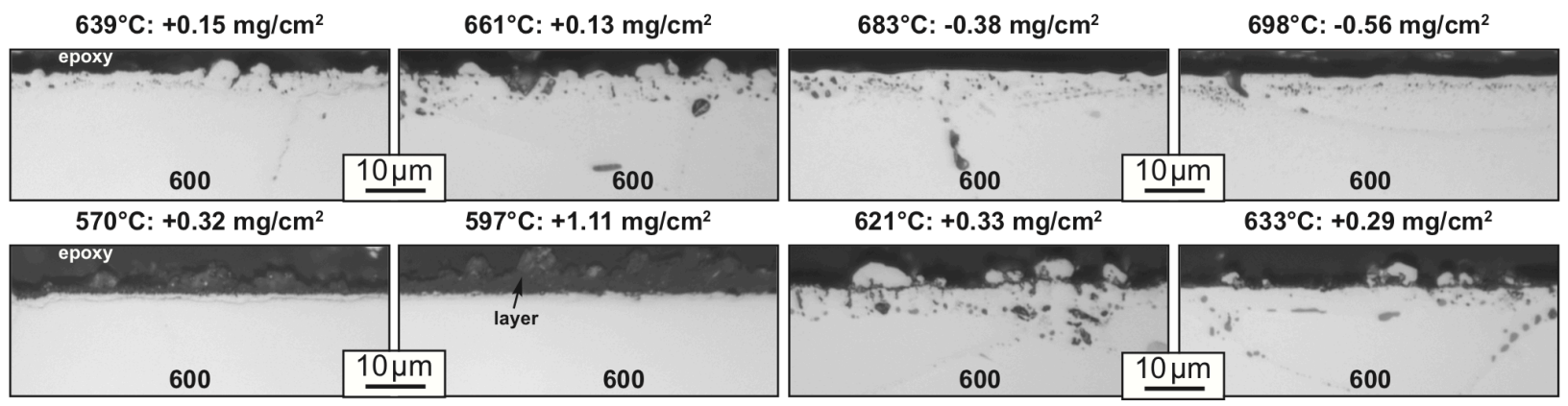

Figure 58. Light microscopy of polished cross-sections of alloy 600 coupons after 1000 $\mathrm{h}$ exposures in flowing dried industrial-sourced salt $+0.05 \% \mathrm{Mg}$ identified by their estimated temperature in the hot (top row) and cold leg (bottom row).

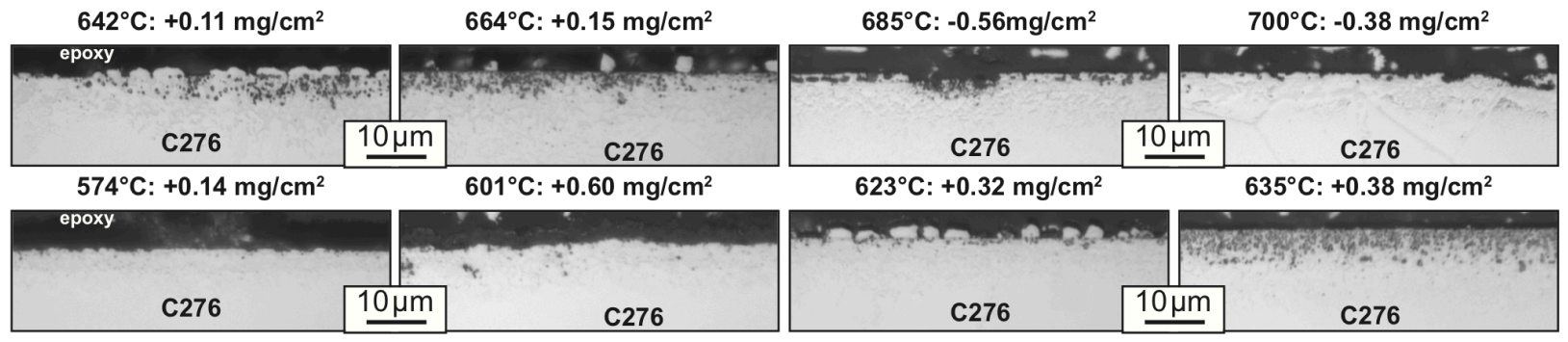

Figure 59. Light microscopy of polished cross-sections of alloy C276 coupons after 1000 $\mathrm{h}$ exposures in flowing dried industrial-sourced salt $+0.05 \% \mathrm{Mg}$ identified by their estimated temperature in the hot (top row) and cold leg (bottom row). 

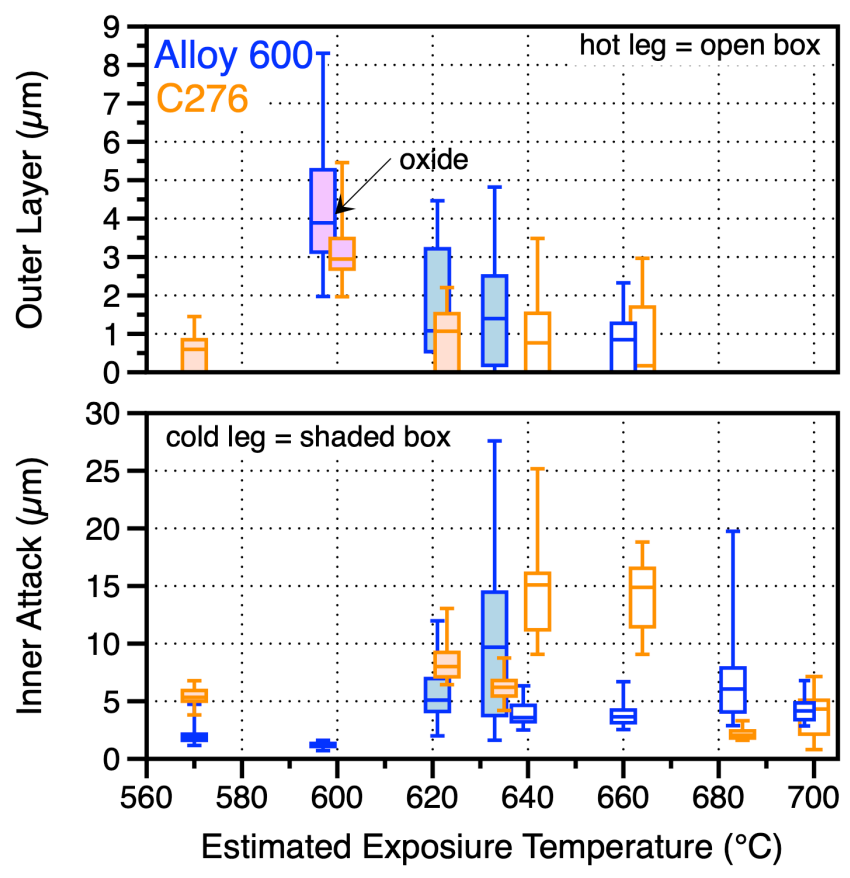

Figure 60. Box and whisker plots of the depth of attack and outer layer thickness measured for the alloy 600 and C276 coupon specimens exposed for $1000 \mathrm{~h}$ in dried flowing industrial-sourced salt with $0.05 \% \mathrm{Mg}$ as a function of estimated exposure temperature. The whiskers show the maximum and minimum values measured and the boxes mark the $25 \%$ and $75 \%$ values with the median value noted.

Figures 61-64 show SEM images and associated EDX maps of several alloy 600 specimens from the $\mathrm{HL}$ and $\mathrm{CL}$. At $683^{\circ} \mathrm{C}, \mathrm{Cr}$ dissolution and Fe enrichment were evident
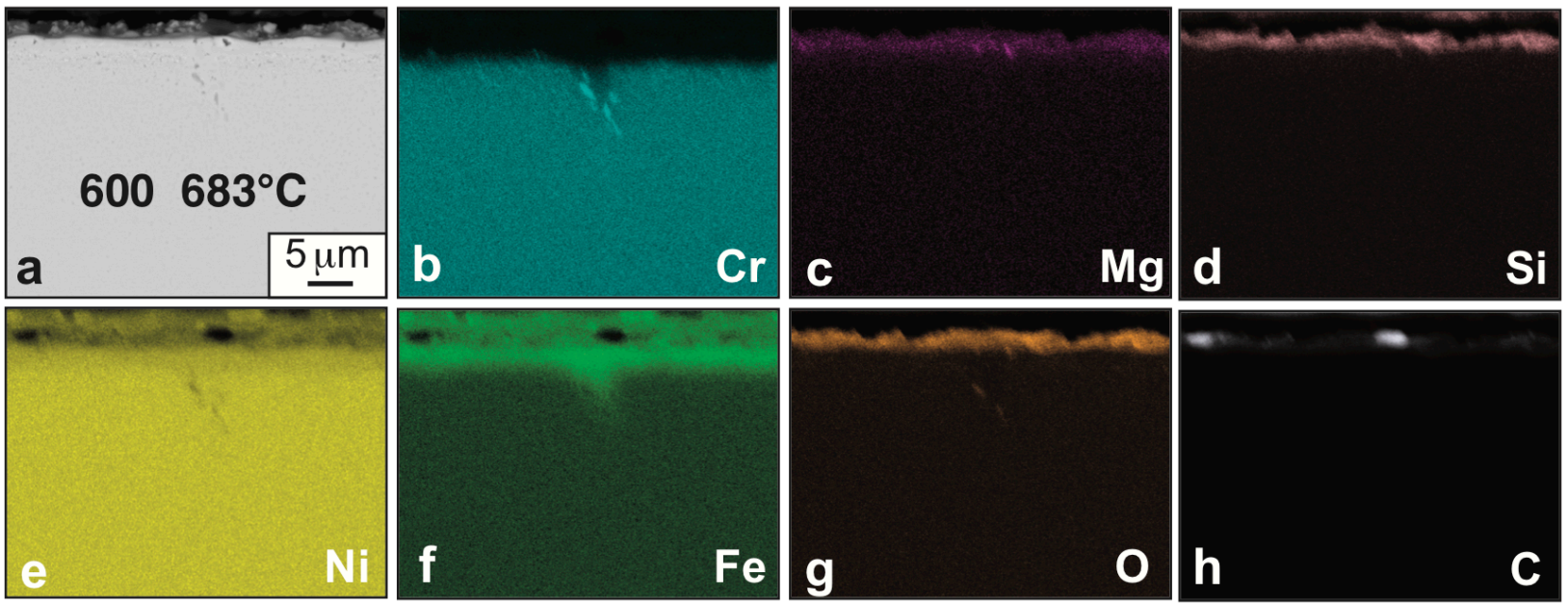

Figure 61. (a) SEM backscattered electron image of polished section of alloy 600 after $1000 \mathrm{~h}$ in the hot leg at $\sim 683^{\circ} \mathrm{C}$ in flowing dried industrial-sourced salt $+0.05 \% \mathrm{Mg}$ and EDX maps of the area in (a): (b) $\mathrm{Cr}$, (c) Mg, (d) Si, (e) Ni, (f) Fe, (g) O and (h) C. 


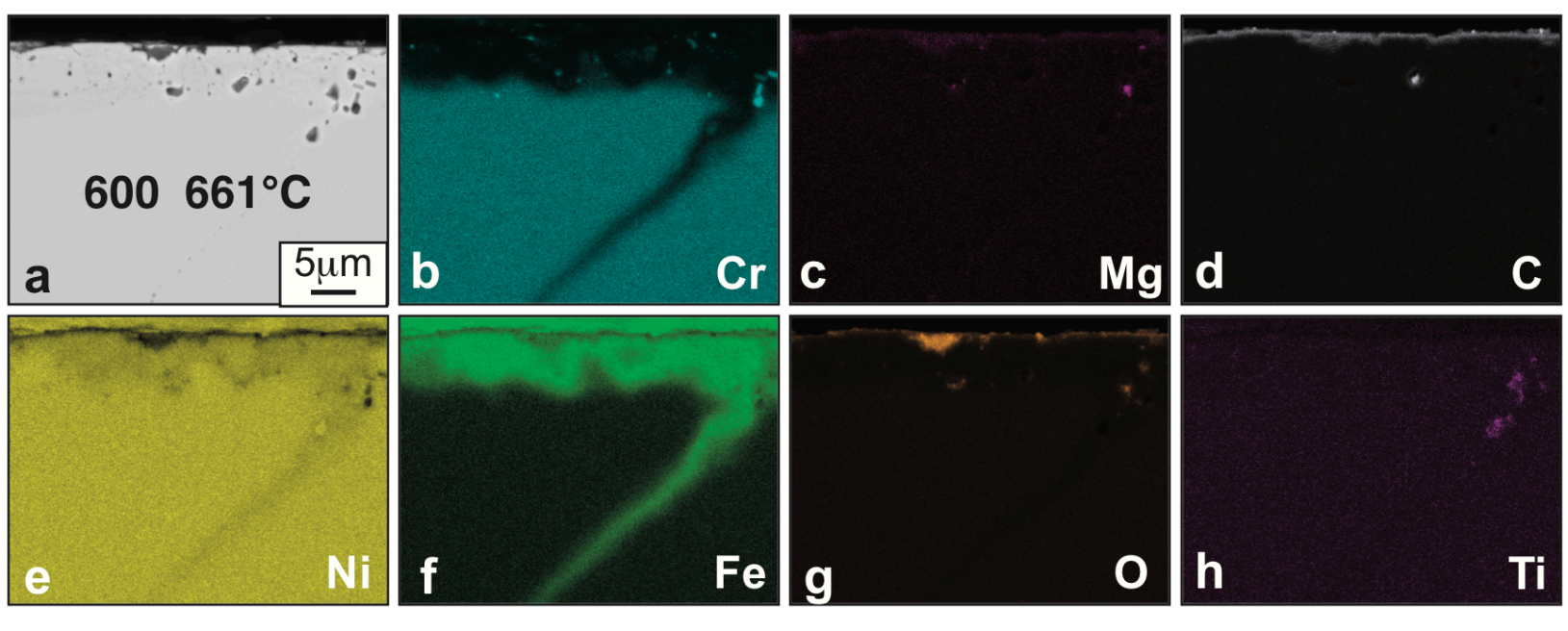

Figure 62. (a) SEM backscattered electron image of polished section of alloy 600 after $1000 \mathrm{~h}$ in the hot leg at $\sim 661^{\circ} \mathrm{C}$ in flowing dried industrial-sourced salt $+0.05 \% \mathrm{Mg}$ and EDX maps of the area in (a): (b) $\mathrm{Cr}$, (c) Mg, (d) C, (e) Ni, (f) Fe, (g) O and (h) Ti.

but were accompanied by a thin O-rich surface layer containing Si and Mg, Figure 61 . EDX line profiles from the same specimens are shown in Figure $65 a$ and quantify the change in $\mathrm{Cr}$ and $\mathrm{Fe}$ at the surface as well as some Si enrichment. At $661^{\circ} \mathrm{C}$, the specimen surface was similarly depleted in $\mathrm{Cr}$ and enriched in $\mathrm{Fe}$, Figure 62, particularly along an alloy grain boundary where diffusion is expected to be faster. $\mathrm{The} \mathrm{Cr}$ and $\mathrm{Fe}$ levels are shown in EDX line profiles in Figure 65b. In this case, a C- and O-rich layer was observed with less $\mathrm{Mg}$ detected. Precipitates on the grain boundary were Ti-rich, Figure $62 \mathrm{~h}$. In the $\mathrm{CL}$ at $633^{\circ} \mathrm{C}$, the $\mathrm{Cr}$ depletion was not as uniform but the O-rich layer was more evident in the EDX maps in Figure 63. The line profiles from this specimen

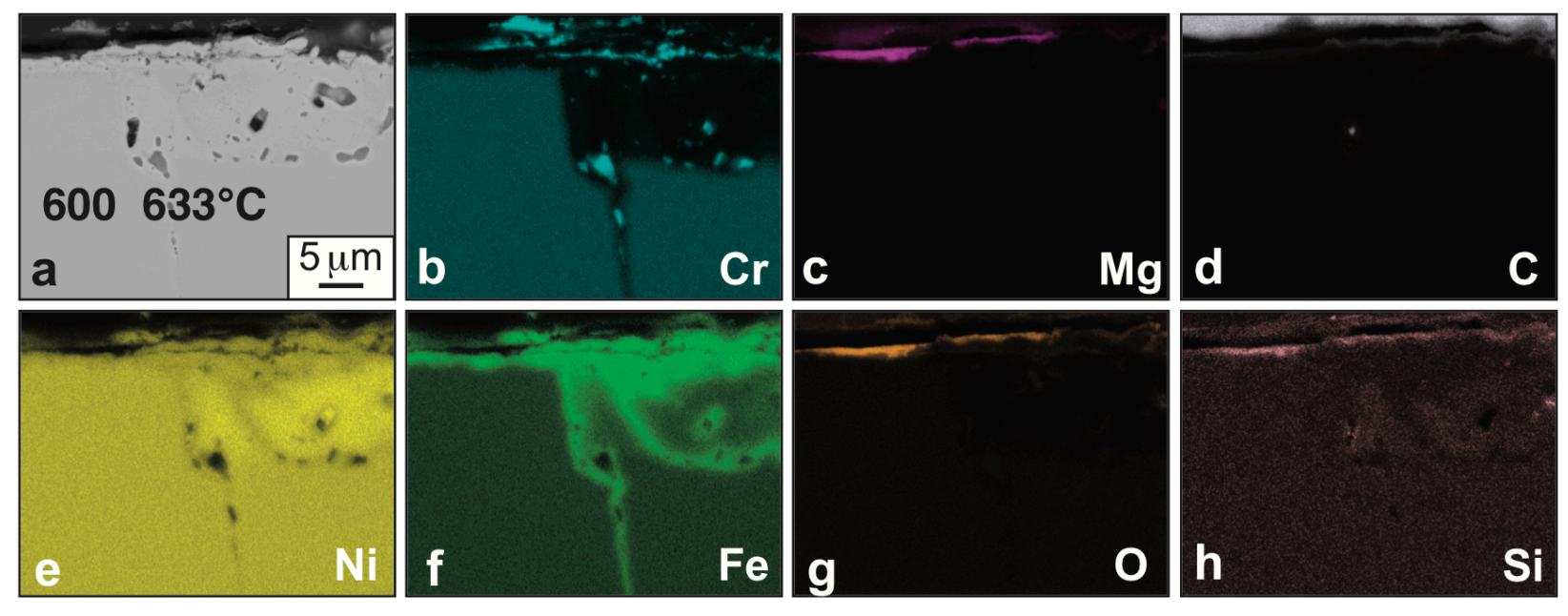

Figure 63. (a) SEM backscattered electron image of polished section of alloy 600 after $1000 \mathrm{~h}$ in the cold leg at $\sim 633^{\circ} \mathrm{C}$ in flowing dried industrial-sourced salt $+0.05 \% \mathrm{Mg}$ and EDX maps of the area in (a): (b) $\mathrm{Cr}$, (c) $\mathrm{Mg}$, (d) C, (e) Ni, (f) Fe, (g) O and (h) Si. 

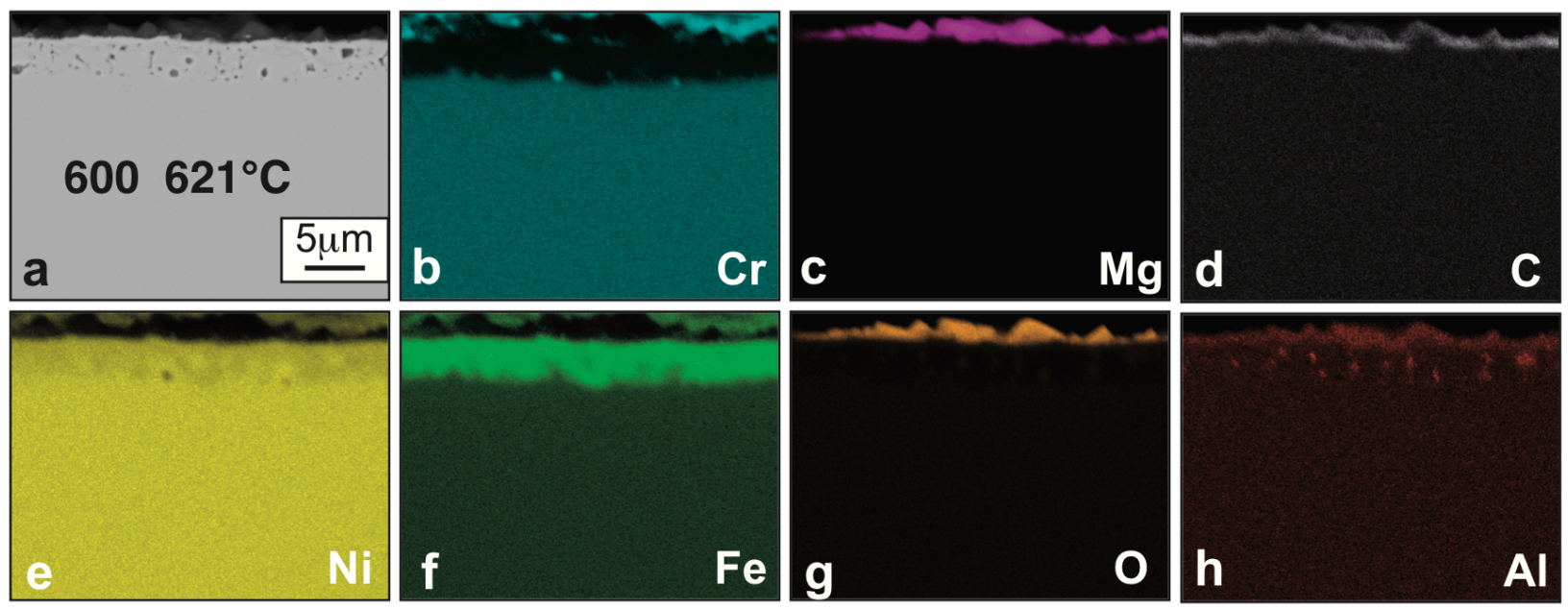

Figure 64 (a) SEM backscattered electron image of polished section of alloy 600 after $1000 \mathrm{~h}$ in the cold leg at $\sim 621^{\circ} \mathrm{C}$ in flowing dried industrial-sourced salt $+0.05 \% \mathrm{Mg}$ and EDX maps of the area in (a): (b) $\mathrm{Cr}$, (c) $\mathrm{Mg}$, (d) C, (e) Ni, (f) $\mathrm{Fe},(\mathrm{g}) \mathrm{O}$ and (h) Al.

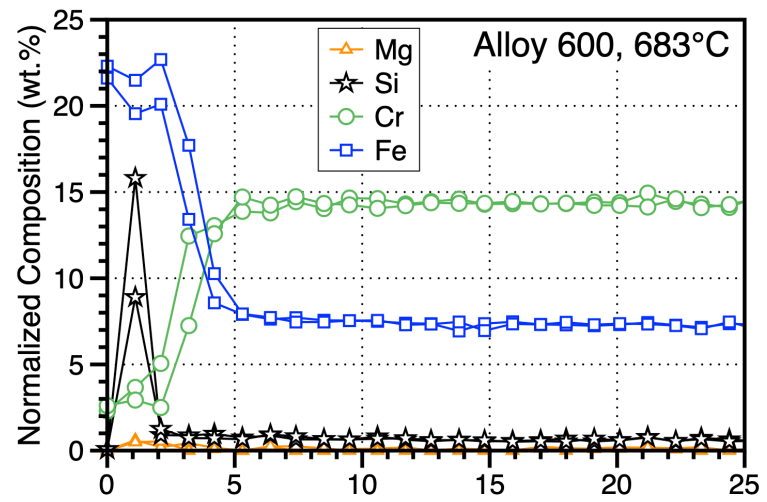

a

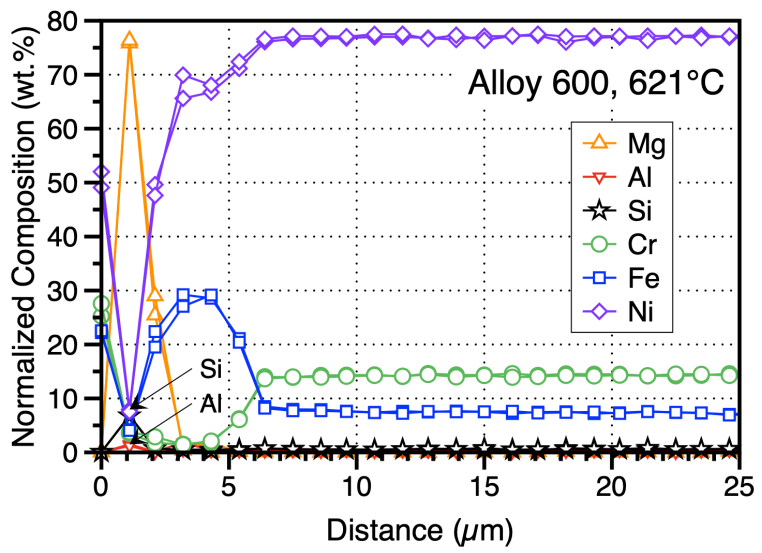

Figure 65. EDS line profiles from alloy 600 coupon specimens exposed to dried industrialsourced salt for $1000 \mathrm{~h}$ at estimated temperatures of (a) $683^{\circ} \mathrm{C} \mathrm{HL}$ (hot leg), (b) $661^{\circ} \mathrm{C}$ $\mathrm{HL}$, (c) $621^{\circ} \mathrm{C} \mathrm{CL}$ (cold leg) and (d) $597^{\circ} \mathrm{C} \mathrm{CL}$. 
showed a very high $\mathrm{Mg}$ level in one case but still significant $\mathrm{Cr}$ depletion and $\mathrm{Fe}$ enrichment at the surface, Figure $65 \mathrm{c}$. The specimen exposed at $621^{\circ} \mathrm{C}$ in the $\mathrm{CL}$ also showed Fe enrichment and a thicker O-rich surface layer, Figure 64. Figure 65d shows the very high $\mathrm{Mg}$ levels detected and less $\mathrm{Fe}$ enrichment and $\mathrm{Cr}$ depletion beneath. The strong surface $\mathrm{Fe}$ enrichment in these specimens suggests that some Ni may have been removed as well as $\mathrm{Cr}$ but it may be simply due to $\mathrm{Cr}$ loss.

Less characterization was conducted on the C276 specimens as the project was concluding. Figure 66 shows EDX line profiles from two coupon specimens shown in Figure 59. Similar to the alloy 600 specimens, there was Fe enrichment and $\mathrm{Cr}$ depletion in both the $\mathrm{HL}$ specimen exposed at $700^{\circ} \mathrm{C}$ and in a $\mathrm{CL}$ specimen exposed at $635^{\circ} \mathrm{C}$. For this alloy, Mo and W were enriched at the surface to some degree. Also, Mg enrichment was observed for the $\mathrm{CL}$ specimen where an $\mathrm{O}$ rich layer formed. While only a few line profiles were measured for $\mathrm{C} 276$, the depth of $\mathrm{Cr}$ depletion was actually deeper at $635^{\circ} \mathrm{C}$ than at $700^{\circ} \mathrm{C}$, perhaps because of faster diffusion at the higher temperature resupplied $\mathrm{Cr}$ from the bulk of the specimen. Diffusion simulations are needed for further study.

All of the tensile specimens were broken after exposure at room temperature and the results are summarized in Figures 67 and 68 and plotted versus the estimated exposure temperature. As with the mass change data, the results from the previous TCL experiment (Figure 40) are included for comparison along with as-received values in the shaded areas in each case. For alloy 600 in Figure 67, only slight drops in YS and UTS were noted after exposure. Perhaps slightly lower UTS values were observed compared to the first TCL experiment but very similar YS values were measured. In Figure 67b, the total elongation was decreased to a larger degree than in the previous experiment but still retained $35-50 \%$ ductility.

Figure 68 shows similar room temperature tensile data for the C276 specimens compared to baseline data for unexposed C276 (shaded areas). In general, the as-received UTS and $\mathrm{YS}$ are higher for this alloy (due to the Mo/W solution strengthening) but the postexposure values appear to decrease with increasing estimated exposure temperature. In

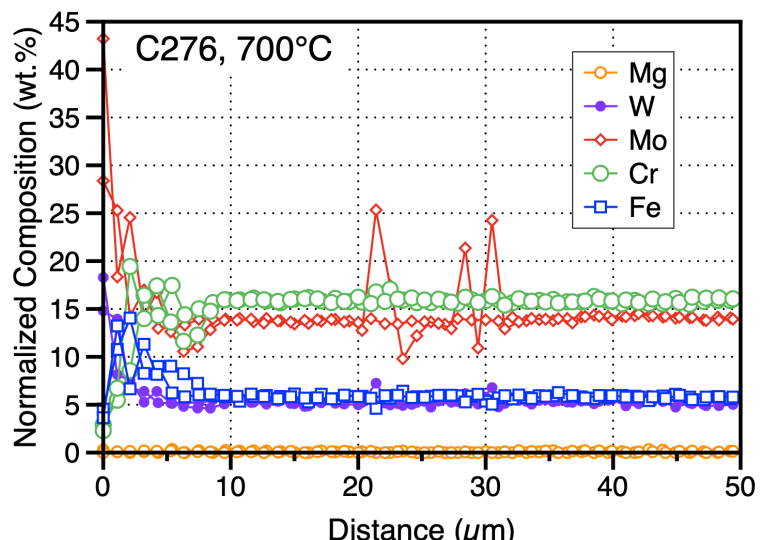

a

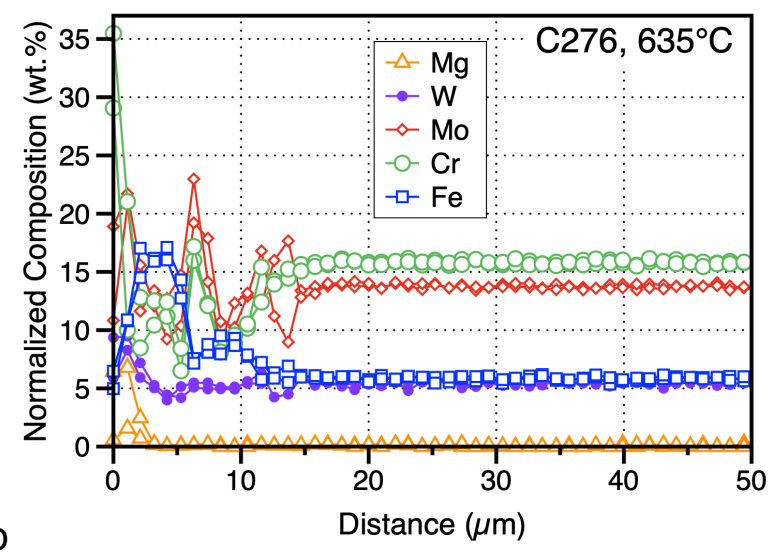

b

Figure 66. Two EDS line profiles from $\mathrm{C} 276$ specimens exposed to dried industrialsourced salt for $1000 \mathrm{~h}$ at estimated temperatures of (a) $700^{\circ} \mathrm{C} \mathrm{HL}$ and (b) $635^{\circ} \mathrm{C} \mathrm{CL}$. 
CPS 33873

Progression to Flowing Molten Salts

ORNL Pint
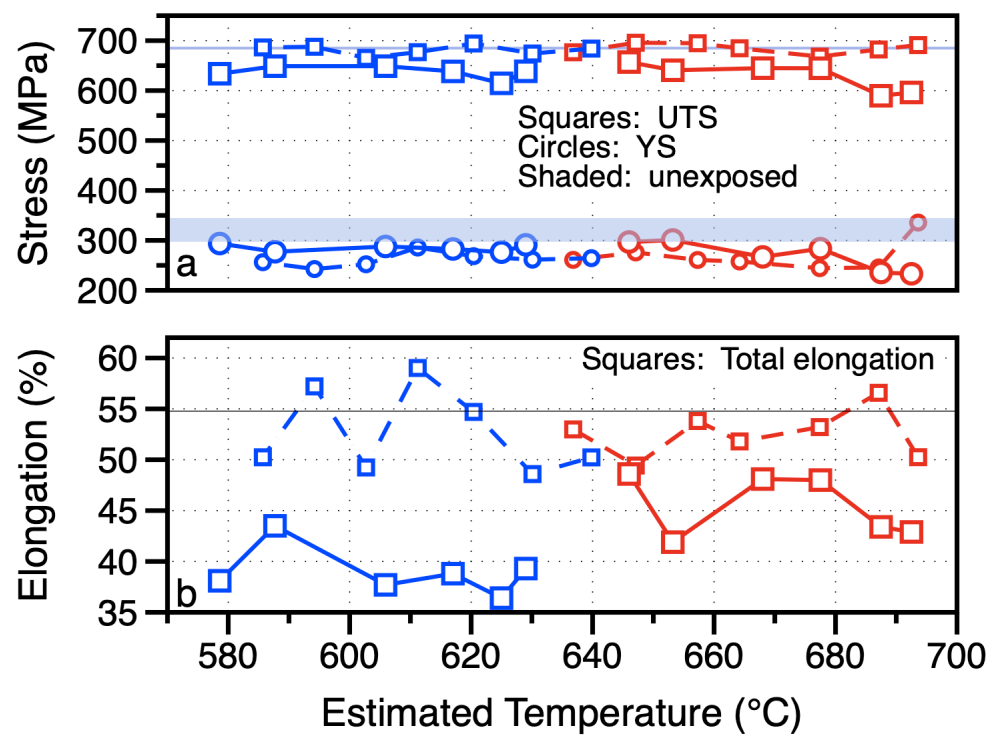

Figure 67. Room temperature tensile properties with a $10^{-3} \mathrm{~s}^{-1}$ strain rate for alloy 600 specimens after $1,000 \mathrm{~h}$ exposures in flowing dried industrial-sourced salt $+0.05 \% \mathrm{Mg}$ identified by their estimated temperature in the hot leg (red) or cold leg (blue). (a) $0.2 \%$ yield stress (YS) and ultimate tensile stress (UTS) and (b) total elongation. The shaded regions show the range of values for unexposed alloy 600 specimens. The dashed lines are data from the Task 1.2 loop.

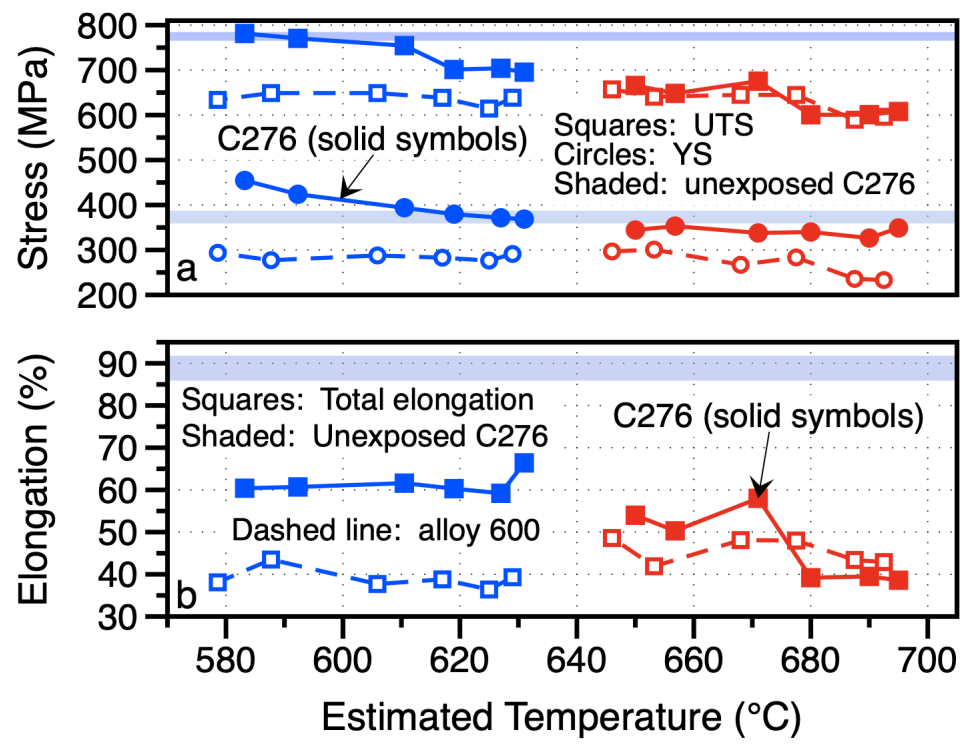

Figure 68. Room temperature tensile properties with a $10^{-3} \mathrm{~s}^{-1}$ strain rate for C276 specimens after $1,000 \mathrm{~h}$ exposures in flowing dried industrial-sourced salt $+0.05 \% \mathrm{Mg}$ identified by their estimated temperature in the hot leg (red) or cold leg (blue). (a) $0.2 \%$ yield stress (YS) and ultimate tensile stress (UTS) and (b) total elongation. The shaded regions show the range of values for unexposed $\mathrm{C} 276$ specimens. The dashed lines are data for alloy 600 specimens from Figure 67. 
particular, the total elongation dropped significantly, especially at the highest exposure temperatures. However, even the lowest values are $\sim 40 \%$ ductility so this is not cause for concern. Unfortunately, time and budget constraints did not allow a better baseline comparison to be developed. Vacuum anneals at $600^{\circ}-700^{\circ} \mathrm{C}$ would provide some information on how these material react to the $1000 \mathrm{~h}$ thermal exposure, independent of the environmental effects. For example, the drop in C276 ductility after exposure in Figure 68 , may be a result of thermal embrittlement rather than the salt environment.

Finally, returning to Table 9, the salt chemistry was measured after the loop was operated. It was interesting to note that the $\mathrm{Cr}, \mathrm{Ni}, \mathrm{Mn}$ and $\mathrm{W}$ levels increased after exposure indicating dissolution. The $\mathrm{W}$ may be from the $\mathrm{W}$ rods of the sensor which are periodically cleaned during operation. The $S$ and possibly the Al levels decreased suggesting a possible reaction with the metallic components. The Fe level in the salt did not change but many of the specimens showed Fe enrichment at the surface, which may be explained by both $\mathrm{Cr}$ and $\mathrm{Ni}$ being selectively attacked in alloy 600, leaving behind an Fe-rich surface. Thermodynamic modeling of activities and relative diffusivities is needed to understand the post-exposure line profiles.

\section{Significant Accomplishments and Conclusions}

During this two year project, considerable progress was made in understanding chloride salt compatibility. Contrary to the recent literature, low mass losses could be achieved for Ni-based alloys 600 and C276 after $1000 \mathrm{~h}$ flowing salt experiments at $\sim 560-700^{\circ} \mathrm{C}$ and the performance metric was met. Contrary to the older MSRE literature, good compatibility was observed for both commercially-sourced $\mathrm{KCl}-\mathrm{MgCl}_{2}-\mathrm{NaCl}$ salt that was purified to low $\mathrm{O}$ levels and salt that was dried and still contained relatively high $\mathrm{O}$ content. The low attack results with dried salt suggest that $\mathrm{H}_{2} \mathrm{O}\left(\mathrm{or} \mathrm{OH}^{-}\right)$is the main impurity that needs to be controlled for compatibility to $700^{\circ} \mathrm{C}$. Overall, the success is attributed to a return to the MSRE paradigm of focusing on salt handling, impurity control and lowering the $\mathrm{Cl}$ potential. In all of the flowing experiments, $\mathrm{Mg}$ was added to the salt. In earlier capsule experiments without $\mathrm{Mg}$, significantly more attack (including pitting and $\mathrm{Cr}$ depletion) was observed. This is a good example that the observations from the isothermal experiments (crucibles and capsules) also were critical to the success. These experiments along with the thermodynamic calculations and additional exposures showed the importance of the container material and not relying on mass change to quantify the attack. Many of the results point to the importance of solubility and thus the need for flowing experiments with a temperature gradient to truly understand salt compatibility.

As noted above, the project pivoted in the second year from purified (i.e. low $\mathrm{O}$ ) industrialsourced salt to dried (low $\mathrm{H}_{2} \mathrm{O}$ ) salt. However, the purified salt result created an important baseline to compare the later results. In particular, the $0.04 \% \mathrm{Mg}$ addition to the purified salt left no significant $\mathrm{Mg}$ or $\mathrm{O}$ deposition to the specimens in the Task 1.2 and 1.3 flowing experiments and very limited attack in the cold leg. However, with the dried salt, $\mathrm{Mg}$ and $\mathrm{O}$ deposits were observed along with $\mathrm{Cr}$ depletion in the majority of the coupons analyzed from Task 2.2. 
These successful flowing experiments may help to change the general perception of chloride salts as being too corrosive for the Generation 3 CSP application. However, a handful of experiments are not sufficient to answer all of the important questions. Nevertheless, these results can change the focus of future work. Now that $700^{\circ} \mathrm{C}$ appears possible, higher temperatures can be a new goal. With this methodology, the materials exist to build a series of TCL experiments using $740 \mathrm{H}$ tubing to test compatibility at $700^{\circ}$ and even $800^{\circ} \mathrm{C}$, if warranted.

The TCL experiments also provided a test bed for successfully deploying the ANL sensor. While not described in this report, the sensor was successful in noting the ingress of impurities and the onset of $\mathrm{Cr}$ in the salt. The gasket leak in the last TCL experiment also confirmed that salt leaking out of the loop is likely far more corrosive than salt inside the loop. The lid of the pot where the gasket leaked was significantly damaged with more metal wastage observed (Figure 54).

The alloy C276 loop that was built in Phase 1 was not operated in Phase 2 where additional tasks were eliminated due to overspending in Phase 1. Thus, only a limited amount of corrosion data for $\mathrm{C} 276$ was generated in this project relevant to the pumped loop being built at ORNL using C276. Also, the TCL experiment with a peak temperature of $750^{\circ} \mathrm{C}$ only operated for $\sim 110 \mathrm{~h}$ before failing. The mass changes were similar to the $1000 \mathrm{~h} / 700^{\circ} \mathrm{C}$ experiment suggesting an increased rate of attack with increasing temperature. However, considerably more work is needed to understand the effect of temperature in $\mathrm{Cl}$ salt compatibility for this application.

\section{Publications}

B. A. Pint, J. W. McMurray, A. W. Willoughby, J. M. Kurley, S. R. Pearson, M. J. Lance, D. N. Leonard, H. M. Meyer, J. Jun, S. S. Raiman and R. T. Mayes, (2019) "Reestablishing the paradigm for evaluating halide salt compatibility to study commercial chloride salts at $600^{\circ}-800^{\circ} \mathrm{C}$," Materials and Corrosion, 70 (2019) 1439-1449.

B. A. Pint, S. S. Raiman and J. R. Keiser, "Lifetime modeling for a supercritical $\mathrm{CO}_{2-}$ molten salt CSP power block," AIP Conference Proceedings 2126 (2019) 160005; presented at SolarPaces 2018, Casablanca, Morocco, Oct. 2018.

\section{Path Forward}

While these results may have changed the perception of chloride salts as being "too corrosive" to use, the next phase of experiments needs to establish an engineering basis for operation including determining degradation kinetics as a function of temperature for the leading structural materials. Since only one time was operated at each condition, no kinetic rate law could be determined to extrapolate these results to longer operating times. Unfortunately, the $750^{\circ} \mathrm{C}$ TCL experiment only ran for $\sim 110 \mathrm{~h}$, limiting the information learned from that experiment. Also, the third TCL experiment with the dried salt in Phase 2 had several differences from the Phase 1 experiments: different salt chemistry and purification process, the addition of a Mg coupon in the 
flowing salt and the gasket leak, which possibly allowed some air ingress. Thus, there is still uncertainty about how these variables affected the final observation.

New project tasks are recommended to address:

(1) Quantifying the effects of salt composition (e.g. NaCl content), impurities (e.g. O, $\mathrm{OH}, \mathrm{Br}, \mathrm{S}$ content) and additives (e.g. Mg in the salt vs. solid additions (rod or coupon)). For example, running a flowing test with and without a Mg coupon.

(2) Reliable salt chemistry measurements. A task is needed to develop a standard procedure for measuring the salt chemistry and impurities, including $\mathrm{Br}, \mathrm{S}, \mathrm{O}$ and $\mathrm{OH}$, followed by round robin testing to assure accuracy. The industrial salt vendors appear to have exceptional capabilities to measure ppm levels of impurities in $\mathrm{Cl}$ salts.

(3) Materials for $800^{\circ} \mathrm{C}$ salt compatibility. No compatibility work has been conducted on alloy $740 \mathrm{H}$ and very little has been performed on low $\mathrm{Cr}$ alloys (e.g. Figure 24a). Higher temperature alloys are typically $\gamma^{\prime}$ strengthened and contain $\mathrm{Al}$ and $\mathrm{Ti}$, which are more stable chlorides than $\mathrm{Cr}$ (Figure 1a) and may be selectively attacked. Also, high $\mathrm{Cr}$ alloys have a higher $\mathrm{Cr}$ activity and are more susceptible to deeper attack than lower $\mathrm{Cr}$ alloys (e.g. Figure 24a).

(4) Thermodynamic and kinetic (diffusion) modeling. To further understand the EDX line profiles (Figures 65 and 66) and support \#3 above, thermodynamic and kinetic modeling is needed to understand the relative activities of, for example, $\mathrm{Ni}, \mathrm{Cr}$ and $\mathrm{Fe}$, to understand if the $\mathrm{Fe}$ enrichment is due to only $\mathrm{Cr}$ dissolution or if $\mathrm{Ni}$ dissolution also occurs.

\section{References}

J. Ambrosek, (2011) "Molten Chloride Salts for Heat Transfer in Nuclear Systems," Ph.D. Thesis, University of Wisconsin, Madison, WI, 2011.

S. Boghosian, A. Godo, H. Mediaas, W. Ravlo, T. Ostvold, (1991) "Oxide Complexes in Alkali Alkaline-Earth Chloride Melts," Acta Chem. Scand. 45 (2), 145-157.

R. W. Bradshaw, (1987) "Thermal-Convection Loop Study of the Corrosion of Incoloy 800 in Molten $\mathrm{NaNO}_{3}-\mathrm{KNO}_{3}$," Corrosion 43(3), 173-178.

G. S. Chen, I. W. Sun, K. D. Sienerth, A. G. Edwards, G. Mamantov, (1993) "Removal of Oxide Impurities from Alkali Haloaluminate Melts Using Carbon-Tetrachloride," Journal of the Electrochemical Society 140 (6) 1523-1526.

J. H. DeVan, (1979) "Compatibility of Structural Materials with Fusion Reactor Coolant and Breeder Fluids," Journal of Nuclear Materials 85-86, 249-256.

W. Ding, H. Shi, Y. Xiu, A. Bonk, A. Weisenburger, A. Jianu, T. Bauer, (2018) "Hot corrosion behavior of commercial alloys in thermal energy storage material of molten $\mathrm{MgCl}_{2} / \mathrm{KCl} / \mathrm{NaCl}$ under inert atmosphere," Solar Energy Materials and Solar Cells 184, 22-30. 
L. F. Epstein, (1957) "Static and Dynamic Corrosion and Mass Transfer in Liquid Metal Systems," Liquid Metals Technology, Chem. Eng. Prog. Symp. Ser. 20, 53, 67-81.

J. C. Gomez-Vidal, A. G. Fernandez, R. Tirawat, C. Turchi, W. Huddleston, (2017) "Corrosion resistance of alumina-forming alloys against molten chlorides for energy production. I: Pre-oxidation treatment and isothermal corrosion tests," Solar Energy Materials and Solar Cells, 166, 222-233.

P. N. Haubenreich and J. R. Engel, (1970) "Experience with the Molten-Salt Reactor Experiment," Nuclear Applications and Technology, 8(2), 118-136.

J. E. Indacochea, J. L. Smith, K. R. Litko, E. J. Karell, (1999) "Corrosion performance of ferrous and refractory metals in molten salts under reducing conditions," Journal of Materials Research 14, 1990-1995.

M. Ito and K. Morita, (2004) "The solubility of $\mathrm{MgO}$ in molten $\mathrm{MgCl}_{2}-\mathrm{CaCl}_{2}$ salt," Mater. Trans. 45, 2712-2718.

J. R. Keiser, J. H. DeVan and E. J. Lawrence, (1979) "Compatibility of Molten Salts with Type 316 Stainless Steel and Lithium," Journal of Nuclear Materials 85-86, 295-298.

N. Klammer, C. Engtrakul, Y. Zhao, Y. Wu and J. Vidal, (2020) "Method To Determine $\mathrm{MgO}$ and $\mathrm{MgOHCl}$ in Chloride Molten Salts," Anal. Chem., 92, 3598-3604. doi.org/10.1021/acs.analchem.9b04301

M. J. Lance, D. N. Leonard and B. A. Pint, (2018) "The Use of Glow Discharge Optical Emission Spectroscopy to Quantify Internal Carburization in Supercritical $\mathrm{CO}_{2}$," in Proceedings of the 6th International Symposium on Supercritical $\mathrm{CO}_{2}$ Power Cycles, Pittsburgh, PA, March 2018, Paper \#117.

H. Mediaas, J. E. Vindstad, T. Ostvold, (1997) "Solubility of MgO in mixed chloridefluoride melts containing $\mathrm{MgCl}_{2}$," Acta Chem. Scand. 51, 504-514.

D. Olander, (2002) "Redox condition in molten fluoride salts: Definition and control," Journal of Nuclear Materials 300, 270-272

T. Ostvold, (1972) "Emf-Measurements of Change in Chemical Potential of One Component on Mixing in Fused Binary Alkali-Alkaline Earth Halide Systems," High Temperature Science 4 (1), 51.

S. J. Pawel, (2012) "Compatibility Assessment of Advanced Stainless Steels in Sodium," Fusion Science and Technology 61:1T, 369-374.

S. J. Pawel and K. A. Unocic, (2017) "Compatibility of an FeCrAl Alloy with Flowing Pb$\mathrm{Li}$ in a Thermal Convection Loop," Journal of Nuclear Materials 492, 41-51.

B. A. Pint, S. J. Pawel, M. Howell, J. L. Moser, G. Garner, M. Santella, P. F. Tortorelli, F. W. Wiffen and J. R. Distefano, (2009) "Performance of MHD Coatings in Flowing Li at $700^{\circ} \mathrm{C}$," Journal of Nuclear Materials 386-388, 712-715.

B. A. Pint, J. W. McMurray, A. W. Willoughby, J. M. Kurley, S. R. Pearson, M. J. Lance, D. N. Leonard, H. M. Meyer, J. Jun, S. S. Raiman and R. T. Mayes, (2019) "Reestablishing the paradigm for evaluating halide salt compatibility to study commercial chloride salts at $600^{\circ}-800^{\circ} \mathrm{C}$," Materials and Corrosion 70, 1439-1449. 
S. S. Raiman and S. Lee, (2018) "Aggregation and data analysis of corrosion studies in molten chloride and fluoride salts," Journal of Nuclear Materials 511, 523-535.

S. S. Raiman, R. T. Mayes, J. M. Kurley, R. Parrish and E. Vogli, (2019) "Amorphous and partially-amorphous metal coatings for corrosion resistance in molten chloride salt," Solar Energy Materials and Solar Cells 201, 110028.

H. Sun, J. Wang, Z. Lia, P. Zhang, X. Su, (2018) "Corrosion behavior of 316SS and Nibased alloys in a ternary $\mathrm{NaCl}-\mathrm{KCl}-\mathrm{MgCl}_{2}$ molten salt," Solar Energy 171, 320-329.

H. Susskind, F. B. Hill, L. Green, S. Kalish, L. E. Kukacka, W. E. McNulty and E. J. Wirsing, Jr., (1960) "Corrosion Studies for a Fused Salt-Liquid Metal Extraction Process for the Liquid Metal Fuel Reactor," Brookhaven National Laboratory Report BNL 585 (T146) Upton, NY (1960). And Chemical Engineering Progress 56, 57-63.

P. F. Tortorelli, (1992) "Dissolution Kinetics of Steel Exposed in Lead-Lithium and Lithium Environments," Journal of Nuclear Materials 191-194, 965-969.

K. Vignarooban, P. Pugazhendhi, C. Tucker, D. Gervasio, A. M. Kannan, (2014) "Corrosion resistance of Hastelloys in molten metal-chloride heat-transfer fluids for concentrating solar power applications. Solar Energy 103, 62-69

J. E. Vindstad, H. Mediaas, T. Ostvold, (1997) "Hydrolysis of $\mathrm{MgCl}_{2}$-containing melts," Acta Chem. Scand. 51, 1192-1200.

D. F. Williams, (2006) "Assessment of Candidate Molten Salt Coolants for the Advanced Highi-Temperature Reactor (AHTR)," ORNL/TM-2006/69, ORNL, Oak Ridge, TN.

J. P. Young, G. Mamantov, J. E. Coffield, S. Dai, (1990) "In-line Sensors for Electrolytic Magnesium Cells," project report, Oak Ridge National Laboratory, Oak Ridge, TN.

G. Zheng and K. Sridharan, (2018) "Corrosion of Structural Alloys in High-Temperature Molten Fluoride Salts for Applications in Molten Salt Reactors," JOM 70, 1535-1541. 


\title{
Appendix A. Salt Purification Protocol of Anhydrous Carnallite (AC)
}

\author{
Version 5/10/2019
}

This protocol is aimed at providing a unified procedure for handling and purifying anhydrous carnallite at $1-5 \mathrm{~kg}$ scale. The goal is to ensure the quality of the purified salt in order for the Salt Collective to perform consistent corrosion tests, thermophysical property measurements, etc. Hence the material selection, furnace design, salt storage method, etc. may not be suitable for salt purification at $>10 \mathrm{~kg}$ or $>100 \mathrm{~kg}$ scale. For future scale-up to $>100 \mathrm{~kg}$, discussion with NREL's Topic 1 team is highly encouraged.

1. Store the as-received ICL anhydrous carnallite (AC) and SPK halite (from Albemarle) in an inert glove box or any airtight container, e.g., in a glove box with ultra-high-purity

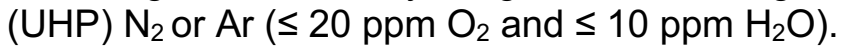

2. Perform ICP-MS/AES/OES analysis on AC and SPK halite to determine salt compositions. Measure at least the following elements ${ }^{1}$ : $\mathrm{Na}, \mathrm{K}, \mathrm{Mg}, \mathrm{Br}, \mathrm{Ca}, \mathrm{Fe}, \mathrm{Cr}, \mathrm{Mn}$, $\mathrm{Ni}, \mathrm{Zn}, \mathrm{Cu}, \mathrm{P}, \mathrm{S}$ (or $\mathrm{SO}_{4}{ }^{2-}$ ), As, Sr, Si, and Mo. These elements are relevant based on ICP measurements from ICL and NREL (see Table 2 at the end of this document) and because of the use of quartz and/or Mo components. If your ICP instrument cannot measure $\mathrm{SO}_{4}{ }^{2-}$ and $\mathrm{Br}^{-}$content, ion chromatography can be used. Perform titration to determine initial $\mathrm{MgOHCl}$ content (Titration procedure sent by NREL). Perform a separate vacuum-drying process for $2 \mathrm{~h}$ at $150^{\circ} \mathrm{C}$ using $5-10 \mathrm{~g}$ of as-received salt to estimate the content of physically absorbed moisture.

a. Samples for these measurements should not come from directly taking a few grains of $A C$ salt. Mortar and pestle at least $25 \mathrm{~g}$ of $A C$ randomly picked from the inventory. After thorough mixing, sample from the mixture for measurements.

3. Quartz crucible will be used for purification. Clean quartz crucible with ethanol, isopropanol, or acetone before use. Large volume quartz crucible ${ }^{2}$ can be sourced from AdValue Technology and Technical Glass Product.

4. Purification vessel setup:

a. Figure A1 gives the schematic of the purification vessel showing the crucible with salt, locations of gas sparger, gas inlet and outlet. A zoom-in of gas outlet design is shown in Figure A2.

i. The sparger is made

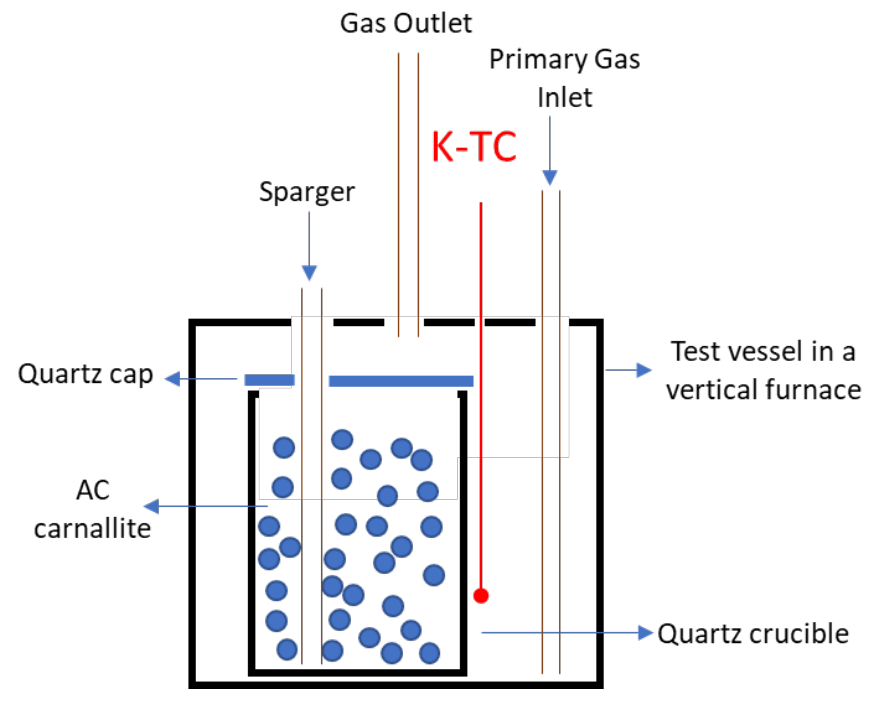
of Mo or quartz ${ }^{3}$ with

Figure A1 Schematic of the test vessel. Not to scale.

\footnotetext{
${ }^{1}$ Certain ICP-MS/AES/OES gives a large number of elements for each sample.

${ }^{2}$ For example, NREL sourced a 6 -inch OD by 14 -inch height (i.e., $>6 \mathrm{~L}$ in volume) quartz crucible from AdValue for $\$ 315$. The lead time was 50 days because the crucible was custom-made to fit NREL's furnace vessel. Crucibles with smaller volume or non-custom dimensions might be shipped faster.

${ }^{3}$ Please remember to use ICP to check either Mo or Si if using either material for the sparger.
} 
size compatible with the furnace port (ideally $1 / 8$ inch OD or larger). Mo tubing can be sourced from Eagle Alloys

https://www.eaglealloys.com/molybdenum/. Quartz can be sourced from AdValue Technology and Technical Glass Product. The sparger will remain in the salt until furnace cooldown starts. Sparging inside molten salt has been observed to be effective at carrying out $\mathrm{HCl}$ gas during purification in a recent experiment at NREL. As a precaution, a desiccator should be used to pre-dry inlet gas. The inlet gas of $A r$ or $\mathrm{N}_{2}$ should be of at least UHP grade (i.e., $\leq 1 \mathrm{ppm}$ moisture and oxygen). Since Mo can oxidize above $550^{\circ} \mathrm{C}$ and Mo oxide is highly volatile, low oxygen level must be ensured by performing a leak check (step 6d) of the test vessel and the section of Mo tubing exposed to air just outside the furnace should be cooled (by cooling fans, for example).

ii. The primary gas inlet is made of stainless steel 316 (or other compatible metals) with size compatible with the furnace port (ideally $1 / 4$ inch OD or larger). A desiccator should be used as a precaution to pre-dry inlet gas (it can be the same desiccator use for sparging gas). The inlet gas of $\mathrm{Ar}$ or $\mathrm{N}_{2}$ should be of at least UHP grade (i.e., $\leq 1 \mathrm{ppm}$ moisture and oxygen).

iii. The gas outlet is made of stainless steel 316 (or other compatible metals) with size compatible with the furnace port (ideally $1 / 2$ inch OD or larger).

iv. Other than the thermocouple(s) that controls the furnace, at least one more thermocouple (type-K or other high-temperature, chemically resistant type) should be inserted inside the test vessel and as close as possible to the outside of quartz crucible to record salt temperature. Use thermocouples that are sheathed in chemically resistant metals (such as Inconel) or ceramics. Do not use bare thermocouple wires without protection. Thermocouple sheathed in a closed-one-end Mo tube or quartz tube can be placed directly inside the salt to have better temperature measurement. This thermocouple needs to be pulled out before salt solidification starts.

v. A crucible cap (with a hole to insert the sparger) made of quartz should be used to prevent reflux and dripping of corrosion products back into the salt melt. If machining on quartz is not available, other compatible materials (such as a Ni plate or a refractory plate) can be considered since the cap is not in direct contact with the salt.

b. Gas outlet: to avoid condensation of corrosive species such as $\mathrm{HCl}$ at the gas outlet, heating tape wrapped around the metal tube should be used.

i. The metal outlet tube should be as short as the furnace setup allows to minimize possible exposure to corrosion while

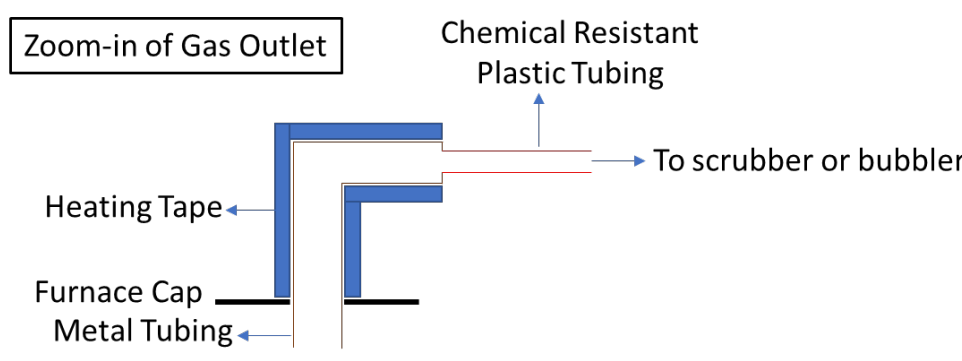

Figure A2 Schematic of the recommended gas outlet design to avoid excessive condensation of corrosive species. Not to scale 
ensuring the connection between the metal outlet tube and plastic tubing (see below) remains below $200^{\circ} \mathrm{C}$. The goal is to keep $\mathrm{HCl}$ above its boiling point of $108^{\circ} \mathrm{C}$ everywhere in the metallic tube using the heating tape until $\mathrm{HCl}$ gas transitions to the chemically resistant plastic tubing.

ii. Chemical resistant plastic tubing (e.g. PFA, PTFE) should be connected to the metal tubing. Optional heating tape can be used around the plastic tubing until the gas species is collected in a scrubber or bubbler. If a bubbler is used, make sure the gas flow rate (see step 6f) is on the high side to prevent back diffusion of solvent (especially for aqueous-based solution).

5. Weigh AC salt, SPK halite and Mg before purification

a. AC loading: load as-received $A C$ without grinding. Each grain of $A C$ salt is $>2$ $\mathrm{mm}$.

b. $M g$ recipe: $2.5 \mathrm{~g}$ of $\mathrm{Mg}$ for each $1 \mathrm{~kg}$ of $\mathrm{AC}$ salt. $\mathrm{Mg}$ can be either chips or wafer. If using chips, they can be purchased at Sigma-Aldrich (e.g., 99.98\% trace metals basis, 6-35 mesh, part \# 245118-250G). If using wafer, it will be provided by SRNL (contact Brenda Garcia-Diaz brenda.garcia-diaz@srnl.doe.gov or Luke Olson Luke.Olson@srnl.doe.gov).

c. Halite recipe: $65 \mathrm{~g}$ of SPK halite for each $1 \mathrm{~kg}$ of $\mathrm{AC}$ salt.

6. Purification procedures:

a. Make sure the test vessel is clean and dry before purification. A bakeout of the test vessel under vacuum $(<-25 \mathrm{inHg}$ or $-0.085 \mathrm{MPa})$ at $700^{\circ} \mathrm{C}$ for $1 \mathrm{~h}$ prior to purification is recommended.

b. Load AC salt, Mg and SPK halite into the quartz crucible in the inert glove box.

c. Quickly transfer loaded salt/crucible to furnace vessel. Minimize exposure time of salt to ambient atmosphere (including loading of crucible/salt, closing and sealing of vessel, etc.).

d. With crucible cap, sparger, thermocouple(s) and gas inlet in place, close the test vessel and leak check. One example method to check for leakage is to vacuum or pressurize the vessel and see if vessel can hold the pressure. Other methods ${ }^{4}$ include He sniffer if the lab has the equipment, as well as liquid leak detectors such as Snoop ${ }^{\odot}$.

e. Vacuum to $<-25 \mathrm{inHg}(-0.085 \mathrm{MPa})$ and refill the vessel with UHP or highergrade nitrogen (or $\mathrm{Ar}$ ) at least three times before next step.

f. Flow cover gas through primary gas inlet at $>500 \mathrm{sccm}$ and through sparger at $150 \mathrm{sccm}$ with a vessel pressure at 1 psig (pressure above ambient ${ }^{5}$ ) for at least

\footnotetext{
${ }^{4}$ These methods all have different sensitivities and not all labs have the same equipment. The procedure for leak check is therefore aimed at providing a guideline that requires a step for leak check and repair of your furnace setup with your best effort if a leak is detected, instead of providing an absolute required leak rate. With high flow rate given in step $6 \mathrm{f}$, impact of minor leaks should be mitigated.

${ }^{5}$ Make sure there a pressure gauge connected to the furnace vessel. To achieve 1 psig vessel pressure, one example is to place a needle valve in the gas outlet line (away from where corrosion can occur). Adjust the valve until the pressure gauge reads about $1 \mathrm{psi}$. Manual adjustment of the needle valve may be necessary during the
} 
30 min before heating up (step 6h). The slight over-pressure of 1 psig is used to prevent air ingress. The higher end of the flow rate range is preferred for both the primary gas inlet and sparger in order to reduce the gas residence time in the furnace. An even higher flow rate can be considered if deemed necessary in your setup. A recent experiment at NREL using high flow rate ${ }^{6}$ to purify $350 \mathrm{~g}$ of AC showed almost no sign of corrosion on the furnace vessel (cap, vessel body, quartz liner, and outlet gas tube). See Figure A5.

g. The grains of as-received $A C$ salt are $>3 \mathrm{~mm}$ in size and weigh $>500 \mathrm{mg}$ each. High flow rate through the sparger should not entrain the salt grains.

h. Heating schedule: keep the flow rate of cover gas during the entire purification process. High flow rate is used to carry out $\mathrm{HCl}$ and water generated during purification as fast as possible to avoid corrosion at the gas outlet. If you use a different thermocouple than the thermocouple located next to the quartz crucible to control the furnace, make sure you adjust your furnace set point to achieve the actual temperature seen by the salt/Mg mixture (heating schedule below). The hold time of $3 \mathrm{~h}$ at $670^{\circ} \mathrm{C}$ was determined at NREL by performing a purification with $300-500 \mathrm{~g}$ of salt. For larger scale, the hold time needed may vary and it can be determined by monitoring the release of $\mathrm{HCl}$. A bubbler ${ }^{7}$ filled with $2.9 \mathrm{M}$ acetic acid $(\mathrm{pH} \sim 4.4)$ as buffer solution was installed after the furnace gas outlet at NREL where a $\mathrm{pH}$ sensor was used to monitor the $\mathrm{pH}$ drop and $\mathrm{pH}$ plateau of the buffer during purification which indicates $\mathrm{HCl}$ formation and end of $\mathrm{HCl}$ formation (see Figure A6). NREL determined the hold time of $3 \mathrm{~h}$ at $670^{\circ} \mathrm{C}$ for $\sim 350 \mathrm{~g}$ of salt using this simple setup. Therefore, it is recommended to use a similar setup to determine the true hold time with $>1 \mathrm{~kg}$ of salt (if other than $3 \mathrm{~h}$ ).

Table 1 Heating schedule for AC salt purification

\begin{tabular}{|c|l|c|l|}
\hline $\begin{array}{c}\text { Salt } \\
\text { Temperature }\end{array}$ & Ramp rate & Hold Time & Note \\
\hline R.T. to $120^{\circ} \mathrm{C}$ & The ramp rate your & \multicolumn{1}{|c|}{$2 \mathrm{~h}$} & \\
\cline { 4 - 4 } & $\begin{array}{l}\text { equipment is } \\
\text { capable of, or } 0.5- \\
670^{\circ} \mathrm{C} \text { to }\end{array}$ & $\begin{array}{l}3 \mathrm{~h} \text { or } \\
\text { determined by } \\
1^{\circ} \mathrm{CH} / \mathrm{min}\end{array}$ & $\begin{array}{l}\text { Sparger should remain in } \\
\text { molten salt }\end{array}$ \\
\hline $670^{\circ} \mathrm{C}$ to R.T. & $\sim 1^{\circ} \mathrm{C} / \mathrm{min}$ & NA & $\begin{array}{l}\text { Pull out sparger (and } \\
\text { thermocouple if it's placed } \\
\text { inside the melt) at the } \\
\text { beginning of this step to } \\
\text { avoid agitation Mg when } \mathrm{Mg} \\
\text { should settle down }\end{array}$ \\
\hline
\end{tabular}

${ }^{*} 120^{\circ} \mathrm{C}$ instead of $100^{\circ} \mathrm{C}$ for physical moisture removal and $670^{\circ} \mathrm{C}$ instead of $650^{\circ} \mathrm{C}$ for $\mathrm{Mg}$ purification provide $20^{\circ} \mathrm{C}$ of margin if the sample temperature is slightly lower than the thermocouple temperature.

purification process. In case of pressure buildup due to clogging of the valve, a check valve is recommended to ensure safety.

${ }^{6}$ The actual rate was not available because it was out of range on the flow meter. Rough estimate is on the order of liter/min range. For a 20-h purification including slow heating, holding for $2 \mathrm{~h}$, and slow cooling,

${ }^{7}$ Install a gas diffuser if high flow rate is used. 
i. Heat the gas outlet metal tube at $110-150^{\circ} \mathrm{C}$ with heating tape during entire purification process. If heating tape is used for plastic tubing (e.g., PFA or PTFE which is stable at $200+^{\circ} \mathrm{C}$ ), heat at $110-150^{\circ} \mathrm{C}$ during entire purification process without damaging the plastic tubing. The purpose is to keep $\mathrm{HCl} /$ water from condensing on the metal tube section to cause corrosion.

7. Salt removal

a. After furnace is cooled down to R.T., open the test vessel and transfer quartz crucible/salt into the inert glove box

b. The easiest way to remove large amount of salt in the quartz crucible is to carefully break the quartz crucible with a hammer.

c. Find the approximate location of the interface between the sludge and clean salt. See Figure A3 for an example of $\mathrm{AC}$ remelted at $620^{\circ} \mathrm{C}$ for $2 \mathrm{~h}$ (without addition of halite and $\mathrm{Mg}$ and no sparging) in quartz crucible where a sludge phase can be easily identified. Cut at a location that is $2-3$ times of the sludge

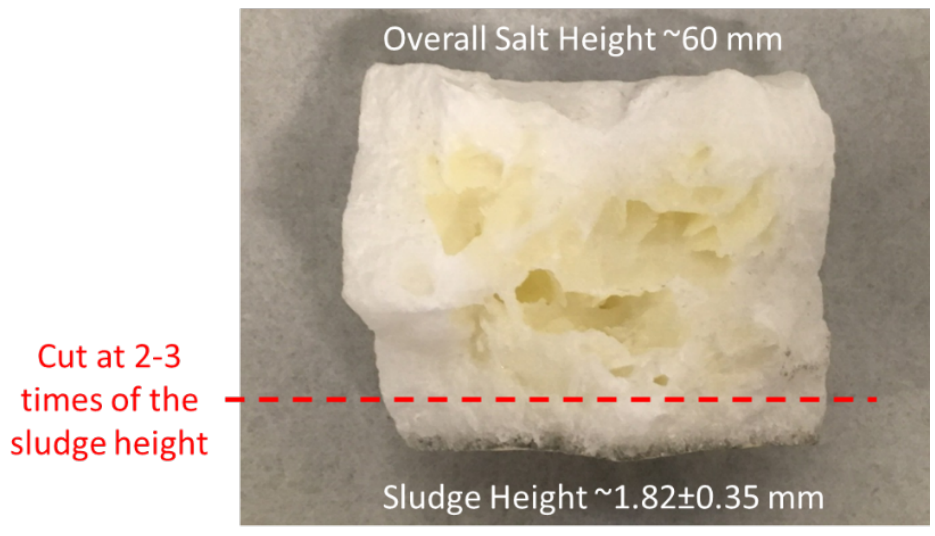

Figure A3 Example of AC salt re-melting (without addition of halite and $\mathrm{Mg}$ ) showing sludge formation and where to cut the salt after salt purification height above the interface with a chisel or saw. Make sure not to include any sludge phase and excess Mg. $0.5 \mathrm{wt} \% \mathrm{Mg}$ is not in excess at small-scale $(<10 \mathrm{~g})$ as shown by NREL's experiments. For larger-scale, this amount may be in

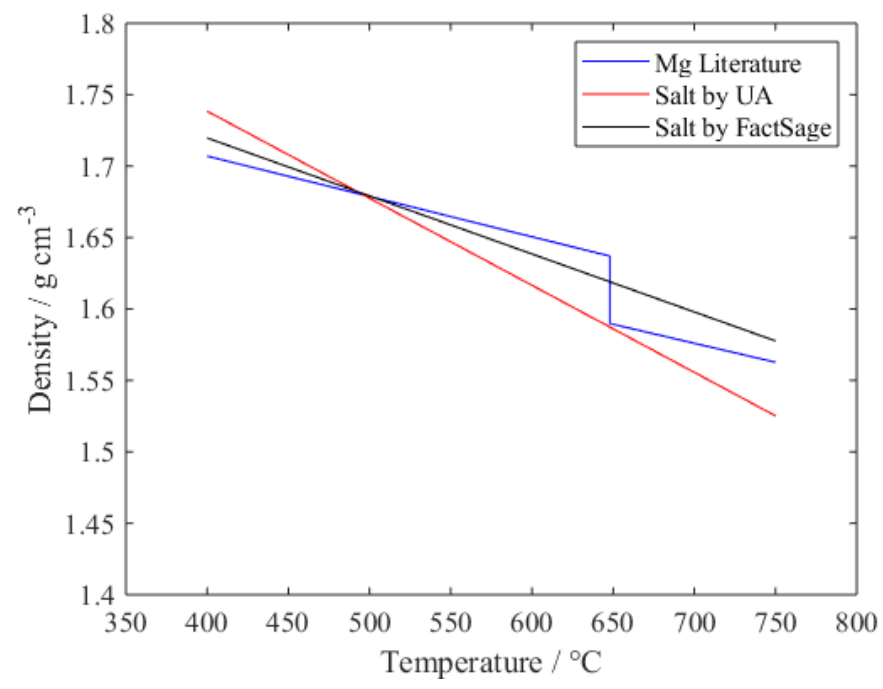

Figure A4 Density of $\mathrm{Mg}$ in both solid and liquid state and density of molten chlorides measured by UA and calculated by FactSage 
excess. In a separate experiment at NREL with $0.5 \mathrm{wt} . \%$ of $\mathrm{Mg}$ (chips) in $350 \mathrm{~g}$ of AC (no sparging), excess Mg appeared at the crucible bottom as well as surface of salt. No Mg was discovered in the bulk of the salt. Hence the Mg removal may require additional cutting to remove top surface of salt too using the same margin (i.e., 2-3 times of the height of that top layer that contains excess Mg). Another experiment using $0.1 \mathrm{wt} . \%$ of $\mathrm{Mg}$ (chips) in $350 \mathrm{~g}$ of $\mathrm{AC}$ (sparging inside molten salt at $150 \mathrm{sccm}$ ) showed no excess $\mathrm{Mg}$ at either bottom or top of the salt. Only sludge was formed at the bottom. Therefore the protocol chooses $0.25 \mathrm{wt} \%$ of $\mathrm{Mg}$ instead of $0.5 \mathrm{wt}$ \% based on NREL's experiments with $350 \mathrm{~g}$ of AC (i.e., two experiments with $0.5 \mathrm{wt} . \%$ and $0.1 \mathrm{wt} . \%$ of $\mathrm{Mg}$, respectively) and order-ofmagnitude estimation based on hydrate content in AC. In case of excess Mg, cutting at a location that is 2-3 times of the sludge height should provide enough margin such that no excess $\mathrm{Mg}$ is included. Slow cooling rate specified in Table 1 should also help solid $\mathrm{Mg}$ sink to the bottom during the temperature window of $500-650^{\circ} \mathrm{C}$ when $\mathrm{Mg}$ is solid and salt is liquid. Figure A4 gives the density of $\mathrm{Mg}$ and molten salt. Between $400^{\circ} \mathrm{C}$ (i.e., the expected melting point of salt) and $500^{\circ} \mathrm{C}$, solid $\mathrm{Mg}$ has lower density than molten chlorides which may slightly complicate the removal process. If concerns with excess $\mathrm{Mg}$ removal persists, Mg wafer instead of chips can be used.

d. Keep purified salt sealed in a gas-tight container in inert glove box for future use.

8. Perform ICP-MS/AES/OES to determine final salt composition and perform titration to determine final $\mathrm{MgOHCl}$.

a. Sample for $\mathrm{MgOHCl}$ titration should not come from taking a few grains of purified $\mathrm{AC}$ salt. Mortar and pestle at least $25 \mathrm{~g}$ of $\mathrm{AC}$ randomly picked from the purified salt. After thorough mixing, sample from the mixture for ICP and titration.

Table 2 ICP from ICL and NREL on anhydrous carnallite

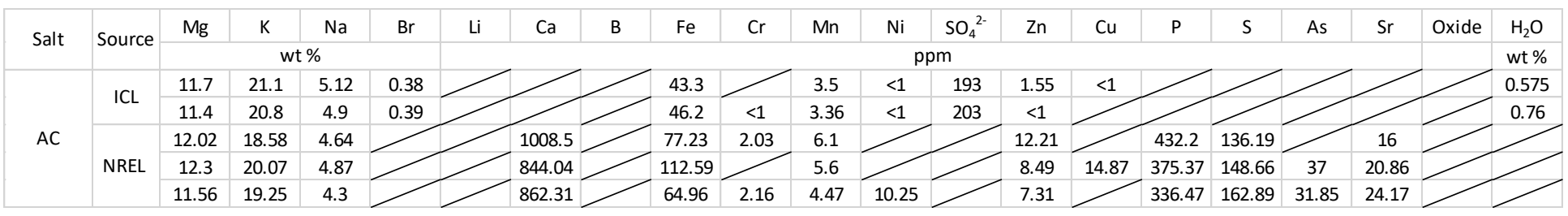


CPS 33873

Progression to Flowing Molten Salts

ORNL Pint

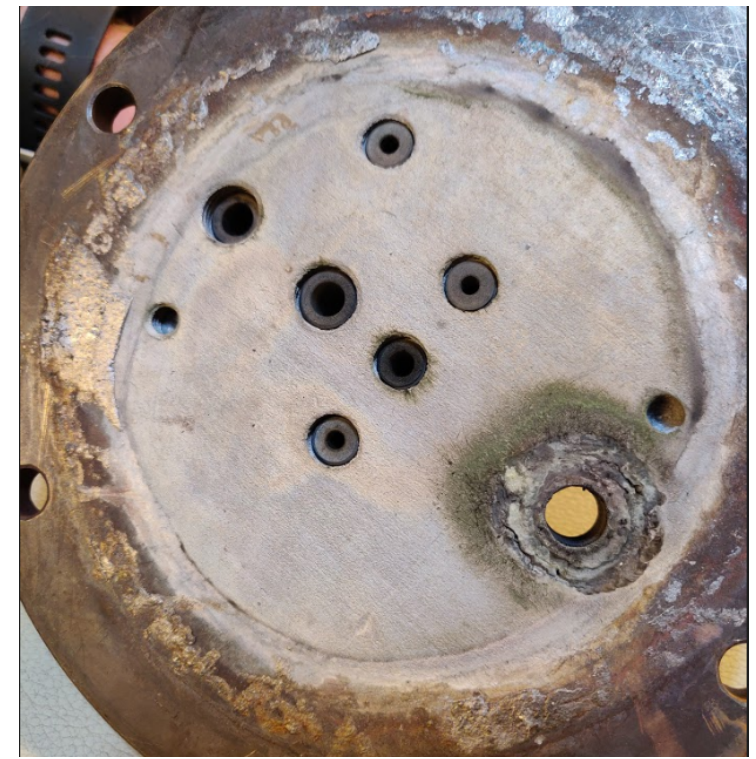

Figure A5 Furnace cap after purification of $350 \mathrm{~g}$ of AC and $1.75 \mathrm{~g}$ of $\mathrm{Mg}$ with high flow rate of $\mathrm{N}_{2}$ cover gas (no sparging inside salt) showing negligible sign of corrosion. The green residue and sign of damage on the lower right corner were corrosion damage from previous purifications.

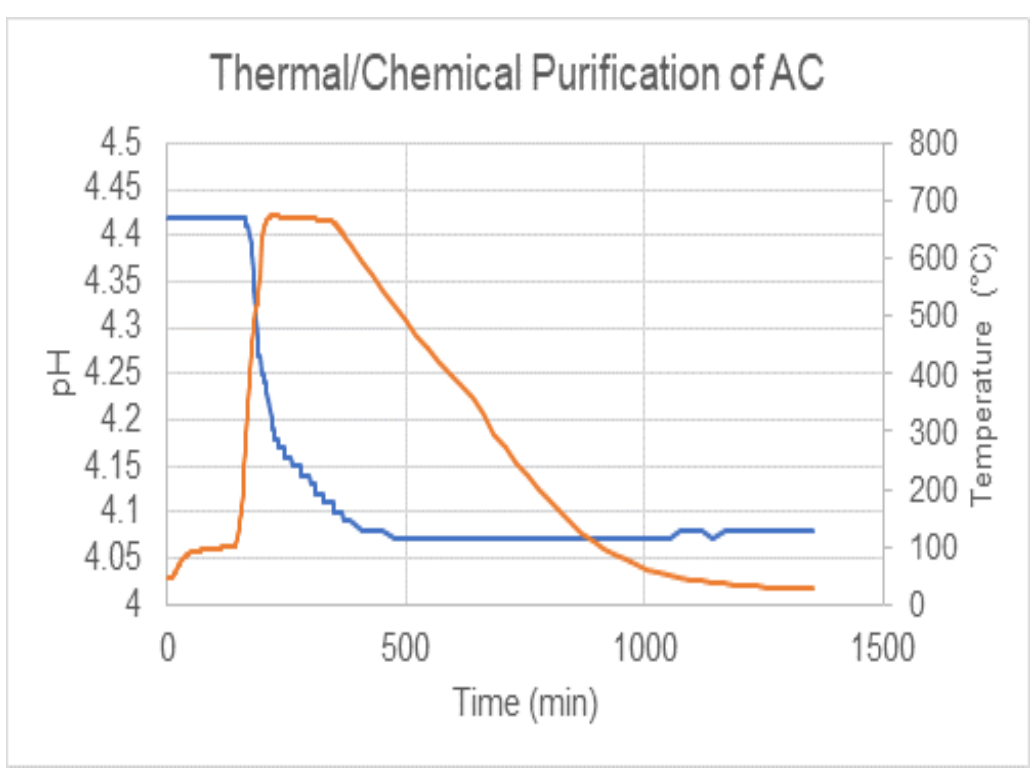

Figure A6 Variation of pH (blue) and sample temperature (orange) as a function of time during purification of $350 \mathrm{~g}$ of $\mathrm{AC}$ at NREL. Roughly $168 \mathrm{~min}$ is needed for the $\mathrm{pH}$ drop to stabilize indicating finish of $\mathrm{HCl}$ production, or end of purification.

\section{Corrosion Testing Protocol}

\section{Prepare corrosion vessel.}

a. Use a quartz crucible with $250-500 \mathrm{ml}$ total volume (e.g., FQ-1250 or FQ-2500 from AdValue Technology, or BLF300 from Technical Glass Product) and a Ni

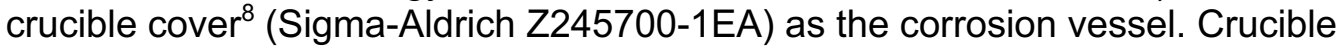
and cover are used as-received with no special treatment. Drill a $\sim 3.1-\mathrm{mm}-$ diameter hole at the center of the cover. Use ethanol to remove organic residues

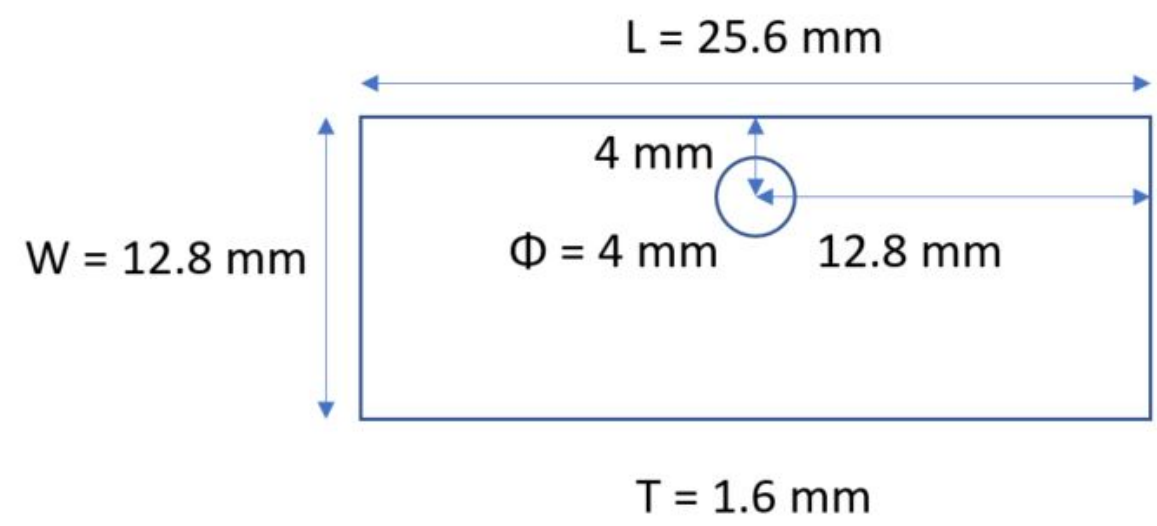

Figure A7 Schematic showing the dimensions of the machined Haynes 230 coupons

\footnotetext{
${ }^{8}$ Quartz cover can be used too, although machining is much more difficult.
} 
after machining.

b. Machine Haynes 230 coupons (by waterjet cutting or EDM) into dimensions with position of a hole given by the following schematic in Figure A7. Use no special treatment on the coupons except normal ethanol cleaning after machining. Polish coupons with 120 grit sand paper with water.

c. Measure initial dimensions and record weight of each coupon. Use a scale with a minimum of four significant digits, although five or six significant digits is preferred (i.e., x.xxxxx or x.xxxxxx gram).

d. Connect three Haynes 230 coupons with a Ni wire (e.g. 99.98\%, 1-mm diameter, Goodfellow NI005171) following the schematic in Figure A8 and the photo in Figure A9. Note that Figure A9 shows four coupons from a previous experiment instead of three.

e. Use an alumina tube, an alumina plate and a quartz disc (with a 3.2-mmdiameter center hole, e.g. AdValue Technology FQ-D-1N-N1/16) as described in Figure A8 to prevent electrical contact and galvanic coupling between coupons and $\mathrm{Ni}$ cover $^{9}$. SRNL suggests using an alumina washer or disc instead of the quartz disc because quartz can be attacked by salt.

i. The alumina tube should be long enough to sheath the total distance from the alumina plate to the top of the Ni hanger triangle without sliding. If the alumina tube is too short so that it slides down during corrosion test, then potential electrical contact between $\mathrm{Ni}$ cover and the unsheathed portion of the Ni wire can occur.

ii. Check if there is any potential electrical contact between $\mathrm{Ni}$ wire and $\mathrm{Ni}$ cover.

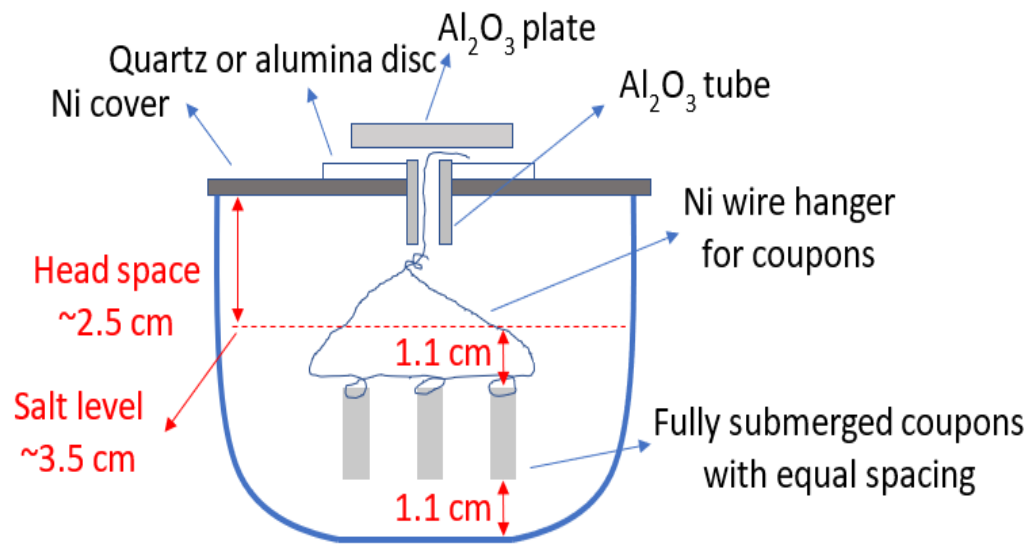

Figure A8. Schematic of corrosion test setup showing all components and spatial arrangement of metal coupons inside the corrosion vessel

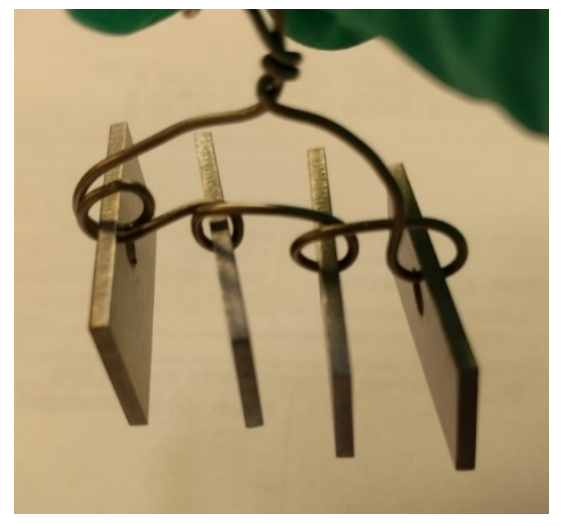

Figure A9. Picture showing the Haynes 230 coupons connected by $\mathrm{Ni}$ wires. Note that this picture shows four metal samples instead of three.

\footnotetext{
${ }^{9}$ Concerns of galvanic coupling are greatly reduced by using quartz crucible. Electrical insulation used here is a precaution.
} 
f. In the glove box, weigh $200-250 \mathrm{~g}$ of salt collected from step $7 \mathrm{~d}$ and place them around coupons in the quartz crucible (as shown in Figure A10 where a Ni crucible was used in the past). $200-250 \mathrm{~g}$ of salt for each corrosion test should provide ample salt volume to fully submerge three or four Haynes 230 coupons.

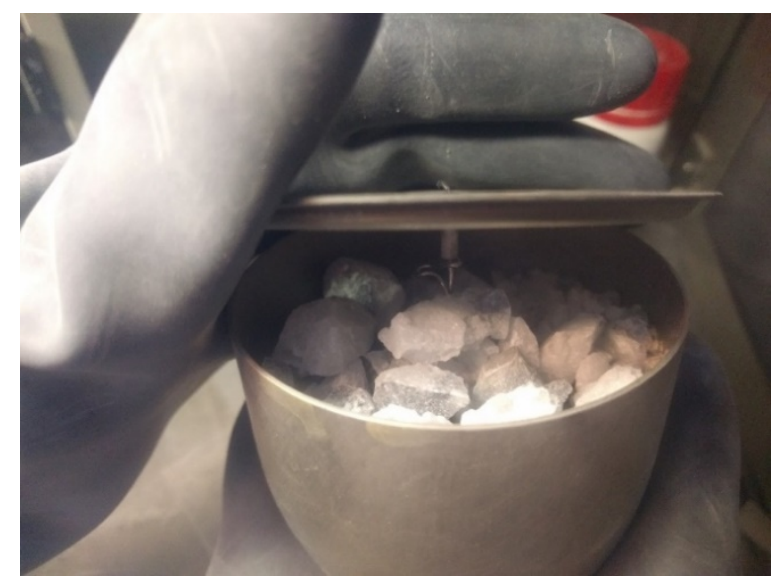

Figure A10. Photo showing placement of salt pieces around Haynes 230 coupons inside the corrosion vessel before corrosion test. Note that a quartz crucible is used instead of $\mathrm{Ni}$ crucible as shown in the picture.

g. Depending on the height of the quartz crucible you ordered, adjust the vertical position of the coupons to be about $1.1 \mathrm{~cm}$ from the bottom of the crucible, as shown in Figure A8, to assure full immersion of coupons and avoid contact with crucible. Headspace can vary if your crucible does not have the same dimensions as shown in Figure A8. The salt level can also vary depending on the exact amount of salt used (please use around 200-250 g). Adjust the spacing between coupons to be about $1 \mathrm{~cm}$.

10. Place the corrosion vessel with coupons and salt inside a stainless-steel bag (e.g., McMaster $3438 \mathrm{~K} 13$ or $3438 \mathrm{~K} 27$ ) with a Ta foil as oxygen getter (http://beantownchem.com/products/07-ELEMENT@@2c\%20ALLOY/07-TANTALUMZIRCONIUM/07-TANTALUM/07\%20TA-THIN\%20FOIL.aspx). Additional Ta foil can be used to wrap the stainless-steel bag. Fold the opening of the stainless-steel bag several times to avoid excess release of salt vapor from the corrosion setup into the stainlesssteel test vessel used to host the corrosion setup.

11. Make sure the furnace test vessel is clean and dry before purification. A bakeout of the test vessel under vacuum ( $<-25 \mathrm{inHg}$ or $-0.085 \mathrm{MPa})$ at $700^{\circ} \mathrm{C}$ for $1 \mathrm{~h}$ prior to purification is recommended.

12. Transport the corrosion setup into the test vessel as quickly as possible.

a. Make sure the corrosion setup is leveled.

b. Place SS bag/corrosion vessel at the center of the furnace.

C. Set up thermocouple, primary gas inlet, gas outlet following the schematic in Figure A1. No sparger is used during corrosion test.

d. With thermocouple(s) and primary gas inlet in place, close the test vessel and leak check (as described in step 6d). 
e. Vacuum to $<-25 \mathrm{inHg}(-0.085 \mathrm{MPa})$ and refill the furnace vessel with UHP or higher-grade nitrogen (or $\mathrm{Ar}$ ) at least three times before next step.

13. Use the following heating schedule for the corrosion test shown in Table 3. All temperatures given in the following table are actual salt temperature instead of furnace control temperature. Temperature fluctuation at $800^{\circ} \mathrm{C}$ should be less than $10^{\circ} \mathrm{C}$. Test vessel pressure is $\sim 1$ psig.

Table 3 Heating schedule for corrosion test

\begin{tabular}{|c|c|c|c|}
\hline $\begin{array}{c}\text { Temperature range, } \\
{ }^{\circ} \mathbf{C}\end{array}$ & $\begin{array}{c}\text { Ramp rate, } \\
{ }^{\circ} \mathbf{C} / \mathbf{m i n}^{* *}\end{array}$ & Hold time, $\mathbf{h}$ & Gas flow rate \\
\cline { 1 - 1 } RT-117 & $\begin{array}{c}\text { The rate your } \\
\text { furnace is capable } \\
\text { of, or } 0.5-1^{\circ} \mathrm{C} / \mathrm{min}\end{array}$ & 8 & \multirow{2}{*}{$100 \mathrm{sccm}$} \\
\cline { 1 - 3 } $117-800$ & $\sim 1^{\circ} \mathrm{C} / \mathrm{min}$ & $\mathrm{NA}$ & \\
\hline $800-\mathrm{RT}$ & & 100 & \\
\hline
\end{tabular}

14. Remove post-corrosion products

a. After furnace is cooled down to room temperature, transport the corrosion vessel with the metal coupons and salt to the glove box as quickly as possible.

b. Invert the quartz corrosion vessel with the solidified surface facing the floor and tap the vessel with a mallet. The salt should fall out with a few taps. Otherwise carefully break the quartz crucible with a hammer. Break the salt and retrieve post-corrosion coupons. Be careful not to damage the corrosion surfaces on the coupons.

\section{Post Exposure Coupon Cleaning}

1. Remove post-corrosion coupons from the Ni hanger.

2. Immerse coupons in deionized (DI) water and ultra-sonicate for $15 \mathrm{~min}$ to remove residual salt. Visually inspect sample and, if necessary, repeat for another $15 \mathrm{~min}$.

3. After ultrasonication, rinse coupons with ethanol and allow to dry, followed by storage in an inert glove box, under vacuum or in a desiccator.

4. Measure post-corrosion dimensions and weigh coupons with the same scale used for initial weight measurement.

5. Convert weight loss to $\mu \mathrm{m} /$ year corrosion rate and $\mathrm{mg} / \mathrm{cm}^{2}$ based on initial coupon dimensions. 
Sample Cross-Sectioning and Preparation for Scanning Electron Microscopy/Energy-Dispersive $X$ ray Spectroscopy (SEM/EDS)

1. Use a diamond saw to cut the sample along the red dashed line shown in Figure A11. The cut surface should be about $6-7 \mathrm{~mm}$ from the short edge.

2. Perpendicularly mount the cut piece with cut side facing down. Polish the mounted surface to a mirror finish.

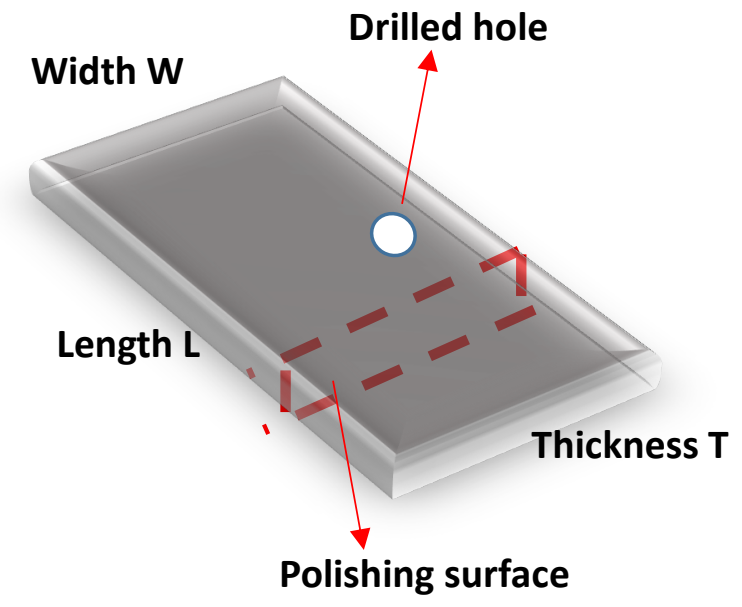

Figure A11 Schematic showing the cut and polishing surface

\section{Cr-depletion Determination with EDS}

1. Parameters for EDS analysis

a. Use $>20-k V$ accelerating voltage.

b. EDS scan dwell times can vary, but they generally need a long enough time for sufficient counts for good statistics.

c. Do not use EDS with a variable-pressure SEM unless operating at high-vacuum setting.

d. One-minute dwell time is usually adequate for point scans. Look for the following elements: $\mathrm{Na}, \mathrm{K}, \mathrm{Mg}, \mathrm{Br}, \mathrm{Ca}, \mathrm{Fe}, \mathrm{Cr}, \mathrm{Fe}, \mathrm{Mn}, \mathrm{Mo}, \mathrm{Ni}, \mathrm{Zn}, \mathrm{Cu}, \mathrm{P}, \mathrm{W}, \mathrm{Si}$ (which are major constituents from either the salt or the Haynes 230 coupons). Note that there is a well-known EDS peak overlap between Mo and S.

e. A minimum of one EDS point scan of the surface is needed. Three or more scans at least 10 microns away from previous scans is preferred for better statistics.

f. A sample without a coating is acceptable although a coating with carbon, $\mathrm{Au}$, or Pd can be used.

g. An example of sample mounting is shown in Figure A12. 
CPS 33873

Progression to Flowing Molten Salts

ORNL Pint

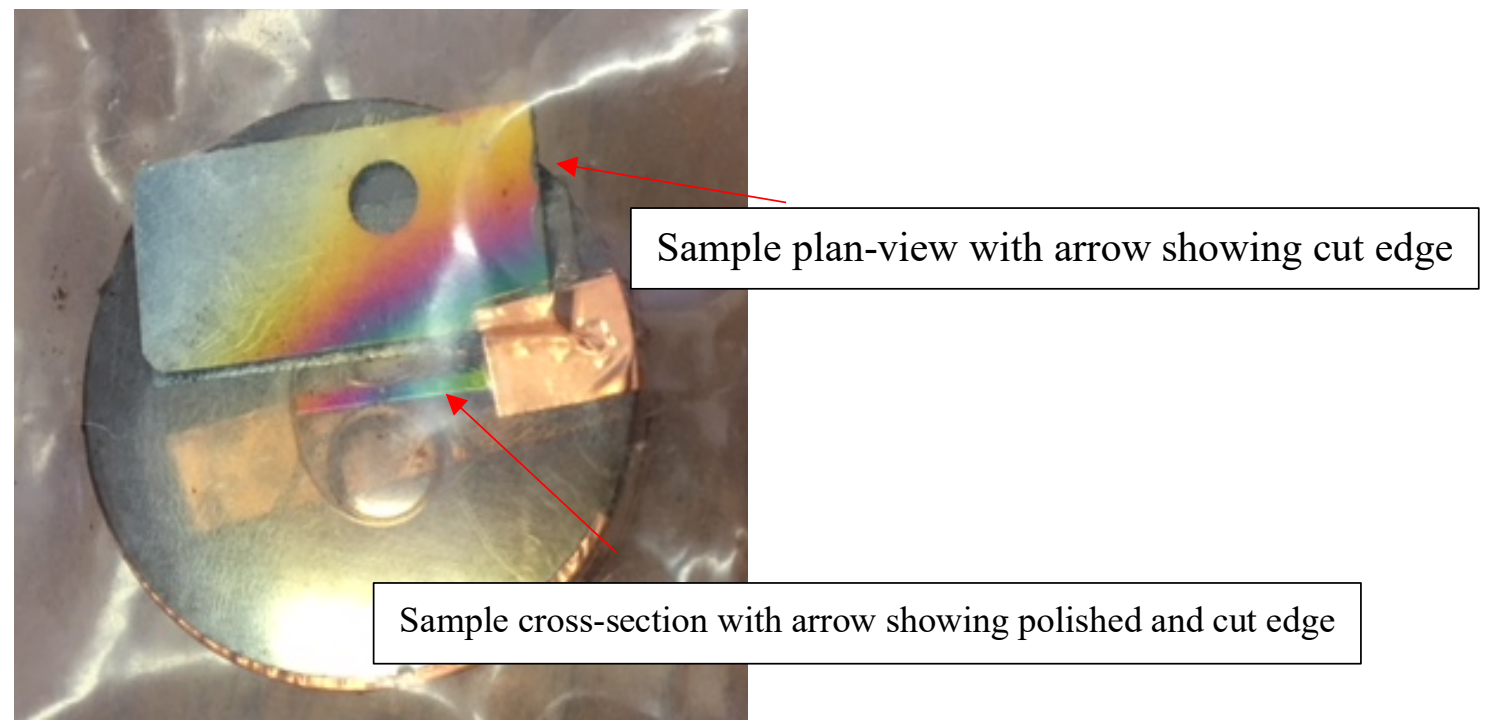

Figure A12 Mounted and polished cross-section, with plan-view sample taped on top of mount so data can all be taken during one SEM session.

2. EDS line-scans should be performed at three locations on the coupon cross-section surface as shown in Figure A13. If more than one line-scan is performed at each location, they should be at least 50 microns apart.

\section{Line $1 \quad$ Line $2 \quad$ Line 3}

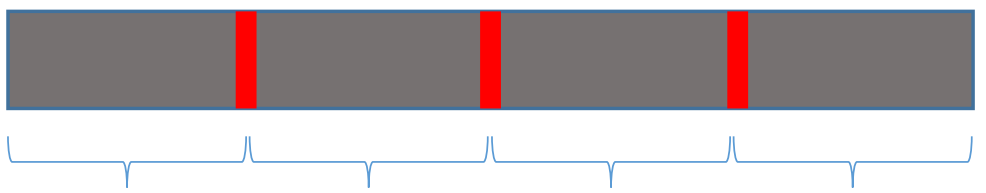

\section{Equal spacing}

Figure A13 Schematic showing the locations of three EDS line-scans

3. If grain-boundary attack occurs, then three additional, 10-micron-long (maximum) line scans should be made over the grain-boundary region at 5 microns, 25 microns, and 100 microns into the coupon surface. This should give some quantification of grainboundary attack. 